Research Report No. 31/2011

\title{
New Approaches to Enforcement and Compliance with Labour Regulatory Standards: The Case of Ontario, Canada
}

Leah F. Vosko

Eric Tucker

Osgoode Hall Law School of York University, etucker@yorku.ca

Mary Gellatly

Mark P. Thomas

Follow this and additional works at: http://digitalcommons.osgoode.yorku.ca/clpe

\section{Recommended Citation}

Vosko, Leah F.; Tucker, Eric; Gellatly, Mary; and Thomas, Mark P., "New Approaches to Enforcement and Compliance with Labour Regulatory Standards: The Case of Ontario, Canada" (2011). Comparative Research in Law \& Political Economy. Research Paper No. 31/ 2011.

http://digitalcommons.osgoode.yorku.ca/clpe/69 


\section{OSGOODE}

OSGOODE HALL LAW SCHOOL

YOR K U N I VERSITY

\section{OSGOODE HALL LAW SCHOOL}

Comparative Research in Law \& Political Economy

RESEARCH PAPER SERIES

Research Paper No. 31/2011

New Approaches to Enforcement and Compliance with Labour Regulatory Standards: The Case of Ontario, Canada

Leah F. Vosko, Eric Tucker, Mark P. Thomas, Mary Gellatly

\section{Editors:}

Peer Zumbansen (Osgoode Hall Law School, Toronto, Director Comparative Research in Law and Political Economy)

John W. Cioffi (University of California at Riverside)

Leeanne Footman (Osgoode Hall Law School, Toronto, Production Editor)

Comparative Research in Law \& Political Economy 


\title{
New Approaches to Enforcement and Compliance with Labour Regulatory Standards: The Case of Ontario, Canada
}

\author{
Leah F. Vosko, Eric Tucker, Mark P. Thomas, Mary Gellatly ${ }^{1}$
}

This paper was prepared as commissioned research for the Law Commission of Ontario in its project on vulnerable workers and precarious work. It does not necessarily reflect the views of the $L C O$. 


\begin{abstract}
This report maps current enforcement and compliance measures and practices in Ontario's regulation of employment, particularly as they relate to precarious employment. It evaluates the effectiveness of Ontario's enforcement regimes, focusing on Employment Standards (ES) and Occupational Health and Safety (OHS) legislation, and sets these regimes in the context of those operating in jurisdictions across and outside Canada. Through this process, it identifies and evaluates potential reforms to improve regulatory effectiveness, particularly for workers in precarious jobs. The central argument is that there are fundamental deficiencies in both of these enforcement regimes: each, albeit in different ways, is out of step with the realities of the contemporary labour market and each demands more proactive approaches to regulation combined with, where appropriate, innovative reactive and voluntary measures that are embedded in strong public enforcement.
\end{abstract}




\section{TABLE OF CONTENTS}

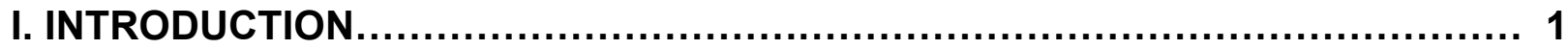

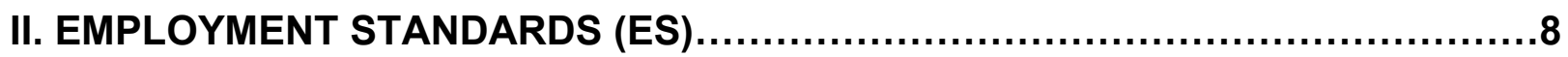

A. Ontario Legislation -- The Employment Standards Act.....................8

B. Mapping ES Enforcement..................................................13

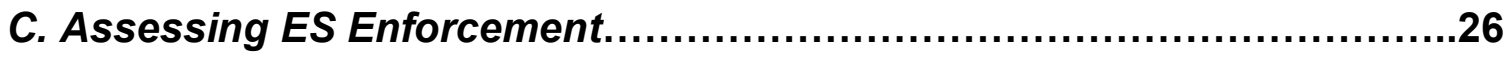

III. OCCUPATIONAL HEALTH AND SAFETY (OHS) ..................................40

A. Ontario Legislation - The Occupational Health and Safety Act.............40

B. Mapping OHS Enforcement................................................... 45

IV. COMPARISONS OF ES AND OHS ENFORCEMENT IN ONTARIO.................55

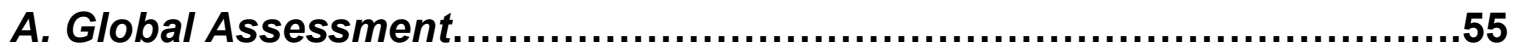

B. Voluntary Compliance..........................................................57

C. Reactive Enforcement......................................................... 58

D. Proactive Enforcement..................................................... 59

V. BEST PRACTICES OUTSIDE ONTARIO ...........................................60

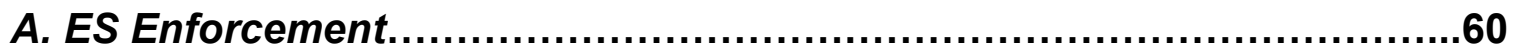

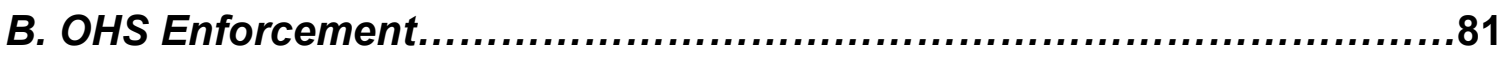

VI. POLICY RECOMMENDATIONS....................................................

A. ES Enforcement............................................................101

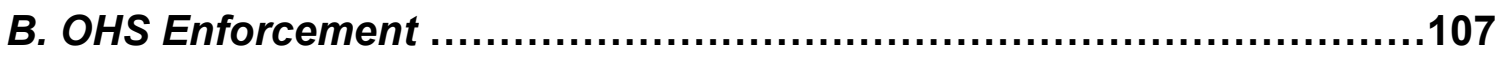

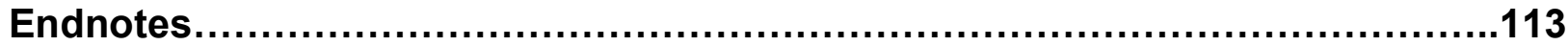




\section{LIST OF FIGURES}

\section{LIST OF GRAPHS}

$\begin{array}{ll}\text { Graph } 1 & \text { ES Penalties } \\ \text { Graph } 2 & \text { ES Proactive Inspections } \\ \text { Graph } 3 & \text { OHS Investigation and Inspections } \\ \text { Graph } 4 & \text { OHS Orders } \\ \text { Graph 5 } & \text { OHS Penalties } \\ \text { Graph } 6 & \text { OHS Prosecutions }\end{array}$

\section{LIST OF TABLES}

Table 1 ES Wages Assessed and Recovered

Table 2 Comparison of ES Individual Claims to Proactive Inspections 


\section{LIST OF ABBREVIATIONS}

AMES Administrative Manual for Employment Standards

CSR Corporate Social Responsibility

DOL Department of Labor (U.S.)

ERS External Responsibility System

ES Employment Standards

ESA Employment Standards Act

ESO Employment Standards Officer

FLA Fair Labour Association

FLSA Fair Labor Standards Act

HSR Health and Safety Representative

ILO International Labour Organization

IRS Internal Responsibility System

JHSC Joint Health and Safety Committee

LABPW Los Angeles Board of Public Works

LAUSD Los Angeles Unified School District

LICO Low Income Cut-Off

LSB Legal Services Branch

MCTF Maintenance Cooperation Trust Fund

MSAWPA Migrant and Seasonal Agricultural Workers Protection Act

MOL Ministry of Labour

NAFTA North American Free Trade Agreement

OBA Open for Business Act

OHS Occupational Health and Safety

OHSA Occupational Health and Safety Act

OHSD Occupational Health and Safety Division

OHSM Occupational Health and Safety Management

POA Provincial Offences Act

SAWO Safe At Work Ontario

SEIU Service Employees International Union

TCF Textile, Clothing and Footwear

WHD Wages and Hours Division (U.S. Department of Labor) 


\section{INTRODUCTION}

This report maps current enforcement and compliance measures and practices in Ontario's regulation of employment, particularly as they relate to precarious employment. It evaluates the effectiveness of Ontario's enforcement regimes, focusing on Employment Standards (ES) and Occupational Health and Safety (OHS) legislation, and sets these regimes in the context of those operating in jurisdictions across and outside Canada. Through this process, it identifies and evaluates potential reforms to improve regulatory effectiveness, particularly for workers in precarious jobs. The central argument is that there are fundamental deficiencies in both of these enforcement regimes: each, albeit in different ways, is out of step with the realities of the contemporary labour market and each demands more proactive approaches to regulation combined with, where appropriate, innovative reactive and voluntary measures that are embedded in strong public enforcement.

While the report focuses on enforcement practices related to ES and OHS legislation, it is instructive to begin with a brief discussion of both the broader principles that underpin these pieces of legislation and the general models of enforcement that aim to implement these principles.

At a normative level, both ES and OHS legislation aim to promote 'decent work.' The concept of 'decent work' as developed through the International Labour Organization (ILO) is defined as jobs that provide income and employment security, equity, and human dignity. ${ }^{2}$ This aim is articulated in regulations at multiple scales and at the international level it is the rationale for ILO standards. ${ }^{3}$ Specifically, the norm of decent work is rooted in the ILO's 1998 Declaration on Fundamental Principles and 
Rights At Work and more recent 2008 Declaration on Social Justice for Fair Globalization. The 1998 Declaration defines these fundamental rights to be: freedom of association and the effective recognition of the right to collective bargaining; the elimination of all forms of forced or compulsory labour; the effective abolition of child labour; and the elimination of discrimination in respect of employment and occupation. ${ }^{4}$ In 2008, the Declaration on Social Justice for a Fair Globalization built on this framework committing members to implementing the Decent Work Agenda through four interconnected objectives: (i) promoting decent work by creating a sustainable institutional and economic environment; (ii) developing and enhancing measures of social protection - social security and labour protection - which are sustainable and adopted to national circumstances; (iii) promoting social dialogue and tripartism; and (iv) respecting, promoting and realizing the fundamental principles and rights at work. ${ }^{5}$ The norm of decent work shapes regional labour standards agreements as well. For example, in North America this norm informs the labour standards side agreement to the North American Free Trade Agreement (NAFTA), the North American Agreement on Labour Cooperation, including its principles on ES, non-discrimination, prevention of, and compensation for, occupational injuries, and protection of migrant workers. ${ }^{6}$

In Canada broadly and in Ontario in particular, the pursuit of decent work entails three normative goals: the promotion of social minima, universality, and fairness. Social minima refers to "ensuring that workers benefit from minimum acceptable conditions of employment and ... actively promot[ing] the adoption of socially desirable terms and conditions of employment. ${ }^{\prime 7}$ This is historically a primary rationale for ES legislation, which is meant to establish a legislative floor below which conditions of 
employment are not to fall. Such a floor is recognized as necessary to protect against employer exploitation due to unequal bargaining power between workers and employers (see goal of fairness below).

The second goal is universality. This objective involves "extend[ing] the minimum benefits of the legislation to the greatest possible number of employees." While universality is a stated goal of legislated standards, special exemptions and/or conditions are often built into legislation to exclude particular employee groups from coverage of some or all standards depending on the circumstances of their employment.

Finally, the goal of fairness refers to "safeguard[ing] workers against exploitation and ...protect[ing] employers against unfair competition based on lower standards." ${ }^{9}$ Underlying the principle of fairness lies the imperative to address the fundamental power imbalance that exists between employers and employees, particularly those workers who are without union representation and in the most precarious forms of employment.

These normative goals contribute to, and are reinforced by, the workplace policy objectives of assuring basic labour standards, protecting against major down side risks associated with employment and mitigating against power imbalances and resulting abuses. ${ }^{10}$ Such workplace objectives translate into, and are shaped by, both OHS laws (protections against exposure to unacceptably hazardous working conditions and provisions for worker involvement in OHS management) and ES laws (standards governing payment of wages, hours of work and eating periods, overtime pay, minimum 
wage, public holidays, vacation with pay, equal pay for equal work, benefit plans, leaves of absence, and termination and severance of employment).

Such laws are then enforced through a range of regulatory strategies that differ in the way they deploy available enforcement tools. In broad terms, there are three general forms of enforcement: (i) proactive enforcement; (ii) reactive enforcement; and (iii) voluntary compliance.

Proactive enforcement relies heavily on inspections and expanded investigations when violations are detected. Orders to pay and prosecutions are used to achieve both specific and general deterrence. In this form of enforcement, inspections are carried out in order to determine whether or not violations are taking place, rather than as a response to a specific complaint. ${ }^{11}$ Proactive inspections may be used in forms of 'strategic enforcement', where employers in sectors known to have high levels of violations are targeted for inspection. ${ }^{12}$ The underlying assumption of this strategy is that the proactive approach will not only detect un/underreported violations, but also that the fear of possible inspection will create pressure for employers in these sectors to improve compliance. Moreover, the proactive approach is favoured by many labour organizations and advocates as workers in high violation sectors are often the most vulnerable to employer power and the least likely to complain. ${ }^{13}$

Proactive enforcement can take other forms as well. For example, among others, Weil ${ }^{14}$ discusses the use of a strategy known as the 'hot cargo' boycott, which utilizes a provision of the Fair Labor and Standards Act in the US to enable state boycotts or the embargoing of goods that are manufactured in violation of the Act. This tactic caused garment manufacturers to pressure subcontractors to improve compliance with 
legislated standards. Additional forms of proactive enforcement may come from collaborative efforts between government agencies or even forms of tri-partite collaboration, integrating unions and civil society organizations into the enforcement process alongside government and employers. ${ }^{15}$

Reactive enforcement depends on complaints to trigger regulatory intervention, and typically emphasizes negotiated settlements, reserving more coercive measures such as orders to pay and prosecution for egregious cases. The most common form of reactive enforcement is complaints from individual workers who have experienced violations of legislated standards. ${ }^{16}$ Typically, these complaints will initiate an investigation by the relevant government agency, which may lead to prosecution and penalties for employers and settlements for workers ${ }^{17}$ As workers in precarious jobs are often reluctant to raise complaints about violations due to fear of job loss, systems of anonymous complaints are considered to be more conducive to protecting workers' rights in such situations. ${ }^{18}$ As a means to increase pressure on employers to comply with legislated standards, Kent Elson ${ }^{19}$ argues for private prosecution of employers who violate employment standards, suggesting that this would not only punish violators but could also foster new norms of compliance through both stiff penalties and social stigma.

As with proactive enforcement, forms of collaboration between public and private actors have been identified as offering possibilities for reactive enforcement. Collaborative strategies may include public regulation of private (voluntary) codes of conduct, ${ }^{20}$ and union-government partnerships in conducting labour standards inspections. ${ }^{21}$ As with collaborative proactive strategies, the aim in these approaches is 
to bring state agencies and private actors together in the enforcement process to improve compliance. Using the Australian case as an example, however, Hardy and Howe $^{22}$ caution that as unions are integrated into this process, they may be drawn towards reactive strategies and lose their capacity to engage in preventative (proactive) forms of enforcement.

Finally, voluntary compliance is an enforcement strategy that depends heavily on education for both workers and employers about legislated standards, as well as employer strategies of 'self-regulation' through private codes of conduct. Voluntary compliance strategies may also lead to negotiated settlements when complaints arise. Prosecutions may be used, but generally as a last resort. With practices and principles of corporate social responsibility becoming commonplace in recent years, employer self-regulation often takes the form of voluntary codes of conduct that companies develop themselves to regulate working conditions, including working conditions across transnational supply chains ${ }^{23}$ As they are voluntary, there is great variation across these types of codes, though they may build from principles of international labour standards developed through the ILO. While they are developed and implemented privately, they may involve forms of 'monitored self-regulation', for example through third-party auditing of the application of the standards contained within the codes. ${ }^{24}$ Advocates of self-regulation/voluntary compliance through corporate codes of conduct suggest that such codes hold potential to improve compliance with legislation as companies will be more inclined to comply with practices they develop themselves. Critics, however, warn that self-regulation without backing by 'hard law' does not offer an effective mechanism of monitoring or enforcement. ${ }^{25}$ 
Governments may play a role in promoting voluntary compliance strategies as well. Specifically, government strategies to foster voluntary compliance include producing and disseminating information materials to raise awareness about legislated standards, ${ }^{26}$ engaging in 'naming and shaming' campaigns to publicize information about egregious violations, ${ }^{27}$ and developing public procurement policy agreements that award government contracts to companies that have strong compliance practices. ${ }^{28}$ The assumption underlying these practices is that the role of government should be to foster employer 'self-reliance' in complying with legislation, rather than taking a proactive approach to enforcement or relying on prosecutions and fines.

Each of these models of enforcement is outlined in specific detail in the report's sections on the ESA (S.II), the OHSA (S.III), and in its discussion of 'best practices' (S. V). 


\section{EMPLOYMENT STANDARDS}

\section{A. Ontario Legislation -- The Employment Standards Act}

ES are legislated standards that set minimum terms and conditions of employment in areas such as wages, working time, vacations and leaves, termination and severance. ES generally apply to most workers in a labour market but are often the only source of workplace protection for workers in non-unionized jobs. The majority of Ontario's over 6 million workers in over 370,000 workplaces rely on ES. This section of the paper provides both a chronological overview of the development of ES legislation in Ontario, and a summary of recent reforms to Ontario's Employment Standards Act (ESA).

\section{$1.1969-1995$}

Ontario's ESA was enacted in 1969. The ESA provided a minimum wage for both men and women and established maximum hours of work at 8 per day and 48 per week. An overtime rate of time and a half was set for anything over 48 hours a week and the Act established the right to refuse overtime work. It also provided for time and a half on 7 statutory holidays and guaranteed 2 weeks of paid vacation per year. The principles behind the development of the Act were consistent with normative framework outlined above. Specifically, the legislation was designed to set minimum standards for Ontario's labour market and provide legislative protection for those most vulnerable to employer exploitation. $^{29}$

The core standards of the ESA were altered through minor reforms in the 1970s, 1980s, and early 1990s, most of which added to the scope of legislative protections for workers in the province. Termination notice requirements were added in 1971. In 1972, a pregnancy leave provision was added that gave employees with at least 1 year of 
seniority in workplaces of 25 or more up to 12 weeks ( 6 and 6 ) of pre- and post-natal leave, and entitlement to their former or a comparable position. In 1975, the overtime pay (time-and-one-half) threshold was reduced from 48 hours to 44 , and pregnancy leave provisions were expanded to cover up to 17 weeks of leave. In 1976, the province introduced a differential (lower) minimum wage rate for servers in the hospitality industry.

Severance pay provisions were introduced in $1981{ }^{30}$ These provisions provided employees with a minimum of 5 years of service with 1 week's pay for each year worked up to a maximum of 26 weeks in cases of mass termination. Under amendments made in 1987, employers were required to provide termination notices 1 week in advance for any employee employed longer than 3 months, with an additional week's notice for each year of employment, up to a maximum of 8 weeks. ${ }^{31}$ Workers with 5 years of employment at a business with an annual payroll of at least $\$ 2.5$ million became eligible for severance pay. In addition, the new severance provisions were extended to workers whose temporary lay-off extended beyond 35 weeks in a 52-week period. Further, in the case of mass layoffs, the legislation required that employers provide the Ministry of Labour (MOL) with an explanation of the economic circumstances surrounding the termination, a summary of consultations with employees and the affected community, any proposed measures to help those laid off, and a statistical profile of affected workers.

Bankruptcy protection legislation was introduced in the Spring of $1991 .{ }^{32}$ The Employee Wage Protection Program was designed to provide employees with compensation for unpaid wages, commissions, overtime wages, vacation pay, holiday 
pay, and termination and severance pay, up to a maximum of $\$ 5000$ per employee. The program was administered through the Employment Standards Branch of the MOL and Employment Standards Officers (ESOs) were given the ability to order payments under the program. The program was funded out of general provincial revenues. Upon payment of a claim, the government would attempt to recover funds from employers and businesses.

\section{2. $1995-2001$}

Beginning in 1995, Ontario's ES underwent a three-stage reform process. The reforms pursued constituted a break from the normative framework of ES outlined above. Specifically, they were designed primarily to promote 'flexibility' for employers, in particular through changes to working time standards introduced in 2001.

First, in 1995 the Employee Wage Protection Program was terminated and the minimum wage was frozen at $\$ 6.85$, a wage freeze that would last for 9 years. Second, in 1996, the Employment Standards Improvement Act reduced the time limit for workers to register formal complaints from 2 years to 6 months, and placed a $\$ 10,000$ limit on monetary awards for ESA violations, regardless of the value of lost wages. The Act also introduced a provision preventing unionized employees from filing ES complaints with the MOL, requiring employees with union representation to resolve ES complaints through the grievance arbitration process, placing the cost of administering ESA complaints in the hands of unions, rather than the Ministry. ${ }^{33}$

Finally, major legislative changes were implemented in the ESA, 2000. These amendments increased weekly maximum hours of work from 48 to 60 and allowed for the calculation of overtime pay to be based on an averaging of overtime hours across a 
4-week period: employers could schedule overtime hours without compensation at time and a half provided the total for the 4-week period was less than 176 hours. They also revoked the system of government permits required for excess hours (more than 48 per week), introducing instead a requirement for employee "consent" to the new excess hours and overtime averaging provisions. The ESA 2000 also introduced anti-reprisal protections and family crisis leave. In addition, the government expanded the parental leave provisions of the Act, to bring them in line with federal amendments to the Employment Insurance program, allowing for up to 52 weeks of unpaid, job protected leave for birth mothers and up to 37 weeks for new parents (generally fathers or adoptive parents).

\section{3. $2004-10$}

Between 2004 and 2010, ES reforms displayed a partial return to decent work principles, with the introduction of ES legislation targeted at particular groups of 'vulnerable workers': specifically, workers employed through temporary help agencies and live-in caregivers. ${ }^{34}$ In developing this legislation, the government assumed that most employers will comply with minimum standards legislation and aimed to target legislative reforms at employers in sectors where violations are high.

The Employment Standards Amendment Act (Temporary Help Agencies) 2009 developed new standards for workers in temporary help agencies. It introduced requirements that temporary agencies must provide information about the agency (name and contact information) and working conditions (incl. pay, hours, nature of work) to workers. It extended ESA coverage for public holiday pay and termination and severance to these workers. Finally, it introduced some prohibitions on charging fees to 
clients for entering into employment agreements with assignment employees. Specifically, agencies are permitted to charge clients a fee if an employee is offered a permanent position in first six months of an assignment with that client.

In 2010, the Employment Protection for Foreign Nationals Act (Live-in Caregivers and Others), introduced a series of legislative protections for those employed as live-in caregivers. Specifically, it banned fees charged by recruiters and employers, allowed live-in-caregivers up to $3 \frac{1}{2}$ years to make a complaint to recover prohibited fees, prohibited reprisals against live-in caregivers for exercising their rights under the legislation, and prohibited an employer or recruiter from taking possession of a live-in caregiver's property (incl. documents such as passports). The Act also authorized ESOs to proactively enforce the legislation.

\section{2010 to present}

Finally, the most recent reforms to the ESA were introduced through the Open for Business Act, 2010 (OBA). This Act focused on enforcement, modifying enforcement practices with the stated aim of making these practices more 'efficient'. Specifically, the OBA alters ES enforcement procedures fundamentally by, among other things, requiring workers facing ES violations to first approach their employers for a resolution, mandating that workers and employers provide information on their claims before they will be accepted by the MOL, and giving new powers to ESOs to facilitate settlements between workers and employers, including unprecedented discretion over monetary compensation for workers. ${ }^{35}$ Like the ESA reforms of 2001, the OBA was a clear departure from the norms of decent work outlined above, prioritizing the efficient resolution of claims over the aim of protecting vulnerable workers. 
First, employees are required to notify their employer before the MOL will initiate an ES claim. ${ }^{36}$ The assumption behind this requirement is that "[m]ost employers want to do the right thing and they will often remedy the situation promptly and voluntarily, if they agree there is a valid claim.. ${ }^{37}$ Second, the amendments place responsibility on individual workers to collect the information for their complaints, reducing the requirements on the investigative procedure itself. If an ESO determines that there is insufficient evidence provided by an employee, then the officer may determine there is no violation. Finally, the amendments promote a voluntary approach to ES regulation, specifically through amendments that give ESOs a role in bringing employers and employees to a mediated settlement, with the Act stating that "[n]either party would have to participate in such a settlement unless they agree to it." ${ }^{\text {38 }}$

In addition to the OBA, the MOL struck an Employment Standards Task Force to address the backlog of 14,000 ES complaints that have accumulated in recent years. The Task Force has a two-year mandate to clear this backlog and will operate under the aegis of the reformed ESA. The Task Force will not engage in a process of proactive investigation into ESA violations, but will investigate these existing claims "based on an officer's review of written materials and through telephone discussions with parties." ${ }^{39}$ The Task Force will also utilize the new emphasis on voluntary, mediated settlements as a means to resolve claims and to create efficiencies in the enforcement process.

\section{B. Mapping Employment Standards Enforcement}

Workers' access to minimum ES depends on the government's ability to promote and enforce such standards. The legislation provides the Director of Employment Standards and ESOs with broad powers of investigation (e.g., entering business premises and 
requiring production of records for inspection). Officers have extensive authority to resolve complaints of violations including settlements, orders to pay, fines, compliance orders and prosecutions. There is no statutory provision specifying how investigations and enforcement are to be done. In practice, it is the policies and procedures established by the Branch that determine the choices Officers can make in investigation and enforcement techniques.

The MOL has three main strategies of ES enforcement: self-regulation and compliance by employers; self-enforcement by employees when employers are noncompliant; and proactive enforcement and education to improve employer compliance, largely by targeting employers most likely to be in violation of the ESA. It does this by:

- Providing information to employers and employees, encouraging employers to comply voluntarily;

- Investigating and resolving employees' complaints of employer violations;

- Conducting inspections of employers that are likely to be in violation; and,

- Deterring violations through appropriate penalties. ${ }^{40}$

With almost 6 million employees in over 370,000 workplaces the MOL relies on employers to voluntarily comply with the ESA. When employers do not comply, individual workers are responsible for seeking their unpaid wages or ES entitlements from their employer and, through this process, may file a complaint for ES violations at the MOL. The MOL also undertakes proactive enforcement of employers that are at risk of ES violations. The reality is, however, that the majority of resources on ES enforcement go to investigating individual complaints of employer violations - that is, to reactive enforcement measures. The ensuing discussion examines these compliance 
and enforcement activities.

\section{Employer Self-Regulation / Voluntary Compliance}

The self-regulation strategy hinges on employers acting as good corporate citizens. The

MOL seeks to assist employers' compliance by providing the following types of information: $:^{41}$

Phone: The Employment Standards Information Centre, administered by Service Ontario, provides information about ES. It assisted almost 350,000 in 2009-2010. Legal advice is not provided. The toll-free call centre provides interpreters for its multi-lingual phone service.

Email: The MOL responds to emails from employers and employees - it prepared 9,000 such responses in 2010.

Website: The MOL has a variety of information tools explaining provisions of the ESA, how they may apply, and how to file an ESA claim. Videos showing employers what to expect in an inspection are provided as are videos on what workers can expect once they file a claim. The Ministry also communicates by social media (e.g., facebook and twitter). General information has been translated into 23 languages. ${ }^{42}$

\section{Self-enforcement}

When employers do not comply with ES, it is up to the individual worker to seek remedy from their employer and, failing that, by filing a claim with the MOL for unpaid wages and other ES entitlements. Historically, the MOL has encouraged employees to try and recover unpaid wages and ES prior to filing a claim. For example, when the MOL introduced on-line claims process in 2006-07, it posted a Self-Help kit for employees. This kit was intended to assist workers in learning about their ESA entitlements, determining which ES had been violated, and calculating the amount of unpaid wages 
owing. Employees were then asked to contact their employer to obtain wages owing. With the passage of the OBA in 2010, workers are now required (with some exceptions $)^{43}$ to first contact their employer to seek their ES entitlements. If a worker is unsuccessful in enforcing their ES entitlements, s/he is then allowed to file a complaint at the MOL for investigation.

\section{(i) Individual Claims Investigation}

In general, after a claim was filed by a worker, an ESO investigated the claim to determine whether or not, and if so which, ES violations had occurred. The ESO evaluated evidence provided by the employer and the employee and made a determination on the claim. The institutional practice during investigations was to seek information from both the claimant and employer through telephone calls, letters and fact-finding meetings in which both parties were given the opportunity to present their case. To varying degrees, ESOs could gather evidence in ways that accounted for some of the barriers faced by people in low-wage and precarious employment (e.g., not understanding ES and claims process, language and literacy barriers). However, factors such as increasing numbers of claims, on-line filing of claims with information missing, and difficulties encountered in reaching the parties during ESO working hours contributed to a growing back-log in complaints and pressure to change the investigation process. The OBA introduced a new requirement that certain information be provided in writing on the claim form before a worker's claim would be allowed to proceed. Further, the OBA introduced a section (s. 102.1) that allows ESOs to deal with undue delays by making a decision on the best information available. The OBA places a 
greater burden on workers to provide evidence of employer violations, rather than a reverse onus on employers to refute allegations.

During the 1970's the MOL used individual claims as "levers to pry open and expose to scrutiny" a company's entire range of operations. ESOs were required to conduct full audits to disclose all violations for current employees. The number of employees receiving payments because of investigations and inspections in 1971 was 52,263 . Full audits were generally done as a follow-up to every individual complaint. But rising caseload of complaints in the early 1970s saw the branch shift to 'complainant only' and away from expanded investigations protecting all workers. ${ }^{44}$ The number of expanded investigations has declined since the 1970s. As noted by Ontario's Auditor General in 2004, while violations were found to exist in about 70 percent of complaints filed, few investigations were expanded to protect the employer's current employees who may also be facing violations. ${ }^{45}$ In 2009-10, the Ministry conducted 99 expanded investigations where a workplace was identified for an inspection based on the results found during an individual claim investigation. In that same year, 20,762 claims were investigated and violations assessed totalled almost $\$ 64.4$ million ( $\$ 42.9$ million of which was subject to bankruptcy or insolvency). ${ }^{46}$ There is no follow-up to inform current employees of what their entitlements may be under the ESA to create incentives for future employer compliance.

\section{(ii) Individual Claims Resolution}

Over 80 percent of claims are resolved during the investigation process. Claims are either withdrawn by the claimant, a settlement is reached between the employer and employee, the employer complies with an ESO determination of wages owing, or a 
claim is denied. In less than 20 percent of cases, the ESO issues an Order to Pay to the employer or Director. Claimants and employers have the right to appeal an ESO order to the Ontario Labour Relations Board (OLRB). But few do. Less than 5 percent of such claims proceed to appeal at the OLRB.

Institutional practices for arriving at settlements have allowed claimants and employers to enter into settlements during the claims process. Indeed, the complaint is deemed to have been 'settled' as long as the ESO receives the terms of settlement in writing. In such cases, any orders respecting the employers' contraventions are void ${ }^{47}$. Historically, ESOs were not supposed to "negotiate, promote, or 'broker' settlement agreements. ${ }^{48}$ However, over time, growing pressures were placed on workers to settle during the claims process. ${ }^{49}$ There are no data available on the number of claims settled below statutory minimums.

In response to a substantial backlog in claims in 2009-10, the OBA introduced new powers for ESOs to "attempt to effect a settlement." Employers and employees are given the option of discussing settlement, with the ESO playing a mediating role. Should a settlement not be reached, the ESO resumes the investigation and decisionmaking. An initial pilot project of facilitated settlements found that 21 percent of cases that went to a decision-making meeting were resolved through settlements and that these cases resulted in settlements of, on average, 17 percent lower than was assessed to be owed by the ESO. ${ }^{50}$

When an employer voluntarily complies with an ESO decision that an ES entitlement must be paid to a claimant, the employer either pays what they should have in the first place, or less if a lower settlement is accepted. There are no penalties or 
other costs to the employer. Further, when an ES complaint is settled without an order to pay being issued, there can be no fines levied through contravention notices.

(iii) Penalties

The ESA sets out a variety of sanctions that can be used against employers that are found in violation of the Act. However, the MOL does not provide guidelines or criteria for the use of the sanctions and penalties listed below:

Order to Pay Wages (s. 103) is issued when an ESO finds that wages are owing and the employer has not volunteered to pay the wages. This order is subject to a $\$ 10,000$ cap on unpaid wages (s. 103(2)) and will include an additional administrative fee of 10 percent of wages owing.

Directors' Order to Pay Wages (s. 106 and 2. 107) is issued to a director of a corporation where the employer has not paid the wages required under an Order to Pay.

Order for Compensation (s. 104, 74.16, 74.17) deals with those matters under the Act in which damages are awarded when an ESO determines that an employee has suffered a loss. These orders relate to the reprisals, leaves of absence, retail business establishments and lie detector provisions of the Act.

Order to Reinstate (s. 104 and 74.17) may be issued in the matters outlined under compensation orders.

Compliance Order (s. 108) may be issued when an officer finds that an employer contravened any part of the Act or regulations. Compliance orders may be issued if there has been voluntary compliance to ensure that there is a record 
of the employer's violation and enforcement activity. Such orders require employers to cease violating ES provisions specified by a certain time.

Notice of Contravention (s. 113) are monetary penalties for violations set out in regulation (O. Reg. 289/01) and generally increase from $\$ 250$ to $\$ 1,000$ per contravention per person violated.

Prosecution (s. 132) of employers that contravene the Act or its regulations may take place and if so, on conviction, individual employers may be liable to fines up to a maximum of $\$ 50,000$ or imprisonment of not more than 12 months, or both, and corporations are liable for fines up to a maximum of $\$ 100,000$ and increased fines for subsequent convictions. .

ESOs have the discretion to use or not use the above orders and Part 1 Tickets in inspections and investigations. As Graph 1 demonstrates, the MOL's preferred sanction is to issue Compliance Orders. In 2009-2010, 20,762 claims were investigated finding that employers owed $\$ 64.4$ million to workers yet only 86 fines (notice of contravention) and 298 tickets $(\$ 360)$ were issued. Prosecutions are determined by the Employment Standards Branch and Legal Services Branch of the MOL the latter of which conducts the prosecutions. Prosecutions are for non-compliance with Orders issued from the MOL and do not directly remedy unpaid wages for workers. The Ministry initiated 13 prosecutions of employers in violation in 2009-2010. ${ }^{51}$ 


\section{Graph 1. ES Penalties}

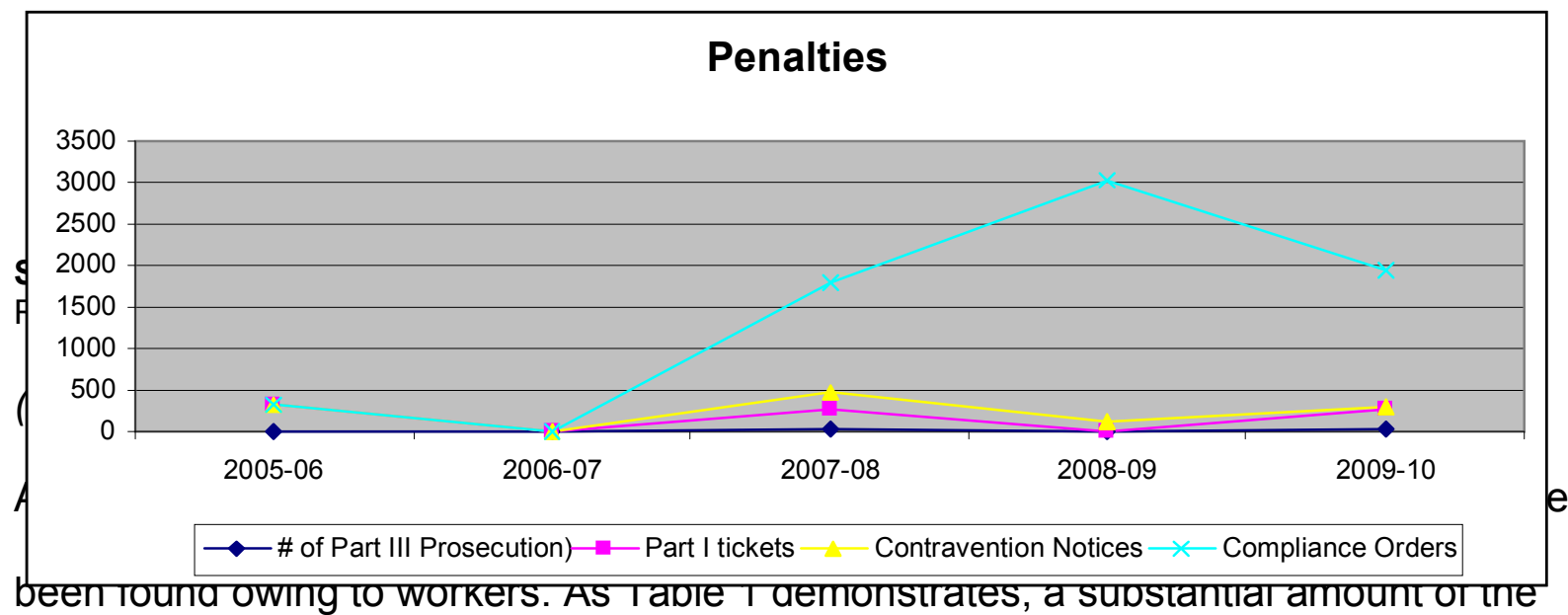

monies owed to workers are from employers who are insolvent or bankrupt. Recovery of unpaid wages in cases of bankruptcy or insolvency is difficult because workers become one of several creditors' owed money and are paid subject to priority ranking as determined by federal bankruptcy and insolvency legislation. The MOL assists employees by filing Proofs of Claim with the Trustee in Bankruptcy or the Monitor. The recession of 2008-9 saw a dramatic rise in bankruptcies.

Table 1 illustrates that an average of 50 to 54 percent of wages assessed to be owed during investigation (excluding bankruptcies) were recovered between 2006 and 2010 through the MOL claims process. A further 6 to 9 percent are recovered by workers during the Labour Board appeal process. Collection agencies recovered between 12 to 16 percent of wages owing in cases sent to collections. ${ }^{52}$

By far, the most successful recovery of wages owing is through proactive inspections. Between 92 to 99 percent of wages assessed during inspections from $2006 / 07$ to $2009 / 10$ were recovered for workers.

Table 1 Wages Assessed and Wages Recovered

\begin{tabular}{|l|c|c|c|c|}
\hline & Fiscal & Fiscal & Fiscal & Fiscal \\
\hline
\end{tabular}




\begin{tabular}{|c|c|c|c|c|}
\hline & $\begin{array}{l}2006-07 \\
(\$ 000 ’ s) \\
\end{array}$ & $\begin{array}{l}2007-08 \\
(\$ 000 ’ s) \\
\end{array}$ & $\begin{array}{l}2008-09 \\
(\$ 000 ’ s) \\
\end{array}$ & $\begin{array}{l}2009-10 \\
(\$ 000 ' s) \\
\end{array}$ \\
\hline $\begin{array}{l}\text { Wages owing assed from claims } \\
\text { investigation }\end{array}$ & $\$ 23,335$ & $\$ 16,560$ & $\$ 15,118$ & $\$ 19,737$ \\
\hline $\begin{array}{l}\text { Wages owing assessed from } \\
\text { inspections }\end{array}$ & $\$ 1,905$ & $\$ 1,289$ & $\$ 2,115$ & $\$ 1,759$ \\
\hline $\begin{array}{l}\text { Wages owing assessed from } \\
\text { bankruptcies and insolvencies }\end{array}$ & $\$ 23,424$ & $\$ 12,309$ & $\$ 48,753$ & $\$ 42,900$ \\
\hline Total wages owing & $\$ 48,664$ & $\$ 30,158$ & $\$ 65,986$ & $\$ 62,637$ \\
\hline $\begin{array}{l}\text { Wages recovered from employers } \\
\text { during claims investigation process }\end{array}$ & $\$ 12,639$ & $\$ 8,201$ & $\$ 7,736$ & $\$ 10,323$ \\
\hline $\begin{array}{l}\text { Wages recovered from employers } \\
\text { during proactive inspections }\end{array}$ & $\$ 1,748$ & $\$ 1,282$ & $\$ 1,928$ & $\$ 1,737$ \\
\hline $\begin{array}{l}\text { Wages paid from employer appeals }(\$ \\
\text { held in trust })^{53}\end{array}$ & $\$ 2,017$ & $\$ 1,425$ & $\$ 952$ & $\$ 1,642$ \\
\hline $\begin{array}{l}\text { Wages recovered from private } \\
\text { collection agency on contract with MOL }\end{array}$ & $\$ 1,000$ & $\$ 889$ & $\$ 1,031$ & $\$ 1,125$ \\
\hline Total wages recovered & $\$ 17,404$ & $\$ 11,777$ & $\$ 11,647$ & $\$ 14,827$ \\
\hline
\end{tabular}

Source: MOL, Employment Standards Program Annual Reports 2007-2008 to 2009-2010

\section{Proactive Inspections}

According to the MOL, proactive inspections aim to: ensure compliance with standards; communicate the requirements of the ESA; raise awareness and understanding by employees and employers of their rights and responsibilities; and promote self-reliance in the workplace ${ }^{54}$ Consistent with a largely reactive approach, the MOL does not use inspections to address individual employee's complaints of ES violations.

The MOL currently focuses efforts and resources largely on investigating claims of ES violations from individuals against former employers. However, this has not always been the focus. Prior to changes to the Act in the late 1960's, the bulk of the Branch's enforcement activity in hours of work and minimum wage protections involved conducting surprise spot checks or planned visits to investigate companies' compliance with the law. With new powers to collect wages beyond the minimum standards in 1969, 
a shift from proactive enforcement through inspections to individual complaints began to take place. ${ }^{55}$

Much of the focus during the 1980's and 1990s was to avoid large backlogs of unresolved claims. As Graph 2 illustrates, ES inspections of workplaces were almost non-existent during that same period.

\section{Graph 2. Proactive Inspections}

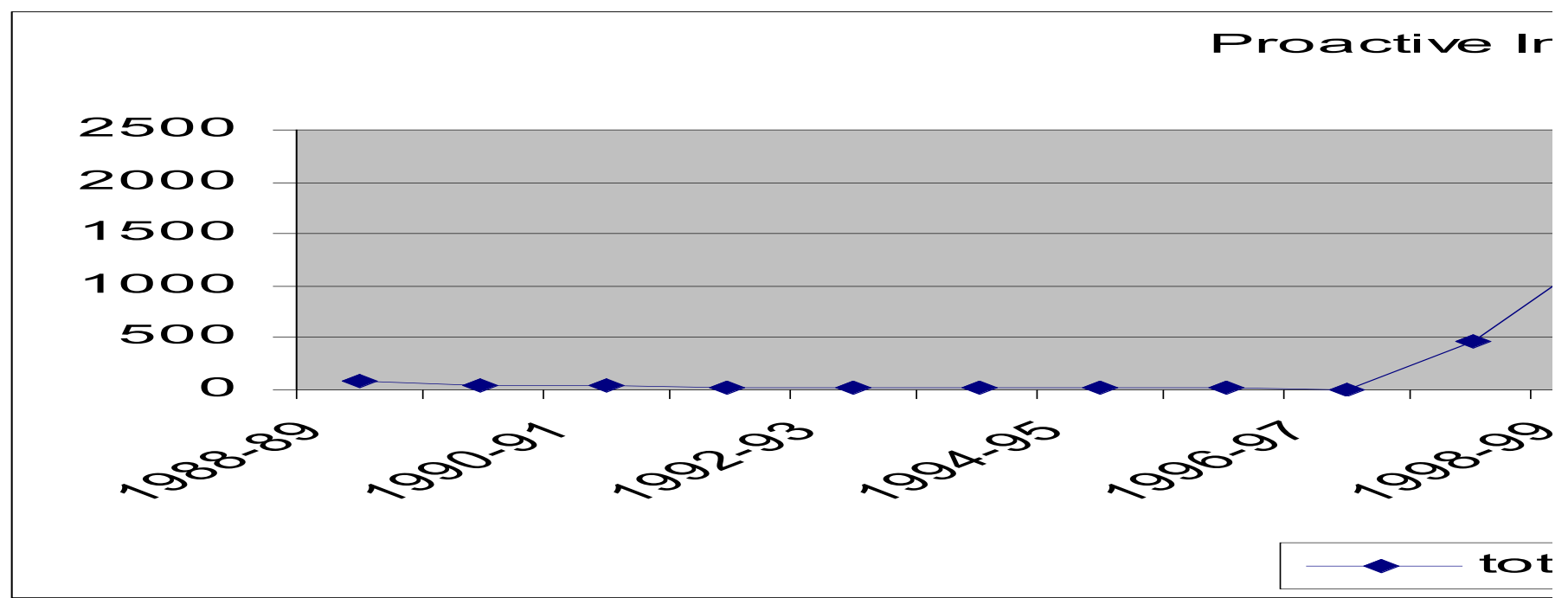

Source: Ontario MOL Fiscal Year Reports, 1088-89 to 2005-07 and Employment Standards Program Annual Reports, 2007-10 (on file with authors).

In April 2004, then Minister of Labour Chris Bentley announced that the government was 'putting enforcement back on the agenda. ${ }^{, 56}$ Alongside legislative changes to the hours of work provisions, the government claimed it would focus on improving education and awareness around both workers' rights and employers' obligations, shorten the time to process claims, dedicate resources to conduct 2,000 proactive inspections, improve collections, and increase the number of prosecutions. In 2004, the MOL allocated 20 ESOs to conduct a target of 2,000 inspections per year. The overall strategy is thus to inspect non-complying companies, or those at highest risk for non-compliance, in order to bring these companies into compliance. The 
Dedicated Enforcement Team conducts inspections in sectors that historically have the highest rates of non-compliance such as retail, restaurant and business management services. Such criteria for targeted inspections are based on violations confirmed through individual claims brought forward. In addition, where sectors of people in precarious jobs have been successful in bringing attention to substandard working conditions, the MOL has responded with targeted sectoral inspections (e.g., garment workers during the 1990s, temporary help agency workers and live-in caregivers in the early 2000s).$^{57}$ There does not appear to be any benchmarking or evaluation program to assess changes in compliance rates in the sectors targeted.

The Administration Manual for Employment Standards (AMES) outlines how officers are required to conduct inspections. The ESO generally gives the employer 10 days notice of the proactive inspection. The employer is asked to prepare payroll records for the inspection. The ESO interviews the employer, as well as a selection of employees, to identify any violations, and performs a test audit on payroll records (for example, in a workplace with 60 or fewer employees, the officer will review 5 employees' records). If the ESO identifies ES violations, action is taken to remedy the contravention. This action is achieved by the employer doing a self audit to determine how much is owed, for example, in unpaid wages, unpaid overtime or public holiday pay. If an employer does not make a voluntary payment, the ESO may issue an order to pay.

Inspection results suggest that the purpose of inspections is to encourage employers to comply. For example, in $2008-09$, of 2,135 inspections covering 60,000 employees, over $\$ 1.9$ million in unpaid wages was uncovered through the inspections. Besides 
paying wages that should have been paid in the first place, enforcement activity focused on encouraging compliance rather than mandating penalties for violations of wage standards. This activity included issuing:

- 487 tickets (of about $\$ 360$ each)

- 2,883 Compliance orders (request compliance by specified time)

- 68 Notices of Contravention (escalating fines per violation per occurrence); and,

- 2 orders to pay ${ }^{58}$

As Table 2 demonstrates, proactive inspections reveal violations of core standards such as minimum wage, unpaid wages and overtime. They also offer greater chances of recovering those wages. Moreover, proactive inspections uncover violations of standards experienced by currently employed workers, whereas individual claims, more typical of reactive approaches, tend to uncover violations reported by workers after the employment relationship is severed. This is a key distinction.

Table 2 Comparison of ES Individual Claims to Proactive Inspections

\begin{tabular}{|l|l|l|}
\hline & $\begin{array}{l}\text { Violations confirmed in } \\
\text { individual claims 2007-2008 }\end{array}$ & $\begin{array}{l}\text { Violations confirmed in } \\
\text { proactive inspections 2007- } \\
2008\end{array}$ \\
\hline Unpaid wages & $33 \%$ & $46 \%$ \\
\hline Vacation pay & $24 \%$ & $6 \%$ \\
\hline Termination & $22 \%$ & 0 \\
\hline Overtime & $5 \%$ & $15 \%$ \\
\hline Public holidays & $5 \%$ & $29 \%$ \\
\hline
\end{tabular}

Source: Ontario MOL (2008) Employment Standards Program Annual Report, 2007-2008.

While roughly half of unpaid wages owed are recovered through the individual claims process (barring bankruptcy), 92 to 99 percent of unpaid wages confirmed during proactive inspections are recovered through this process. This finding, depicted in the 
table above, suggests that proactive inspections are more effective than the investigation of individual claims in recovering workers unpaid wages.

\section{Assessing Employment Standards Enforcement}

The re-regulation of ES in the late 20th century through inadequate funding, economic restructuring, and the shift from proactive measures to individual claims resolution, has increasingly placed the onus for enforcement on workers, on the one hand, and voluntary compliance by employers, on the other hand.

The focus of this report is on people in precarious jobs and enforcement practices. Precarious jobs are taken to mean work for remuneration, characterized by high levels of job and income insecurity, low wages and limited access to regulatory protections and employment benefits. Moreover, precarious jobs are often associated with temporary employment and self-employment (especially the own account variety, where the self-employed person does not employ others), rather than permanent paid employment. Workers in precarious jobs also tend to lack meaningful access to employment rights. As precarious employment has developed over recent decades, it has become marked increasingly by processes of racialization and gendering, in other words the ways in which women, immigrant, migrant and racialized workers are incorporated into the labour market, the association of specific forms of employment with these groups of workers, and the over-representation of women and racialized workers in forms of employment characterized by high levels of insecurity. Furthermore, non-racialized and/or Canadian-born workers who work in particular sectors, and/or alongside women, immigrants, migrants and racialized workers, are compelled to labour

under similar conditions in work that is marked by feminization and racialization. ${ }^{59}$ 
Precarious employment is not new; in fact, many of these conditions are longstanding. They are reminiscent of the "sweating system" of outsourcing in the garment industry, of employment practices in employment agencies, and of immigration practices during the nation-building periods of the late $1800 \mathrm{~s} .{ }^{60}$ It is not the case that all employers are violating the ESA or attempting to evade core labour standards. However, precarious employment is growing and ES violations, evasion and erosion are therefore having a much larger impact on the broader labour market than during previous eras. Responsible employers are placed under growing pressure when undercut by employers who violate the ESA. As practices linked to precarious employment spread across industries, strategies to lower labour costs and liabilities also spread. The Ontario government is thus facing increasing numbers of individual complaints of employer violation at the same time that employers are shifting forms of violation and evasion through 'new' employment practices. As U.S. researchers studying precarious employment reflect, "[w]hen the floor of labor standards is driven down or dismantled altogether, all of us are affected, not just those at the very bottom." 61

Erosion of employment standards have, as a Law Commission of Canada report observes, developed both actively and passively. ${ }^{62}$ Active erosion of standards has occurred through explicit exemptions in the scope of the ESA being adopted through regulatory changes. For example, workers in agriculture, information technology, and construction do not have the same protections for hours of work and overtime that other workers have. Changes to the ESA in 2000 actively reduced government regulation of workplace standards, promoted greater employer control over work time, normalized 
non-standard employment relationships and increased the vulnerability of workers in non-unionized workplaces. ${ }^{63}$ More passive erosion of standards also undermined the ESA's capacity to protect workers in low-wage and precarious jobs. From the late 1970 's until the early 2000s, Ontario's minimum wage was substantially below the poverty level. ${ }^{64}$ This degradation has contributed to an expanding low-wage labour market in Canada. Data from the OECD show that Canada is second only to the U.S. as a low-wage country. The proportion of Canadian workers who are low paid (less than two-thirds of the median wage) is about double the level in continental Europe (on the magnitude of low wage work in contemporary Ontario, see also Noack and Vosko in this LCO series). ${ }^{65}$

Active or passive, employers have adopted strategies for work organization over the past 3 decades that evade core labour laws and create legal distance between themselves and their workers. ${ }^{66}$ Even harder to quantify than violations of ES are practices of evasion, as they often involve workers found in forms of employment outside the scope of the ESA or differentiated within the ESA - for example, the growing number of workers in forms of employment that fall outside of standard full-time, permanent employment with a single employer ${ }^{67}$ Over a third of total employment is part-time, temporary or own-account self-employment. Yet labour laws, regulatory regimes and employment benefits are still based almost exclusively on an employment model (a standard employment relationship) developed after World War II, which linked decent wages, benefits, working conditions and job security to a full-time continuous employment relationship between an employer and worker where the worker works on 
the employer's premises under direct supervision, a form of employment in which nonracialized men were over-represented. ${ }^{68}$

Historic exclusions of certain types of work organization from ES protections, such as own-account self-employment, have created incentives for employers to move workers into "new" forms of employment. Contracting out work that can be done inhouse is yet another practice that is re-emerging and it has surfaced in sectors from the newspaper industry to home care provision. Contracting out was a common practice in garment production and manufacturing more generally in the beginning of the 20th century. Externalizing employment costs to temporary help agencies is yet another growing strategy for just-in-time labour sourcing. Such practices shift the legal liability that employers have for their employees, working conditions and employment benefits onto intermediaries and, in the case of misclassified independent contractors (i.e., selfemployed workers), onto workers themselves. While employers may argue that these strategies are necessary in an increasingly global market with intense international competition, this rationale does not justify these practices in Ontario. Many employers and industries that are engaged in outsourcing, indirect hiring, and misclassifying workers are part of distinctly local markets, such as restaurants, business services including janitorial and courier services, construction, trucking, home health care, warehousing and manufacturing of locally consumed goods. ${ }^{69}$

Few studies document the scope of violations of ES; but the ones that are available confirm substantial formal violations. In the late 1990's, a federal government Labour Standards Evaluation surveyed employers and found that 25 percent of employers were in widespread violation of the Canada Labour Code and 50 percent 
were in partial violation. ${ }^{70}$ These findings were confirmed a decade later by Statistics Canada $^{71}$ and the Workers' Action Centre. ${ }^{72}$

A survey of people in low-wage and precarious work in the Greater Toronto Area conducted in 2011 provides yet another window into the violations that some of these workers face. This non-randomized survey of 520 casual, temporary, non-standard and low-wage workers conducted in 2011 sought to document the types of violations people in precarious work face. The findings included the following:

- 20 percent earned less than minimum wage

- 39 percent failed to receive earned overtime pay

- 36 percent were fired or laid off without termination pay or notice

- 34 percent struggled to get vacation pay

- 33 percent were owed wages and of those only 23 per cent were ever paid ${ }^{73}$

These findings do not indicate that all or most employers violate ES. Many employers do comply with the ESA. However, the prevalence of violations undermines employers who do comply with minimum labour standards and contributes to a downward pressure on wages and working conditions.

Over the past 30 years, resources and staffing for ES regulation has not kept pace with increases in workers' covered, number of workplaces and complexity of working relationships. While the number of workers covered by the ESA has increased by fully 24 percent between 1997 and 2007, the funding for the ES Program has decreased by fully 33 percent. Even recent increases to the Program in the 2009/10 budget leave it with funding levels of over 10 percent below 1997 levels. ${ }^{74}$ With over 370,000 Ontario workplaces, ES regulation is made more difficult by the growth in 
smaller companies. Companies employing fewer than 50 employees make up more than 92 percent of Ontario's businesses and 66 percent of ESA claims in 2009/10. ${ }^{75}$

\section{Effectiveness of ESA regulation}

The growing trend towards individualized and privatized systems of workplace regulation is increasing workers' exposure to market forces. Ontario ES regulation uses a mix of "hard" law and "soft" law approaches. Soft law approaches include the government's reliance on voluntary employer compliance or self-regulatory behaviour from firms. Detection of violations is largely individualized through workers' self enforcement and individual claims. Hard law approaches are reserved for employers that do not voluntarily comply with assessed violations. These include orders to pay, compliance orders, and fines or prosecution for particularly egregious employers.

(i) Self enforcement / Individualization of claims

The majority of resources for enforcing ES still go towards investigating individual complaints of employer violations. This despite the fact that, as Saunders and Dutil note, the "practice of dealing with compliance one case at a time is expensive and risks overloading the available capacity." ${ }^{76}$ There has been an increase in claims over the last 5 years from an average of 15,000 claims per year to over 20,000 claims per year. By 2010, a backlog in workers' complaints against employers for unpaid wages had grown to over $17,000 .^{77}$ 
(ii) Barriers to self-enforcement while on the job.

On an annual basis, less than 1 percent of workplaces are at risk of being inspected for ES violations. Enforcement of ES and $\mathrm{MOL}$ detection of violations largely relies on individual workers. Yet workers, particularly those in low-wage and precarious work, face significant challenges to enforcing their employment standards while still on the job. The ESA is supposed to remedy the unequal power relationship between workers and employers. There are no institutionalized mechanisms that enable employee voice in ES enforcement. Unlike Ontario's regulation of the Occupational Health and Safety Act, workers cannot make anonymous complaints that will initiate MOL Health and Safety inspections of the workplace. Nor is there interim reinstatement pending investigation that is afforded to fired workers in specific situations under the Ontario Labour Relations Act (OLRA)

There are many factors shaping how workers respond to ES violations. Workers must consider factors such as: wages needed to support themselves and their families; savings; eligibility for and capacity to survive on Employment Insurance benefits while searching for new employment; the realities of getting another job at the same or similar wages; the impacts on immigration status and family sponsorship; and whether they will be successful in securing the minimum ES they should have received in the first place. Workers under the Live-in Caregiver and Temporary Foreign Worker Programs face even greater challenges. Caregivers must complete the equivalent of 24 months of employment within 4 years before being able to apply for permanent residency and are required to live in their employer's home. People who work under the Seasonal Agricultural Program and low-skill Temporary Foreign Worker Program (TFWP) are tied 
to one employer for a specific term. Federal immigration program requirements create conditions ripe for abuse and that limit what workers can do to address violations. ${ }^{78}$

Workers without regularized immigration status have the same ESA rights as other workers. But non-status workers face substantial barriers to enforcing their rights; many in this group face substandard conditions of employment but do not complain due to implicit or explicit threats of reporting their status to immigration officials and the potential of deportation.

Workers' ability and willingness to confront employers over ES violations is also shaped by labour market conditions. Worker's decisions may be shaped by their ability to get a new job at the same or better pay and job security. For workers facing substandard employment conditions, the fraying social safety net reduces workers' options even more. While Ontario had the third highest unemployment rate in 2009, it had the lowest level of El coverage with only 41.3 percent of unemployed workers receiving El benefits. ${ }^{79}$ Workers that do qualify are only eligible for 55 percent of their previous wages. For people in low-wage work, El does not buttress workers displaced from their jobs for trying to enforce their rights. Besides benefit levels well below the poverty line, social assistance is not an option for many people who are trying to regularize their immigration status or sponsor family members. Barriers to filing claims while workers are on the job result in some workers being owed substantial amounts of unpaid wages and entitlements. However the $\$ 10,000$ cap on monies recoverable under the ESA leaves these workers without remedy through the ES claim process.

Together these factors result in substantial barriers to workers in pursuing their ES rights. Power imbalances leave workers with little protection against reprisal or job 
loss. It is little surprise that 9 out of 10 workers who file claims for unpaid wages and entitlements do so after they have left the job. ${ }^{80}$ It is hard to know how many workers move from one substandard job to the next, without seeking to recover unpaid wages, overtime, vacation, termination and public holiday pay. A MOL Inspection of a textile company in 2004 found that 99 workers were owed more than $\$ 136,000$ in wages. Yet only 22 workers had come forward to file ES claims in the months prior to the company closing down, despite considerable media attention about the case in question. Almost 80 percent of the workers never came forward to make claims for their unpaid wages. This case suggests that the 15,000 to 20,000 claims filed each year may only be the tip of the iceberg.

\section{(iii) Barriers in individual claims}

Workers are now required to first seek compliance from employers before being allowed to file an ES claim for unpaid wages. This effectively means that workers must have access to the internet to learn about rights, knowledge about how to apply abstract legal rights to their specific conditions, the ability to gather evidence to prove their case, and, the time and facilities to assemble, package, and deliver it to (former) employers. Most significantly, mandatory self-enforcement requires that workers have the skill set and confidence to confront their (former) employer about violations.

There are substantial structural power imbalances between workers and employers that the ESA seeks to address. Such imbalances in power can create significant fears in workers. A mandatory requirement for workers to contact their employer about wages contravenes the purposes of the ESA, both its four fundamental underlying normative principles (i.e., fairness, social minima, decent work, and 
universality) and its role of providing workers with an administrative process through which to seek redress for contraventions of the Act.

The MOL's ES complaints system relies heavily on individuals being able to access the website. Reliance on internet access creates significant barriers for many people in precarious employment. Statistics Canada reports that there is a digital divide in the rate of internet use on the basis of income, education and age. If someone is poor, older, lives in a rural community, was born outside of Canada, and/or has relatively low levels of education, s/he is less likely to use or have use of the internet. ${ }^{81}$ Recent immigrants often have low incomes and hold highly precarious temporary and part-time jobs. It is workers in such situations, who also often face language barriers, who are most in need of ES protection and assistance in accessing these rights.

ES stand alone in the regulation of employment rights in having no government or quasi-government funded assistance for workers who believe their rights have been violated. The government provides direct and indirect funding for information, education and legal support in areas of Health and Safety, Workplace Safety and Insurance and Human Rights, (e.g., Occupational Health Clinics for Ontario Workers, Office of the Workers Advisor, Human Rights Legal Support Centre). Few legal supports exist for workers requiring assistance with ESA matters. Ontario's Community Legal Clinic system provided ESA representation in 86 cases, 90 brief services and advice for just over 850 workers in $20088^{82}$ There are no legal aid certificates for ESA matters. Furthermore, the $\$ 10,000$ cap on ESA claims means that few private bar lawyers would represent workers on ESA matters. Workers are left to learn how to make a complaint on their own. Workers have to go back and forth between the ESA guide (over 100 
pages), the guide to the claim form, and the claim form itself, often going through the three documents on the MOL website. Workers may not only need legal information about ES, but also knowledge about how to connect that information to their particular situations. They may also need assistance in determining entitlements, in preparing the narrative of what happened, and in identifying supporting documentation. The MOL does not provide this assistance. The ESA has a time limit of 6 months to file a claim. Job dislocation and difficulties learning how to pursue ES rights means some workers only find out about the ES claims process after the 6 month limitation period has passed. The claims process is difficult for workers who are not proficient in written English. A 2008 study on linguistic access to legal services provides a rough estimate that as many as half a million people in Ontario might need an interpreter in pursuing legal matters. ${ }^{83}$ There are no language interpretation services to assist in the filing of claims or investigation of claims. Workers are left to rely on support from friends, family or community members to assist them in filing a claim.

Literacy is also a factor in enforcing ES through the claims process as workers are required to submit a claim form to initiate investigation. Low levels of literacy affects labour market outcomes in a way that establishes a strong link between employability, income and literacy proficiency. People with lower literacy are more likely to be pulled into low-wage and precarious work where higher rates of violations occur. Furthermore, linking literacy and social position, the International Survey of Reading Skills found that "individuals with low literacy skills were older, less educated, immigrants or had a mother tongue other than English or French.." ${ }^{84}$ Even though the ESA is a rightsconferring piece of legislation, the process for addressing violations of those rights has 
shifted to dispute resolution. Workers are expected not only to make a complaint about the violation but also to make their own case that the employer has violated their rights. When the employer holds all of the employment records, this process can be time consuming, with ESOs going back and forth between employer and employee. If there are fact-finding meetings, workers, who are often in another job, must take time off from employment, generally without pay. There is no remedy under the ESA to provide workers with compensation for the substantial time and resources spent trying to obtain the wages and entitlements they have earned, much less any interest on wages that may go unpaid for well over a year.

\section{Minimum Wage}

The Canadian economy has grown in the past 30 years. However, an increasingly unequal distribution of the rewards of employment is leaving more workers struggling to get by. In Ontario, provincially-regulated minimum wages have institutionalized low wages that fail to keep up with the cost of living. Indeed, Ontario's minimum wage has fallen 21 percent below the peak levels of the mid-1970s. A person working in Toronto full-time at minimum wage ( $\$ 10.25$ an hour) has earnings that leave her below Statistics Canada's Low Income Cut-Off (LICO). ${ }^{85}$ Anyone working at minimum wage and supporting a family would earn well below the LICO. Recent immigrants are particularly hard hit by low wages. Racialized women workers earn 47 percent less than nonracialized men and 15 percent less than non-racialized women workers. ${ }^{86}$ This is due, in

part, to the lack of recognition of non-Canadian credentials, experience, and expertise. ${ }^{87}$

To return to the principle of decency outlined at the beginning of this report, as Arthurs concludes in his review of the federal labour code, "no worker should be paid so 
little, that, after working full-time at a regular job for a full year they still find themselves with less money than they need to live at or just above the poverty line." ${ }^{88}$ At present there is no policy formula under the ESA to determine the level of minimum wages. Rather, they are increased in an ad hoc manner.

\section{Compliance, Self-regulation and Enforcement}

The MOL announced recently that the backlog of claims will be eliminated by March 2012, at which point it will partner and consult with employer and employee groups as it shifts resources to inspections: "through our enhanced compliance strategy, we will continue reaching out to employers through a mix of education, outreach and enforcement to help ensure we stem any problems before they arise and enforce the legislation". 89

The compliance model of ES regulation assumes that virtue will trump employer self-interest. ${ }^{90}$ One report prepared by the MOL states:

...[e]mployers want to comply with the law because it is the right thing to do. The ministry is helping them to do just that. Employers also want to comply with the Employment Standards Act because they know it benefits them - compliance can reduce legal costs, improve staff retention and increase productivity. The vast majority of employers know that a fair workplace is a productive and efficient workplace - making for a better bottom line. ${ }^{91}$

This view eclipses employers that face conflicts between ES compliance and profits, particularly when competing with employers operating below minimum standards. Further, this view of employer behaviour does not recognize the power imbalances 
between employers and employees that the ESA is intended to address. While the MOL establishes targeted inspections for those at high risk of violation, it leaves a core model of employer self-regulation and reliance on employer voluntary compliance. ${ }^{92}$

\section{ESA Gaps and Loopholes}

The way work is organized has changed drastically over the past 30 years The ESA does not address these new forms of work organization creating institutional incentives to reduce employer liabilities.

As noted above, unions are prevented from filing ESA complaints. As the discussion of OHS later in this paper demonstrates, the participation of unions in the regulation of OHS has strengthened both health and safety standards and their enforcement. Arguably, the separation of the collectivized voice of unions from nonunionized workers has weakened ES regulation, particularly in terms of testing new forms of work at appeals of ESO decisions at the Ontario Labour Relations Board and pressure for improved minimum standards from which to bargain from.

History demonstrates that employers create new, unforeseen and unprotected work arrangements. That is why an essential step to improving enforcement must be to expand the scope of the ESA to include all who work and all work arrangements. In this way we remove the incentives and statutory mechanisms allowing employers to move some forms of work beyond the reach of employment standards. By requiring all work to meet basic minimum employment standards, we can finally establish a level playing field for employers and a minimum floor of rights and standards for workers and society. 


\section{OCCUPATIONAL HEALTH AND SAFETY (OHS)}

\section{A. Ontario Legislation -- The Occupational Health and Safety Act}

The Occupational Health and Safety Act (OHSA) is the principal vehicle through which the Ontario government protects Ontario's workers from being exposed to unacceptably hazardous working conditions. It does so by imposing duties on employers, supervisors, workers and others to comply with standards established by the Act and the regulations made pursuant to it. As well, it requires the employer to establish a system to manage OHS that includes the appointment of competent supervisors, preparation of a written OHS policy, and provision of information to health and safety representatives or joint health and safety committees. The legislation also provides for workers to be involved in OHS management at their workplaces through a right to know about hazards in the workplace, a right to participate through the appointment of health and safety representatives, and a right to refuse unsafe work without the threat of retaliation for doing so.

The Workplace Safety and Insurance Act is involved in prevention principally through the provision of financial incentives administered through its various experience rating plans. It used to also be involved in prevention through its supervision of safe workplace associations and other educational and promotional activities. However, recently, in response to recommendations from the Expert Advisory Panel on Occupational Health and Safety, known as the Dean Report, ${ }^{93}$ these functions were transferred to the OHS Division (OHSD) of the MOL by Bill 160 (2011). 
Since this report is focused on enforcement and compliance, these educational and promotional aspects of the MOL's mandate are not reviewed here, although they are discussed in the context of best practices. The discussion of enforcement, however, necessarily considers the management systems dimension of the OHSA legislation since the two dimensions of the legislation cannot be separated.

Indeed, it is useful at this point to draw out a distinction between two different kinds of regulation. On the one hand, the OHSA, and the regulations promulgated under it, sets out specific standards that must be obeyed. For example, designated substance regulations limit worker exposure to various harmful substances such as lead and asbestos. These are known as specification standards. On the other hand, the OHSA also requires employers to create or engage in certain processes to manage OHS. A good example is the recent violence and harassment sections of the Act that require employers to prepare policies that have a certain minimum content, conduct a risk assessment, and provide workers with information and instruction (OHSA, Part III.01). These are known as process standards.

The OHSA applies to nearly all provincially regulated employers and binds the Crown (s.2). Sections of the Act also apply to independent contractors (s.4). It does not, however, apply to work performed by the owner or occupant, or a servant of the owner or occupant in or about a private residence (s. 3(1)). As a result, domestic workers employed by the owner or occupant fall outside the act, a matter of some concern given the precarious and vulnerable situation of such workers.

Unlike most employment law, the OHSA is not built on the platform of the contract of employment. Rather, rights and duties depend on establishing a "worker" 
status. Worker is defined as "a person who performs work or supplies services for monetary compensation" (s. 1). Also, employer is defined as a person who employs one or more persons or contracts for the services of one or more workers, and includes a contractor or a subcontractor who performs work or supplies services. As a result, an employer owes the same duties to self-employed persons it hires as it does to employees. Thus, for example, the Ontario Court of Appeal recently held that a company that hires truck drivers as independent contractors was nevertheless required to establish a joint health and safety committee because it regularly employed twenty or more workers. ${ }^{94}$

Inspectors have broad powers to enforce the OHSA. They are authorized to enter into any workplace at any time without a warrant or notice (s. 54(1)). The only exception to this is with respect to dwellings used as workplaces. In this setting, inspectors may only enter with the consent of the occupier or under the authority of a warrant (s. 54(2)). Again, this exception may be significant for some precarious or vulnerable workers who are working at home.

Once in the workplace inspectors have authority to examine and handle equipment and materials that are present, to require production of documents, to conduct tests, to be accompanied and assisted by experts, to require the employer to conduct tests, etc (s. 54(1)). The inspector is also authorized to question any person and every person must assist the inspector in the performance of her or his duties (s. 62). Where the inspection becomes an investigation into a suspected violation of the Act because the inspector has reasonable and probable grounds to believe that an offence has been committed, a warrant will be required and can be obtained under the act. ${ }^{95}$ 
Where the inspector finds a violation of the Act, he or she has a variety of enforcement powers. The inspector can issue an order to comply and specify either that the order be carried out forthwith or at some specified date in the future (s. 57(1)). The inspector may also order the employer to submit a compliance plan (s. 57(4)). Where the inspector finds that the violation presents a danger or hazard to the safety of a worker, he or she can issue a stop work order. Work may not be resumed until the inspector withdraws the order after an inspection. However, work may be resumed pending an inspection if a worker representative advises the inspector that in her or his opinion the order has been complied with (s. 57(6-7)). Inspectors' orders may be appealed to the Ontario Labour Relations Board within 30 days and the Board has the power to suspend the operation of the order pending a disposition of the appeal (s. 61). Inspectors do not have the power to prosecute violations of the act although they can recommend that a prosecution take place. They may, however, issue tickets under Part I of the Provincial Offences Act (POA) for contraventions of the Act that are listed in schedules issued pursuant to $\mathrm{O}$. Reg. 950 promulgated under the POA. There is a set fine that may be paid without a court appearance or a defendant may elect to have the charge tried. Employers, supervisors and workers can be ticketed. The ticketing power was substantially enlarged in 2005. Previously, tickets had been used in construction but they now cover a much wider range of contraventions. There are now 81 ticketable offences. Workers are the target of 30 , supervisors the target of 31 , and employers of $21{ }^{96}$ The set fine is determined by the Senior Justice of the Ontario Court of Justice. They were last updated at the beginning of 2010 . Current fines are either $\$ 195$ or $\$ 295$ per offence. ${ }^{97}$ Inspectors can also issue summonses under Part I for any violation of 
the OHSA. When a summons is issued, the defendant must make a court appearance and the maximum fine on conviction is $\$ 1000$.

More serious offences are prosecuted under Part III of the POA. The decision to prosecute is made by the Legal Services Branch (LSB) of the MOL, which also conducts the prosecution. Defendants can raise a due diligence defense but they bear the burden of proving that they took every precaution reasonable in the circumstances to comply with the law. Upon being convicted, an individual may be fined up to $\$ 25,000$ or to a prison term of not more than 12 months, or both. A corporation may be fined up to $\$ 500,000$.

Finally, it should also be noted that employers may also be charged under the Criminal Code. While in theory employers always could be charged with criminal offences, such as criminal negligence, historically it had been attempted rarely and succeeded only once. ${ }^{98}$ The enactment of the so-called Westray Bill, Bill C-45, in 2003 facilitated the prosecution of such charges. It imposes a duty on all persons "directing the work of others" to take reasonable steps to ensure the safety of workers and the public. It also creates new rules for attributing criminal liability to organizations, including corporations, and identifies factors that should be used to sentence an organization convicted of a criminal offence.

In sum, OHS law imposes enforceable duties on employers, supervisors, workers and others to provide a safe and healthy workplace, to adopt specified OHS management practices and to work safely. To obtain compliance with these duties, OHS inspectors can choose from among a wide range of measures. In addition to nonstatutory mechanisms, such as providing advice and persuading, enforcement actions 
range from issuing an order to launching a criminal prosecution. The important question, which the next section addresses, is how these powers are exercised.

\section{B. Mapping OHS Enforcement}

The translation from law on the books to law in action is crucial to the effectiveness of any regulatory scheme, including OHS. This section examines the current practice of OHS compliance and enforcement activities by the MOL. Before doing so, however, a bit of background on the history of OHS enforcement is necessary since patterns of past practice may play a role in shaping current ones.

OHS regulation has its modern roots in late nineteenth-century factory legislation. The Ontario Factories Act was passed in 1884 and came into force 2 years later. The Act contained special provisions regarding child and female labour, but also set general health and safety standards for all workplaces covered by the Act. In addition to a general duties clause, the law made provision for machine guarding, sanitation, lighting, ventilation etc. Crucially, it also provided for the appointment of inspectors who were empowered to enter workplaces and issue orders. Violation of the Act was an offence punishable by fine and imprisonment.

Consistent with the practice of factory inspectors in other jurisdictions, Ontario's factory inspectors adopted a persuasion model of enforcement. Employers were advised about problems in their workplaces and recommendations for improvement were made. Prosecutions were almost never launched. Inspectors justified this approach on the basis that it was more effective in securing compliance from employers who were generally disposed to comply with the law. Trade unionists, however, took a very different view, arguing that the act was not being enforced and that, as a result, 
workers were being killed and injured at alarming rates. This was especially so in the wake of a second industrial revolution beginning in the late-nineteenth century, which was marked by more mechanization and labour intensification. ${ }^{99}$

Without reviewing debates about the effectiveness of the persuasion strategy, the important point here is that it became institutionally entrenched so that the default practice of inspectors was to engage with employers in a manner that minimized conflict. Essentially, inspectors sought to advance workplace health and safety by providing advice and attempting to convince employers to take remedial measures. Prosecution was a last resort and was resorted to rarely.

This institutional practice received a new impetus when OHS laws were revamped in the late 1970s to create the legislative framework described in the previous section. It will be recalled that among the law's many innovations was the addition of what is now described as an occupational health and safety management (OHSM) approach to regulation, which required employers to adopt certain processes to create what was then called an internal responsibility system (IRS). This existed alongside a more traditional external responsibility system (ERS) that built on specification standards and their enforcement.

In the years immediately following the enactment of OHSA, the government adopted a policy of promoting the IRS with a view that the ERS would play a secondary role, dealing with the projected minority of situations in which the IRS failed to function effectively and, at a minimum, achieve compliance with the minimum specification standards. As a result, inspectors were instructed to minimize the number of enforcement actions they took and instead to get the workplace parties to work 
cooperatively through the joint health and safety committee to better address $\mathrm{OHS}$ concerns and problems. ${ }^{100}$ Such an approach to inspection and enforcement was consistent with the traditional practices of inspectors under the previous regime.

Needless to say, this approach proved to be terribly controversial and worker OHS activists decried what they perceived to be a failure of enforcement, much in the way their predecessors had in the late-nineteenth and early-twentieth century. Ontario governments responded to this pressure in a variety of ways, including amendments to the OHSA that more deeply institutionalized joint health and safety committees and that increased penalties (Bill 208, S.O. 1990, c. 7.). However, it was not until the mid-1990s that a significant change in enforcement practice was implemented, putting greater emphasis on the ERS, entailing both more enforcement actions by the inspectors and prosecutions for offences, especially when violations resulted in fatalities or serious injuries. ${ }^{101}$ This pattern of practice, which still prevails, will now be described in more detail.

There are many measures of enforcement practice. A logical way of mapping is to start with the most basic intervention, in this case simply the fact of an inspection, and to move up to the more assertive measures, here ending with criminal prosecutions.

\section{Inspections}

As Graph 3 demonstrates, in recent years there has been an upwards trend in the activity levels of inspectors, which has been supported by an increase in the complement of inspectors. Between 2005 and 2010, the government doubled the number of OHS inspectors to a total of 430. 


\section{Graph 3. OHS Investigation and Inspections}

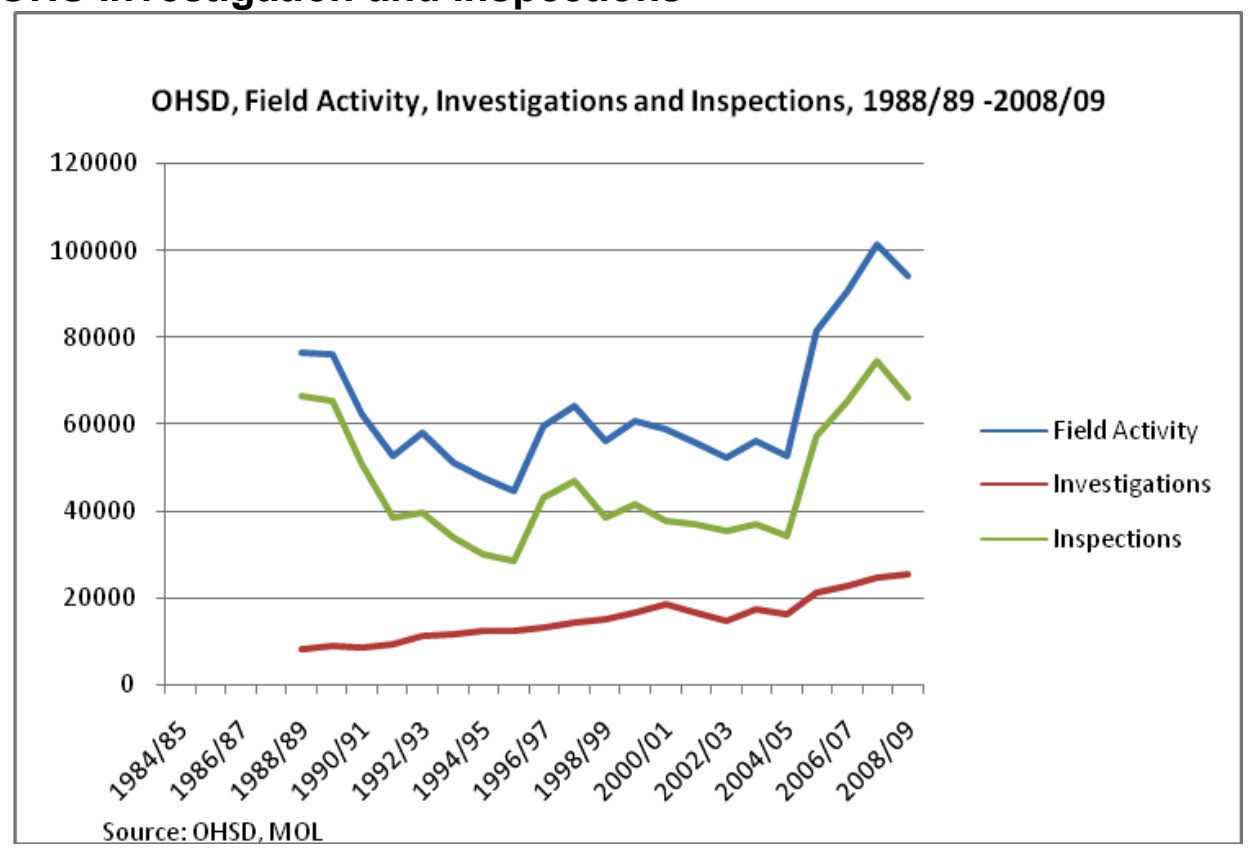

Field activity is the broadest category and includes any visit by an inspector to a workplace to enforce the OHSA. It includes inspections, investigations and consultations. Inspections are a subset of field activity and include visits to monitor compliance and to promote the IRS. These activities are proactive in that they are planned according to criteria devised by the OHSD. By contrast, investigations are reactive in the sense that they occur for the purpose of investigating a fatality or critical injury, complaint or work refusal. Consultations are a small component of field activity and have not been included in this chart.

What these data show is not only that field activity has significantly increased over the past twenty years, but that the greatest share of this is the result of an increase in proactive investigations. It is necessary, therefore, to say a few words about the criteria that are used to schedule proactive investigations. It is infeasible address the allocation criteria used over the entire 20 -year period. Thus, what follows focuses on the 
most recent strategy adopted by OHSD beginning in 2005/06, which is now known as Safe At Work Ontario. ${ }^{102}$ The OHSD has adopted a risk-based approach to regulation in which they target workplaces for inspection based on a publicly stated set of criteria that include:

- injury rates and claims cost

- compliance history

- hazards inherent to the work

- new businesses

- $\quad$ size of business

- specific events or incidents such as critical injuries and fatalities

- the presence of new and/or vulnerable workers ${ }^{103}$

On the basis of these criteria, sector plans are drawn up that specify how proactive inspection resources will be deployed. The most recent set of plans cover 2011-12. Within this context, heightened enforcement campaigns, better known as "Safety Blitzes" are planned and announced in advance. For example, for the industrial sector, five safety blitzes are planned for the year: new and younger workers; tower crane suppliers; personal protective equipment; racking and storage; and musculoskeletal disorders. ${ }^{104}$

This leads to the next question: what do inspectors do during a field visit? There are actually no field studies that have been conducted examining the practice of inspection and so this description is based on both documentary and statistical sources. Inspectors are accompanied by the employer and a worker representative who is entitled to be paid for the time spent. Where there is no worker representative, the 
inspector is required by statute to consult with a "reasonable" number of workers who are physically present (s. 54(3-5). The Act does not specify whether the inspector is to consult with workers outside of the presence of the employer and the normal practice is unclear.

At the end of an inspection, the inspector prepares a report that may make recommendations and, if there are contraventions a written order to comply within a set time frame will be issued. If there is a contravention that creates an immediate danger to a worker or a member of the public, the inspector may issue a stop work order. Graph 4 presents data on the frequency of these orders over the past 20 years.

\section{Graph 4. OHS Orders}

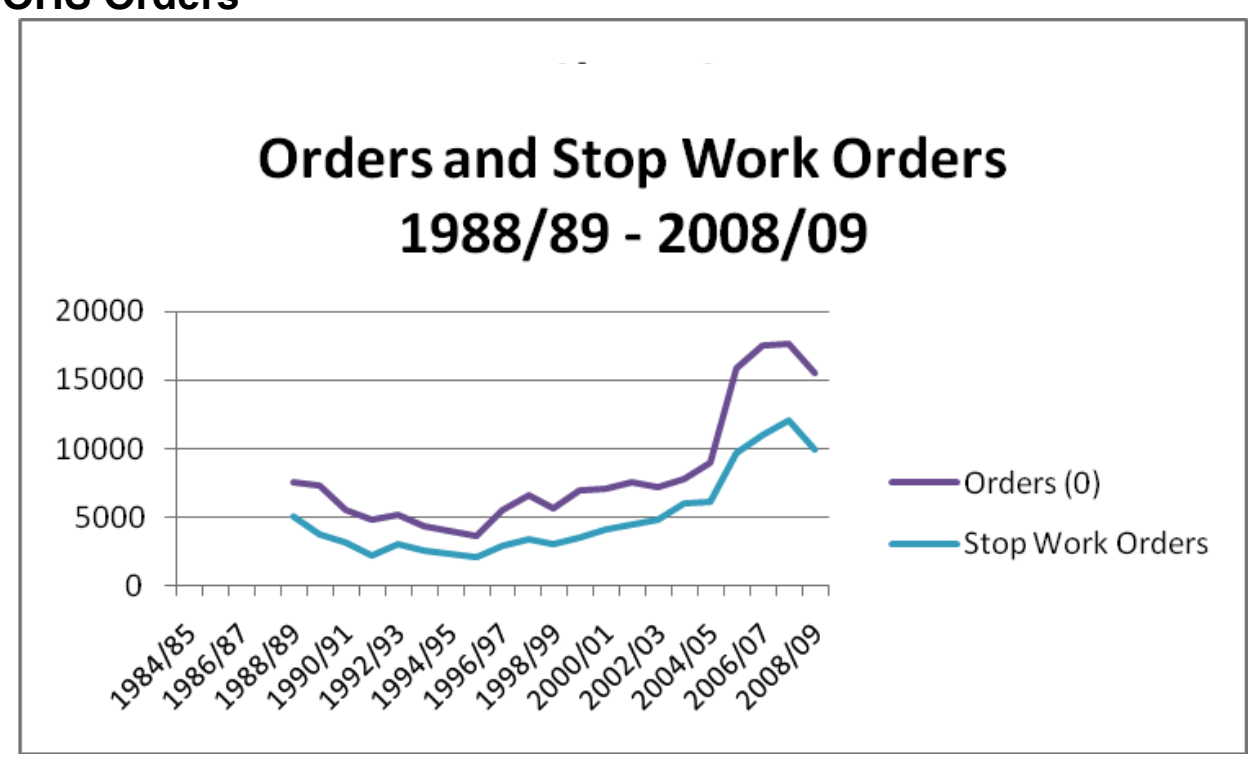

These data indicate there has been an increase in orders and stop work orders that is consistent with the increase in inspection activity, which is evidence that the increase in inspections is not merely cosmetic, in the sense of simply bumping up the numbers, but that enforcement powers are being exercised during these visits, including the stop work power which has immediate consequences to the employer. 


\section{Prosecutions}

Data on prosecutions is kept by the LSB, which over the years has changed the way it records its activities. As a result, it is more difficult to construct a time series. There are however, data from 1993 for fines and from 1997 for convictions that indicate an increase in prosecutions and fines, particularly since 2005 (Graph 5).

\section{Graph 5. OHS Penalties}

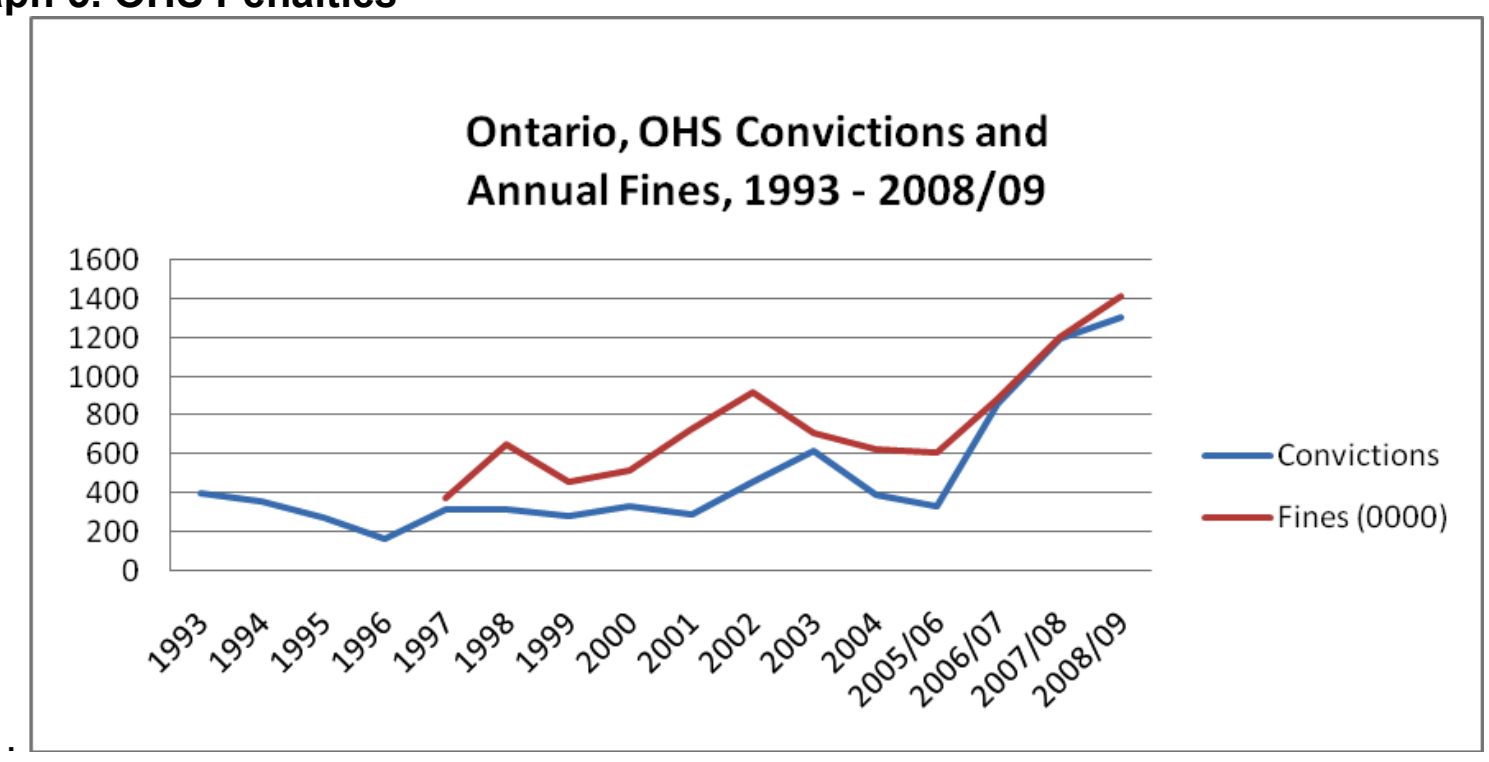

The picture is nevertheless complicated because the data includes both Part I and Part III prosecutions, which means that the numbers after 2005 are inflated by the expansion of the ticketing system, which permits inspectors to impose on-the-spot fines on employers, supervisors and workers. In practice, workers and supervisors receive about 37 percent of summonses each, while employers receive 25 percent. As Garry Gray has noted, this targeting blurs the definition of who is an OHS offender and diffuses responsibility. ${ }^{105}$ It also has resulted in a reduction in the average fine per conviction (Graph 6). 


\section{Graph 6. OHS Prosecutions}

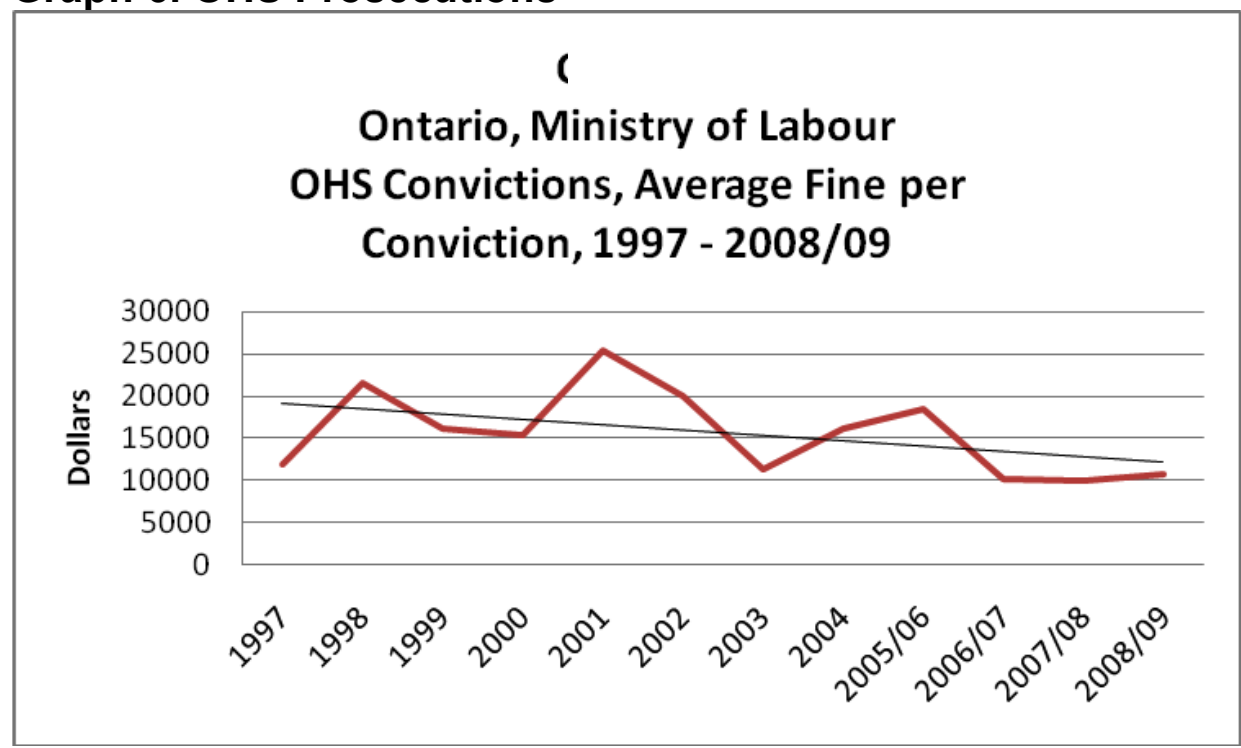

Data that disaggregates Part I and Part III prosecutions have been obtained from the LSB for 3 years, $2007 / 08$ to $2009 / 10$. The data show that while, on the one hand, there has been an increase in the more serious Part III prosecutions over these years, from 369 in 2007/08 to 445 in 2009/10, on the other, the average fine per conviction for these more serious offences has been declined from $\$ 35,303$ to $\$ 28,839$. $^{106}$

There has been little resort to the use of the criminal sanctions notwithstanding the enactment of Bill C-45, which came into force in 2004. Across Canada, less than 10 criminal charges have been laid. Three criminal cases have been brought in Ontario. The first charge criminal charge arose out of ditch collapse that killed a worker in Newmarket, Ontario. The charge was laid in 2004 and was resolved by a plea deal in which the criminal charge was dropped in exchange for a guilty plea to violations under the OHS statute. ${ }^{107}$ The second criminal prosecution in Ontario was launched against Millenium Crane, the company's owner, and the crane operator at the time. However, in this case too the charges were dropped after an engineering report failed to support the prosecution's case. ${ }^{108}$ The third prosecution, which is pending at the time of writing, 
arose out of a scaffolding collapse that killed four workers on Christmas Eve 2009. The accused include the Metron Construction Co. and three of its officials. ${ }^{109}$

In Quebec, two cases have resulted in a conviction. In Transpavé Inc., involving a workplace fatality, the accused pleaded guilty and was fined $\$ 110,000.00 .^{110}$ The first conviction after a trial was obtained against Pasquale Scrocca, a landscape contractor. In that case, an employee died when the brakes on a backhoe Mr. Scrocca was driving failed, pinning the employee against a wall. Scrocca received a conditional sentence of imprisonment for two years less a day to be served in the community with conditions, including a curfew. ${ }^{111}$ One case, R. v. Gagné, Steve Lemieux and Simon Gagné, ended with an acquittal. In that case, charges were laid following a collision between a train and a maintenance vehicle, which resulted in one death and three injuries. The two accused individuals were employees of Québec-Cartier: Steve Lemieux, was the train operator, and Simon Gagné, was a foreman. Justice Dionne found that the mistakes made by the employees arose from a corporate culture of tolerance and deficient training, not wanton and reckless disregard for the lives and safety of workers on the part of the accused. In principle, this finding could have resulted in a conviction of the corporation, but it had not been charged. ${ }^{112}$ There is at least one case still pending, against Mark Hritchuk, the service manager at a car dealership, where an employee died after catching fire due to a broken fuel pump. ${ }^{113}$

Finally, in British Columbia, the United Steel Workers launched a private prosecution in 2010, arising out of the death of a Weyerhauser employee in British Columbia in 2004 . The company was previously assessed a penalty of nearly $\$ 300,000$ by the $\mathrm{BC}$ compensation board. A court has ruled that the union presented enough 
evidence for the case to go forward, but the Crown subsequently intervened to terminate the prosecution. ${ }^{114}$

Overall, the experience so far of using the Criminal Code to prosecute corporations and individuals for OHS crimes is proving to be difficult. In Ontario, two of the three prosecutions ended with the criminal charges being withdrawn. The third case is still pending. Convictions have been obtained in two cases in Quebec. In the Transpavé case, the corporation was sentenced to a fine of $\$ 100,000.00$ which was significantly higher than the maximum penalty $(\$ 20,000)$ then available under Quebec health and safety law. The only jail sentence was against a small business operator who was personally operating the equipment that caused the death. While it is possible that the threat of criminal prosecution has a broader general deterrent effect, and may be used to leverage guilty pleas under provincial legislation, more research would be needed to establish whether that is so.

The analysis returns to an evaluation of the practice of OHS enforcement in subsequent sections on best practices. However, it is worth emphasizing here that proactive inspections, reactive inspections with prosecutions for violations that harm workers, and workers' voice are all strongly embedded in the enforcement regime, in addition to voluntary compliance measures, and that although the relative importance of each has varied over time, these features have survived through Progressive Conservative, Liberal and New Democratic Party governments. Indeed, except perhaps for a short period immediately after the enactment of the OHSA, a strong commitment to state enforcement has undergirded the OHS regulation regime in Ontario. 


\section{COMPARISON OF ES AND OHS ENFORCEMENT IN ONTARIO}

The purpose of this brief section is to compare and contrast ES and OHS enforcement in Ontario globally, as well as on the dimensions of proactive, reactive, and voluntary enforcement.

\section{A. Global Assessment}

At the most general level, it is clear that OHS regulation and enforcement is far more proactive and focused on preventing violations than ES enforcement. The latter is largely dominated by individual complaints about violations that have occurred with a much smaller role played by proactive inspections or other preventive measures. This difference is manifest not just in the allocation of enforcement resources between proactive and reactive inspections, but is also evident with respect to voluntary enforcement. Worker voice in the ES scheme is almost exclusively a reactive voice heard through complaints about violations that have occurred. This tendency has been furthered by recent changes that require, in most cases, that workers first contact the employer before an official complaint will be entertained by the MOL. The picture in OHS regulation is different insofar as employers are required to establish a system for managing OHS in order to prevent violations from occurring in the first instance and workers are given a voice in the detection and correction of problems before violations materialize or, failing that, before violations result in work injuries. Moreover, workers are not required to first exercise their voice internally before seeking enforcement action. They can always call an inspector.

While, on the one hand, these differences might seem to be perfectly understandable based on the difference between wage and hour violations that, in 
principle, can be corrected by financially compensating the worker, compared to health and safety hazards that might materialize in death and disablement for which financial compensation can never be adequate. On the other hand, the differences can also be overstated. Workers who experience ES violations, especially ones that persist over time, may suffer losses to the quality of their lives and the lives of those who depend on their incomes that are not fully redressed even if full compensation is paid retroactively. Enforcement of a minimum floor of ES standards is central to labour market regulation. Further, as the Ontario provincial government recognizes in its Poverty Reduction Strategy, ES are key to creating fair wages and working conditions and reducing poverty. ${ }^{115}$ For these and other reasons, including advancement of the broader principles of decent work, social minima, universality, and fairness, the prevention of ES violations is also an important public policy goal that currently is not being pursued to nearly the same extent that it is in OHS regulation.

Although the best practices section to follow returns to this theme, in a report for a project on vulnerable workers, it is also important to emphasize that this group of workers is most dependent on a strong, state-centred regime for the enforcement of their rights, whether it be in the realm of ES or OHS. Voluntary compliance is less likely to succeed in an environment in which workers are least likely to know their rights and most vulnerable to retaliation or its threat, even when retaliation is unlawful. For the same reasons, reactive enforcement in response to complaints is also less effective for vulnerable workers. Proactive enforcement, supplemented by meaningful participation by worker organizations so that workers' voices can be heard in the regulatory regime, is essential. 


\section{B. Voluntary Compliance}

Substantial reliance is placed on voluntary compliance in ES and OHS regulation in the sense that both systems are built around the assumption that most employers are motivated to obey the law and have the capacity to do so, especially if they are provided with a modest level of compliance assistance by the MOL or other agencies.

In the case of ES, the MOL provides information to both employers and employees through phone, email, and its website. The more important innovation, however, has been the addition of a requirement that workers who believe they have suffered an ES violation first attempt to resolve the matter with their employer before an ES complaint will be accepted by the MOL. Clearly, the objective is to encourage workers to become more self-reliant, give employers the chance to correct errors when they are pointed out to them, and to reduce the flow of complaints to employment standards officers.

In the context of OHS, voluntary compliance is not only a major goal, but it is one that is supported by a much broader range of institutional arrangement than is the case in ES. Not only does the MOL provide information, the law requires the establishment of internal responsibility systems that involve training, information sharing, worker participation, etc. As well, for many years the workers' compensation system had a mandate to improve accident prevention which it did in a variety of ways, not the least of which was to fund safe workplace organizations that provided information, training and support around OHS issues. Recently, the prevention mandate was shifted to the MOL and is overseen by a Prevention Council and a Chief Prevention Officer. 
Workers are also supposed to play a major role in the voluntary enforcement system, not only by working safely themselves, but by being given a voice in the internal responsibility system to participate in hazard identification and the development of firmlevel OHS policies and practices. It is notable, however, that although in the early 1980s the MOL sought to force worker concerns to be run through the IRS before it would act, that policy has long since been abandoned so that it is no longer the case that the MOL will only initiate enforcement activities after it has been demonstrated that the worker cannot resolve the matter directly with the employer.

\section{Reactive Enforcement}

As has been noted, beyond supporting voluntary compliance, reactive enforcement is the principle strategy for addressing ES violations. Moreover, reactive enforcement is generally limited to responding to the specific complaint of the employee. Curiously, the MOL abandoned the strategy of treating a complaint as being good evidence of more systemic problems and launching a broader investigation of ES compliance at firms where employees were registering complaints. This has had the result of eliminating a good risk-based technique for identifying areas where the investment of enforcement resources is likely to produce significant benefit to at-risk workers. In general, the inspection process follows a pyramid-based approach in which the majority of complaints are settled without further administrative action, with a decreasing number being resolved by the use of stronger enforcement measures, including orders and prosecutions for non-compliance.

In the area of OHS, more resources are invested in proactive enforcement than in reactive measures and this trend has been growing for some time. Reactive 
enforcement results in a range of measures being taken when violations are detected, from the provision of advice to issuing compliance orders, issuing stop work orders, provincial offence prosecutions and, rarely, criminal charges. As in ES, there is an enforcement pyramid with the more serious sanctions being reserved for a smaller and smaller number of instances as the seriousness of the violation and resulting harms increases.

\section{Proactive Enforcement}

As noted above, OHS enforcement places a far greater emphasis on proactive measures than ES enforcement. This is true notwithstanding that in response to an auditor general's report in 2004 the ES branch increased the number of proactive inspections. Both branches target proactive inspections using measures that identify areas where non-compliance is likely to be above the norm. Proactive inspections in both areas result in a range of enforcement actions, from providing advice and encouragement at the bottom of the pyramid to issuance of compliance orders and tickets. Interestingly, the pyramid of enforcement measures arising from a proactive ES inspection seems to be higher than in OHS inspections, which rarely go beyond orders and tickets. 


\section{Best Practices from Outside Ontario}

Thus far this report has demonstrated the limitations of Ontario's ES and OHS enforcement regimes. The next step in developing appropriate policy recommendations involves considering practices outside Ontario.

\section{A. Employment Standards Enforcement}

The overarching critique of the ES enforcement regime herein relates to its reactive emphasis with limited use of proactive measures as well as complementary 'softer' measures focusing on voluntary compliance through self-regulation. Recall that proactive enforcement is an approach aimed at preventing violations, that is, in the first instance heavily reliant on inspections and expanded investigations when violations are detected. ${ }^{116}$ In turn, reactive enforcement is a strategy aimed at providing redress for workers dependent upon complaints to trigger regulatory intervention. Finally, voluntary compliance is a strategy of self-regulation involving largely education and promotion in the first instance and negotiated settlements when complaints arise. ${ }^{117}$

Despite this critique of the reactive focus of ES enforcement, it is important to acknowledge that almost all regulatory regimes use a mix of hard law, soft law (e.g., employer awareness programs and self-regulatory techniques), economic incentives, worker participation, etc. and that this will continue to be the reality. The crucial question is how these strategies are best combined to improve the quality of enforcement (i.e., to maximize the effectiveness of investigations and inspections, penalties and settlements, and the voice ${ }^{118}$ of those affected): which 'mixed' models of enforcement have been found to be effective and which models have been found to be ineffective? Furthermore, what innovative community-based practices aimed at 
improved enforcement exist outside Ontario, including those in which workers' advocates and unions play an active role in documenting and redressing violations?

This section addresses these questions by surveying the research literature and government reports covering best practices in ES in Australia, the United Kingdom, and the United States, as well as in other Canadian jurisdictions. ${ }^{119}$ It does so against the backdrop of problems identified with Ontario's ES enforcement regime highlighted in earlier in this paper, in particular the four foremost concerns identified in the 2004 report of Ontario's Auditor General (several of which were reiterated in its 2006 report): first, the limited number of proactive inspections undertaken by the Ministry despite its commitment to conduct them; ${ }^{120}$ second, the lack of extended investigations ${ }^{121}$ of substantiated claims to "cover other employees of the same employer to determine whether additional violations had taken place"122 ; third, the failure to prosecute many such repeat offending employers; ${ }^{123}$ and, fourth, the weaknesses in the collection of amounts in default owed to employee claimants by employers. ${ }^{124}$

In identifying best practices, the analysis is also attentive to other limits of reactive ES enforcement regimes identified in the research literature pertinent to the Ontario case. Such shortcomings encompass, in the area of investigations and inspections, the outmoded nature of ES enforcement regimes with respect to the growth of subcontracting, specifically, the dearth of measures to address the dynamics of supply chains, especially enforcement in small firms operating at the bottom of these chains, ${ }^{125}$ the infeasibility of achieving comprehensive coverage within a geographicallyfocused inspectorate since it requires inspectors to cover an inordinate amount of ground, ${ }^{126}$, the relative inattention to high-risk industries, ${ }^{127}$ the lack of offices of a 
workers' advocate in most jurisdictions, ${ }^{128}$ and the limited interagency collaboration in sharing information pertinent to the detection of violations. ${ }^{129}$ In the area of penalties and settlements, deficiencies commonly identified include the tendency towards minimal penalties or sanctions; this shortcoming relates both to the relatively low level of settlements workers typically receive (i.e., settlements below those statutorily required as a consequence of the mediation process) and, in the case of Ontario, as elsewhere, to the fact that employers "benefit from 'voluntary compliance' [of this sort] ... because it keeps their violation off the enforcement track," meaning that they are unlikely subjects of extended investigations in instances where they might occur, nor are they required to pay fines and administrative fees accompanying orders issued. ${ }^{130}$ Finally, in the area of voice, countless studies point to the failure to provide for third party involvement in the enforcement process in most contexts, that is, from complaints procedures to investigative activities and settlements processes. ${ }^{131}$

A range of best practices from other jurisdictions are noteworthy in responding to problems associated with a principally old style reactive regime. Consistent with the goal of cultivating an effective 'mixed model', in what follows these best practices are divided by those that are proactive, reactive, and voluntary.

\section{Proactive Practices}

The greatest number of promising initiatives for replication fall in the proactive grouping, most of which relate to investigations and inspections and to voice. Many such initiatives emanate from the United States, where a great deal of experimentation is taking place in the context of low rates of unionization, and Australia, a context in which workers have confronted decollectivization in the last few decades, partly via the 
centralization of industrial relations, and the import of a North American style enterprise bargaining, cultivating greater reliance on ES as the main source of protection.

\section{(i) Investigations and Inspections}

With regard to investigations and inspections, a growing body of literature points to the importance of targeting high-risk industries and within these industries structures at the top. Weil characterizes this strategy as critical to 'strategic enforcement' that applies four criteria to enforcement decisions - prioritization (i.e., choosing sectors carefully based on where intervention will have a high impact given factors such as the known level of violation and the vulnerability of the workers), deterrence (i.e., the threat of investigation), sustainability (i.e., the possibility of avoiding repeat offences), and system wide impacts - and he illustrates its effectiveness in several sectors characterized by large pyramidal structures (i.e., garment, fast food and hotels). ${ }^{132}$

Responding partly to the impetus for change coming from Weil's research findings, the Wages and Hours Division (WHD) of the U.S. Department of Labor began to embrace strategic enforcement in its activities under the Obama administration by ramping up inspections, increasing funding, and, most importantly, establishing a new plan/prevent/protect departmental orientation which it describes as follows:

"[b]ased on the principle that employers and others must "find and fix" violations - that is, assure compliance - before a DOL investigator arrives at the workplace. Employers and others in the Department's regulated communities must understand that the burden is on them to obey the law, not the DOL to catch them violating the law. This principle is at the heart of this new DOL worker protection strategy. DOL is going to replace "catch me if you can" with Plan/Prevent/Protect." ${ }^{133}$ 
Through this strategy, the DOL is targeting "fissured industries" in which "employment decisions have been devolved from major employers to a complex network of smaller employers... typically operat[ing] in more competitive markets," ${ }^{\text {"134 }}$ specifically the hospitality, janitorial, construction, and agricultural sectors, for large enforcement sweeps as well as educative campaigns.

For example, in 2011, the Department initiated an enforcement sweep focusing on the bottom of the fissured pyramid of production in the agricultural industry, beginning in South Florida and continuing up the Eastern Coast of the U.S., to increase compliance and inform workers of their rights under the Migrant and Seasonal Agricultural Worker Protection Act (MSAWPA), the Fair Labor Standards Act (FSLA), and the Occupational Safety and Health Act's Field Sanitation Standard. ${ }^{135}$ Under this initiative, by June, it had conducted over 20 investigations, recovered $\$ 670,770$ in back wages for approximately 600 agricultural workers, and assessed over $\$ 128,850$ in penalties, finding violations such as "paying workers less than the federal minimum wage, and paying workers at packing sheds who did not qualify for the FLSA's agricultural exemption 'straight time' for all hours worked, rather than time and one-half their regular rates of pay for overtime work hours as required." ${ }^{136}$ This sweep involved sending teams of investigators to fields and packing houses to assess compliance by "facility owners, growers, farm labor contractors and all other business entities associated with these agricultural operations. Thorough inspections of transportation, field sanitation facilities, employment practices and pay records [were] conducted to ensure compliance with all applicable child labor and agricultural labor standards..137 Additionally, the Department undertook surveillance activities involving interviewing 
workers at key sites, with numerous investigators covering large geographies on the same day and involving departmental lawyers early in preparing cases for future litigation. ${ }^{138}$

On a smaller scale, there are jurisdictions in Canada beyond Ontario that report conducting proactive inspections. It is questionable as to whether they are of the calibre of best practices, as there is little evidence of either an industry or a geographic focus in any. For example, although they give complete discretion to the Director over the enforcement programs insofar as their implementation, Manitoba (S. 123 (1)) initiates proactive inspections against certain employers ${ }^{139}$ and New Brunswick (S. 58 (1)) conducts audits at random. ${ }^{140}$ Newfoundland and Labrador's Labour Standards Act also includes powers of entry and inspection (S. 64) and engages in what it calls "preventative intervention," where ESOs visit workplaces to meet informally with employers and employees to discuss their rights and responsibilities under provincial legislation ${ }^{141}$ These visits may be random or target certain employers or industries where non-compliance is evident.

More innovative in their form, legislative measures introducing a 'positive duty' for employers to prevent illegal workplace practices are also emerging elsewhere. At present, positive duty provisions are most developed in anti-discrimination law in contexts such as the United Kingdom. However, scholars such as Linda Dickens argue that this notion could be used to improve ES enforcement. ${ }^{142}$ Taking such suggestions forward, positive duty provisions are also the main feature of the new model national OHS Bill scheduled to come into effect in Australia (in January 2012), and they require more out of employers in terms of due diligence in health and safety matters than in the 
past; specifically, these preventative measures hold employers more rigorously accountable for preventing violations (i.e., for compliance). ${ }^{143}$ Notably, the Australian model law also has a wide definition of employers, which includes "officer[s]" of "person[s] conducting ...business[s] or undertaking[s]," encompassing a broader range of individuals exercising influence in shaping workplace terms and conditions individuals in various locations in the sub-contracting chain, etc. - rather than an employer-employee relationship, narrowly defined. ${ }^{144}$ In its attempt to respond to fissures in employment structure and industries, this model national OHS Bill's inclusion of a broad range of workplace actors in the model law constitutes an emerging best practice.

Elements of yet another preventative measure operational in the U.S. are also pertinent to this survey as it covers a crucial high-risk industry in which subcontracting is central: namely, the 'hot cargo' (S. 15(a)) provision of the FSLA whereby the WHD uses the threat of embargoing goods manufactured in the garment sector below minimum ES. The hot cargo provision was underutilized in a period in which large inventories were common and shipments arrived infrequently. With the arrival of just-in-time production, and its corollary (i.e., a growing pyramid of fissured production and the proliferation of small enterprises in this sector), the WHD revived it to pursue direct agreements with manufacturers after they have faced an embargo of their goods due to a violation of the FLSA at one of the subcontractors responsible for assembly work; manufacturers therefore enter into monitoring arrangements as a result of enforcement commenced by an investigator. These arrangements cover a variety of practices including the provision of information, agreements to observe minimum standards, and 
periodic compliance inspections and they cover all of the manufacturer's clients, present and future. Agreements also require manufacturers to take timely action to rectify violations on the part of its contractors both by ensuring that back wages are paid in cases where non-payment of wages are discovered and by notifying the WHD of such a finding. Furthermore, they can be revoked at any time if the WHD finds the manufacturer to be in contravention. ${ }^{145}$ While the hot cargo provision has a voluntary cast, in that it leads to monitoring of small firms at the bottom of the contracting hierarchy by the manufacturers at the top (or the brand names) rather than state inspectors directly, it is proactive in the sense that it anticipates violations in high-risk sectors as well as recidivism. In this way, its goals resemble measures undertaken elsewhere (e.g., in Australia) to protect garment workers that effectively treat them (e.g., via deeming) as employees of contractors and/or manufacturers for whom the directly produce goods and services. ${ }^{146}$

Other best practices related to investigations respond to the call for collaboration between various agencies of government in the detection of violations. One concrete example of such collaboration is New York State's Joint Enforcement Task Force on Employee Misclassification operating since $2007 .{ }^{147}$ This Taskforce was created in recognition of the fiscal burden that misclassified workers put on not only workers but the state (i.e., the revenue loss for the state and its agencies). It involves representation from the state Departments of Labor and Taxation and Finance, the Workers' Compensation Board, the Fraud Inspector General, the State Attorney General and the Comptroller of the City of New York, who proactively engage in enforcement sweeps, coordinated assignments, and systematic referrals and data 
sharing to recover lost wages and government revenue. As a result of its efforts, between 2007 and 2010, the Taskforce identified " 50,000 instances of employee misclassification and discovered over $\$ 704$ million in unreported wages" leading to the assessment of " $\$ 21.5$ million in unemployment taxes and over $\$ 1.85$ million in unemployment insurance fraud penalties, over $\$ 16.5$ million in unpaid wages, and over $\$ 2.3$ million in workers compensation fines and penalties". ${ }^{148}$ Initially, joint enforcement sweeps revealing that the construction industry was fraught with violations resulted in a noteworthy initiative: a new law, known as the New York State Construction Industry Fair Play Act, which took effect in Fall 2010. The legislation is designed to curb misclassification by creating a presumption of employment in the construction industry unless an employer can meet a three factor test. ${ }^{149}$ The law also provides new penalties for employers who fail to classify their employees properly (Fair Play Act s. $861(\mathrm{e})$ ). ${ }^{150}$

\section{(ii) Voice}

With respect to the ability of workers' and their organizations to shape enforcement processes and thus exercise control over their conditions of employment, or their voice, a number of innovative community-based practices aimed at improved enforcement also exist in which workers' advocates and unions are involved in documenting and redressing violations. Some such initiatives are institutionalized, such as the Los Angeles Unified School District (LAUSD) and Board of Public Workers Deputization Programs (LABPW), documented by Fine and Gordon. ${ }^{151}$ Under the first program, the LAUSD deputizes and trains business representatives of building trades unions to enforce the prevailing wage on district projects funded by monies from construction bonds. These representatives are known as "work preservation volunteers", are 
provided with badges and business cards, and are authorized to enter school sites to conduct what are effectively compliance visits. The program emanated from a controversial agreement in which construction unions conceded their right to strike over job issues in exchange for the creation of an internal compliance department set up by the LAUSD in which union representatives play this role. With its establishment, the LABPW followed suit, training what it calls compliance group representatives. Both programs are designed to make these on-the-ground inspectors the representatives of labour inspectors from the City and thereby expand their enforcement capacity, as is the case with the hot cargo provision of the FSLA. Agents' duties thus include interviewing employees about hours, wages, job classification, official duties, and problems at work more generally. They also assist workers in filling out forms in the complaint process (i.e., when the perceive violations through their investigatory efforts); but they do not determine violations or assess penalties. Both well established programs, representatives are retrained every year. They are also informed regularly that they are not permitted to use their activities to gather information for their unions, disparage nonunion contractors, or review project data outside a pending complaint.

These examples represent the strongest version of Fine and Gordon's ${ }^{152}$ call for community based enforcement (i.e., enabling civil society groups to deliver information and education, patrol communities, file and investigate complaints, and provide for ongoing deterrents), which has its roots in a failed provision of the FLSA. Specifically, when the FLSA was being drafted, there was an attempt to secure a fair labour standards board to work with enlightened employers and unions to help police sweatshop employment relationships; but the provision never materialized. Instead, a 
weak judicial body emerged and the U.S. Congress effectively banned unions from bringing class actions under the FLSA. ${ }^{153}$ Like this failed vision for the fair labour standards board, as these authors assert, the strength of such programs include their relative permanence and that they are enshrined in public law rather than operating as a program of a particular administration. Although it is difficult to assess their impact on the nature and degree of violations of ES, these programs also follow Weil's ${ }^{154}$ prescription for regulatory jujitsu as their substantive success flows from the business representatives' intimate understanding of sector-based issues, the "contour" of their activities to specific rules applicable to public construction, and their access to detailed data.

Although it is less institutionalized, another example of community based enforcement where workers gain voice is the Maintenance Cooperation Trust Fund (MCTF), a janitorial watchdog involving a California local of the SEIU (Local 1877) and lead contractors engaged in collective agreements with that local. Together, these institutions established a trust fund whose mission is to abolish unfair business practices in this industry through education as well as investigating cleaning contractors conditions to enhance enforcement by public agencies and private attorneys. ${ }^{155}$ Signatory contractors pay between 1 and 5 cents per hour worked by workers to fund such programs, which require a staff of seven to cover the California area. This staff exposes, persuades, and will ultimately sue violators if they refuse to change. It also helps state agencies with fact finding, brings workers to agencies to follow up, and also supports workers engaged in private litigation. As part of its activities, the MCTF enters monitoring agreements with troublesome contractors and helps cultivate interagency 
monitoring. ${ }^{156}$ The main limitations of its activities, compared to the preceding examples, are twofold: first, firms can always choose alternative contractors whereas more traditional justice for janitors campaigns target worksites, and thus building tenants must comply with monitoring agreements rather than firms. Second, the MCTF is not capable of making lasting change inside state agencies.

Still another example of this community based enforcement holds the promise of responding to this criticism: the New York Wage and Hours Watch, a relatively new formal partnership between New York's labour department and six agencies including workers' centres and unions. This arrangement involves a memorandum of agreement signed in 2009 in which the participating organizations agree to identify and train at least six people to serve as wage and hour watch members for two years. In this capacity, these individuals, who are not deputized, provide at least 200 businesses per year with labour-law compliance information and hold sessions for the public and refer potential labour law violations to the labour department but they are not authorised to carry out inspections; they essentially function like "neighbourhood watch" applied to labour standards such that the chief strength of the model they follow is the ongoing partnerships between the state enforcement bureaucracy and community groups. As Fine and Gordon ${ }^{157}$ suggest, to be effective, however, such collaborations must have clear terms of reference regarding the scope of decision-making, funding to enable community participation, and retain a strong enforcement role for the state. ${ }^{158}$

\section{Reactive Approaches}

As elsewhere in the United States, Australia, the UK, and other jurisdictions in Canada, Ontario's ES enforcement system is designed such that there will always been 
individual complaints. Permitting, and even encouraging, complaints from individual workers is acceptable in accordance with the starting principles of decent work, fairness, access to social minima and universality so long as both a better balance is achieved between reactive and proactive approaches and resources dedicated to complaints procedures are used wisely. For example, the MOL's goal of eliminating the backlog in unresolved claims described in Section II is laudable. However, a quantitative approach to achieving this goal by seeking expedited settlements below legislated minima is out of step with the justice principle, that is, the quality of settlements, defined in terms of appropriate levels of penalties and effective collections for individual violators and more broadly in terms of Weil's strategic enforcement pillars of deterrence and prioritization (i.e., individual investigations should aim to be high impact in their effects).

\section{(i) Investigations and Inspections}

In recognition of the fact that, in Tucker's ${ }^{159}$ helpful characterization, "most workers are unlikely to be assertive protagonists" - i.e., it is unreasonable to depend on workers as whistleblowers, particularly in the context of high levels of precariousness in labour markets such as Ontario, as documented in another report prepared for this initiative ${ }^{160}$ - permitting anonymous complaints is a best practice reactive approach in the area of investigations and inspections. Such is the case in Saskatchewan where the MOL offers a complaint option that allows employees to anonymously submit complaints and evidence against an employer who the Compliance and Review Unit then investigates. This option is available if the worker is still "employed at [the] workplace; believes that the Labour Standards Act is not being followed and would like the situation to be 
corrected but does not: but, does not want to file a formal complaint." Under such circumstances, only written complaints with supporting evidence are reviewed. The Compliance and Review Unit also pursues expanded investigations in many such instances; specifically, where a claim submitted by a worker is found to apply to more than one worker at the worksite, the Ministry will expand their inspection to protect all workers present. ${ }^{161}$ Anonymous complaints are also accepted in six labor agencies in the United States; Colorado, New Jersey, California, Connecticut, Illinois, and New York. $^{162}$

\section{(ii) Penalties and Settlements}

With respect to penalties and settlements, two best practices from the U.S. are instructive. The first is found in the State of California, where a section of the Labour Code, colloquially known as the "brother's keeper" law holds user firms in certain low wage industries responsible for subcontractors wage and hours violations under a duty based regime. ${ }^{163}$ This law provides that "a person or entity may not enter into a contract or agreement for labor or services with a construction, farm labor, garment, janitorial, or security guard contractor, where the person or entity knows or should know that the contract or agreement does not include funds sufficient to allow the contractor to comply with all the applicable, local state, and federal laws or regulations governing the labor or services." 164 In other words, if a contracting firm is negligent by failing to uncover and limit employment law violations apparent from its contractual arrangements with labour suppliers, it can be held responsible. ${ }^{165}$ Resembling the hot cargo provision of the FLSA, but applicable to a greater number of industries, the aim of the law is to deter purchasers from entering into labour supply arrangements that are, by their financial 
terms, likely to lead to labour standards violations and more specifically to encourage manufacturers to have contractors put agreements in writing. ${ }^{166}$ In such ways, this law could be characterized as a proactively-oriented reactive measure as it attempts to prevent violations from occurring, distinguishing it from provisions the limited for joint and several liability in Ontario's ESA, which are more genuinely reactive (e.g., those applied to temporary help agencies and their clients). ${ }^{167}$ However, since the brother's keeper law's teeth only come into play after violations have occurred and have been revealed and since it does not necessitate monitoring agreements of the sort mandated by the WHD under the hot cargo provision, it falls in the reactive category. ${ }^{168}$

Spreading across the United States in the last few years, a second area of best practices encompasses Wage Theft Bills, a cluster of policies designed to enforce minimum wage, overtime and other wage related labour standards where cities and states play a central role in "scaling up" struggles for improved enforcement. ${ }^{169}$ This strategy emerged principally through community campaigns responding to the fact that over a dozen U.S. states had minimum wage and overtime protections superior to federal law. They then gradually came to involve counties and states, via the creation of Wage Theft Laws, in the prosecution of wage violations, including, among other things, the collection of extensive damages on behalf of workers, charging employers that violate the law the full cost of administrative proceedings, and revoking the operating licenses of known violators. One success story is found in the county of Miami-Dade, Florida which passed the first county wide ordinance in the U.S. Adopted in February 2010, this ordinance outlaws wage theft and provides the county with the ability to intervene in the recovery of back wages for workers who have experienced 
violations. ${ }^{170}$ Specifically, it provides for triple damages to be paid to workers and requires the violator to pay the administrative costs of claims, as well as damages. In this way, it responds to the concern that mediated settlements are inadequate by bolstering the level of back wages awarded, puts more pressure on collections, and removes the frequent requirement on workers and their representatives for covering administrative fees in the complaints process. Although the system of regulation differs in Canada, where only approximately ten per cent of the workforce is covered by the federal labour code and where ES in the area of wages vary province, the use of levers at the local level to improve enforcement in this U.S. case is the key lesson.

(iii) Voice

In the arena of voice, under Australia's Fair Work Act (2008), which sets out ten new national ES, unions have the right to bring court proceedings in relation to violations of ES if they are entitled to represent the employee in question. ${ }^{171}$ If the violation relates to a workplace agreement (akin to a collective agreement Canadian-style) or workplace determination that binds the union, the union can also make an application in its own right, on behalf of an employee, or both. ${ }^{172}$ This limited space for unions amounts to a degree of third party involvement in the enforcement process. It should be emphasized, however, that this example only represents an improvement when compared to the system operating under Australia's former 'Work Choices' regime since union rights under the new centralized system of industrial relations remain more constrained than two decades ago when they were considerably stronger in most states. 


\section{Voluntary Approaches}

The research literature, including studies on OHS and ES, documents the limits of voluntary measures, especially when they are the exclusive means of enforcement. ${ }^{173}$ It highlights the need to begin with the acknowledgment of the inherent power imbalance between workers and employers and the related recognition that this imbalance is amplified with globalization and the fissuring of production processes, ${ }^{174}$ especially the growth of subcontracting etc. not only in the private but the public sector. Considered on its own terms, there are nevertheless several best practices in voluntary compliance, which essentially amounts to the implementation of regimes of corporate social responsibility (CSR) (encompassing, among other examples, social labelling - or verification systems for a firm's social performance by authorizing the use of a physical label to communicate the social conditions surrounding production - and codes of conduct - a written set of standards, principles and norms to which a firm conforms $)^{175}$ that could potentially complement innovative proactive and reactive strategies in the context of a proactively-oriented mixed regime. ${ }^{176}$ These practices relate principally to investigations and inspections.

\section{(i) Investigations and Inspections}

Considering concrete best practices in voluntarism (narrowly defined), with regard to investigations and inspections, the Fair Labor Association (FLA) is one model applied globally in which brand names commit themselves to a regime of private monitoring. Specifically, these entities, including their entire chain of suppliers, agree to a programme of implementing a code of conduct, internal monitoring, and unannounced independent external monitoring of standards. The model emerged in response to the 
fact that the traditional CRS measures concentrating on auditing fail to address the root causes of non-compliance; in response, it integrates a system of monitoring, rectification and third party complaints. The FLA was formed in 1999 and involves sixteen brand names and is administered by a coalition of benevolent firms, university groups, and NGOs from around the world. It covers 4,000 facilities in eighty countries. The names covered by the model thus implement the FLA principles which are equivalent to the core labour standards of the ILO, conduct internal monitoring, submit to third party audits by FLA accredited auditors in a random sample of 5 percent of their suppliers as well as to publishing the results of these audits on the FLA website after the company has the opportunity to take remedial action, and report to the public on various activities. ${ }^{177}$

A distinctive best practice in voluntary compliance oriented to the public rather than the private sector, and of growing popularity among unions, union centrals, employers and states, ${ }^{178}$ is public procurement policy - agreements that government agencies investing "tax dollars" make with private sector actors in procuring public works projects. Such agreements exist in a range of contexts and at different scales, including in Toronto, whose policy is longstanding. A noteworthy national example is Ireland's Public Sector Procurement Policy, which seeks to "maintain employment standards in the public sector and uphold statutory norms, notably in relation to construction companies tendering for and engaging in public work contracts." ${ }^{179}$ This new agreement calls for adhering to "industry norms in terms of pay and conditions and to prevailing national and/or industry-wide agreements, including health and safety regulations," as well as to "employment standards and statutory norms, including those 
regarding wage levels, while also ensuring competitive tendering and value for money." ${ }^{180}$ It is administered by the Department of Finance, which issues public procurement guidelines, and is promoted by a range of other government agencies, including local government and transport agencies. Under its terms, contracting authorities are also to facilitate access to the Labour Relations Commission Conciliation Service, Labour Court and the Rights Commissioner Service (e.g., in the event of an industrial dispute) in line with Ireland's industrial relations regime ${ }^{181}$

Another national example is the umbrella group known as the Sweatfree Purchasing Consortium, a group of state and local governments in the U.S. who help other cities, states, counties, towns, and school districts to develop and implement policies and rules towards the goal of avoiding sweatshop products. The Consortium works to assist governments in creating codes of conduct, applicable to the contracts in which they engage, requiring that their contractors, abide by "standards that enjoy international consensus and the will of the people of the nation and region of production," specifically, the core conventions of the ILO and its Declaration on Fundamental Principles and Rights at Work and its implementation and monitoring. ${ }^{182}$ The Consortium also provides guidelines for a five step program for the monitoring of such Codes involving: advertising (i.e., public entities are to conduct "targeted advertising campaign[s] to declare their intent to allocate public funds to purchase goods and services that are produced in safe, fair and humane working conditions;";183 prequalification, which involves requiring or encouraging vendors to agree, in advance of making a bid, to conform to the public entity's code of conduct; a process equivalent to certification, which involves requiring bidders that have not fulfilled the 
prequalification requirement to attest through various means that they will subscribe to the code of conduct in question (e.g., documentation may be required to prove that suppliers related to the bidder are required by the bidder to conform to the Code); supplier evaluation, a process in which the advisory team to the Code verifies the vendors' capacities to comply with its terms (i.e., before an award is made); and, performance monitoring, which entails setting out "specific steps to ensure code compliance and responsible supply chain management throughout the duration of the contract as a condition for contract continuation and/or renewal." ${ }^{\text {184 }}$

Still other vehicles of voluntary compliance involve more focussed partnerships between state agencies and industry. One example is the Horticultural Industry Shared Compliance Program, involving the Australia's Fair Work Ombudsman, horticultural industry employers and state agencies in a large-scale attempt to remedy the high level of violations in this sector. ${ }^{185}$ This program adheres to a three stage program of activities, which includes, first, developing a joint publication operating as an employer guide to the Horticultural Award; second, planning for compliance, specifically circulating educational resources to and hosting seminars for employers about employment regulations for the purposes of self-audits and informing them of audit phases of the program; and, third, auditing a randomly selected group of employers towards a nationwide audit. This program is, however, highly voluntary since, at the third stage, even when violations were found, the Fair Work Inspectors work with employers to encourage voluntary compliance rather than pursuing prosecutions. ${ }^{186}$ Another example, also operating in Australia, is the "Proactive Compliance Deed" between McDonald's Australia and the Commonwealth of Australia." ${ }^{187}$ In this 
agreement, which is technically between Fair Work Australia, the federal body responsible for the enforcement of ES, and McDonald's, the latter agrees to follow a national self-audit program to ensure that it is complying with relevant labour laws, especially those related to wage payments. This self-audit covers ten per cent of all employees at twenty-seven McDonald's restaurants and it requires the company to disclose and rectify each contravention found.

Based on these types of examples and their successes and failures, other researchers also call for 'softer' techniques of investigation and inspection to supplement 'hard laws', particularly in what Teague refers to as "Anglo-Saxon" contexts. These techniques include diagnostic monitoring, which uses inspection as a comprehensive review of arrangements and a means of examining reasons beyond non-compliance without the threat of rectification off the bat, and specialized institutions (for example, the UK's Low Pay Commission) designed to educate the public on employment regulations. ${ }^{188}$ For such authors, integrating these arrangements into labour codes offers the potential of broadening enforcement beyond single agencies, and hence a more holistic approach that could be combined effectively with proactive measures in contexts like Ireland, where the principle of rectification is relatively unsuccessful in addressing the standard setting behaviour of forms. Such techniques could be combined with existing strategies of naming violators on government websites to improve compliance over the long term, as is common in several jurisdictions in Canada, including Ontario. ${ }^{189}$ Yet the power of voluntary measures, even those 'best practices', is not compelling, unless they are combined with harder and more proactive measures of enforcement. 


\section{B. OHS Enforcement}

Building on the framework for discussion of best practices in ES, this section addresses best practices in OHS enforcement through the lenses of proactive approaches, reactive approaches, and voluntary approaches. Clearly, there are very substantial differences between the ES and the OHS enforcement regimes, not just in Ontario but in most of the industrialized world. Proactive enforcement and worker voice are much better institutionalized in the OHS regime than they are in ES, as are voluntary approaches. One reason for this is that a vibrant worker OHS movement in the 1970s and 1980s was able to pressure governments and employers to address OHS issues much more aggressively and proactively than they had in the past, and to accord workers and their unions a voice both at the policy and the workplace levels. Therefore, the discussion of best practices in OHS begins from a different baseline than in ES.

\section{Proactive Enforcement}

(i)Inspections

There is widespread agreement on the principle of risk-based regulation. This requires regulators to allocate their enforcement resources on the basis of an assessment of the risks that a firm or a sector (however defined) pose to the regulator's objectives. ${ }^{190}$ In the context of OHS regulation, where the overall objective is to prevent occupational deaths, injuries and diseases, an assessment must be made of the inherent risks posed by an activity and the competence and commitment of firms to mitigate those risks. ${ }^{191}$ The strategic enforcement model developed by Weil ${ }^{192}$ described earlier operates according to similar principles. 
The importance of proactive inspection as a best practice cannot be understated and, as evident in Section III, the OHSD has emphasized this dimension of its enforcement activities in recent years. As well, the OHSD has gone some way toward the adoption of best practices in setting priorities for its proactive enforcement program, by taking into account injury rates and claims cost, compliance history, inherent hazards, new businesses, size and the presence of new and/or vulnerable workers. A strong word of caution, however, should be registered about the use of workers' compensation data in setting priorities. Numerous studies have shown that the use of claims cost data to experience rate firms in workers' compensation produces strong incentives for employers to engage in aggressive claims management that may alter the claims data without addressing the underlying OHS conditions that result in work injuries $^{193}$ As a result, workers' compensation data is an unreliable indicator of the capacity and commitment of firms to manage their health and safety and the data is likely to become even less reliable to the extent that it becomes known that it is used for targeting enforcement resources. It is notable that the Dean Report has called for the development of a common database to measure leading rather than lagging indicators for the purpose of assessing risk and measuring performance. ${ }^{194}$ The development of such a database would provide a much firmer foundation for establishing proactive inspection priorities.

The use of safety blitzes or targeted safety campaigns has also been identified as a best practice for risk-based regulation and has been used in Sweden, Australia, the UK and Quebec ${ }^{195}$ and, as noted above, is being used in Ontario. The literature also suggests that there needs to be a linkage between the results of a safety blitz inspection 
and subsequent proactive enforcement activities. In particular, where a safety blitz inspection or, for that matter, a regular proactive inspection detects a violation, the result should not just be an order to address the particular problem, rather the finding should trigger a broader review of the employer's management system to understand how and why the violation occurred and was not corrected prior to the inspection and to take steps for this to be corrected. This "bottom-up" approach ${ }^{196}$ avoids isolating particular problems or incidents from the bigger picture, as well as from higher levels of management who need to be made to understand that it is their responsibility to institute good OHS management practices in the firm. It is not clear from the documentation whether Ontario follows this best practice.

This raises a larger question about the conduct of inspections and the actions taken when OHS problems are identified. As noted in section III, there has been a shift from compliance assistance to enforcement. The Dean Report ${ }^{197}$ noted this shift and heard differing views from stakeholders on its merits. Not surprisingly, employers expressed some concern about the shift and wanted more compliance assistance, while labour wanted more consistent enforcement in certain areas of non-compliance, including training and JHSC requirement. The Dean Report recommendation split the difference, calling for consistent enforcement of serious and wilful contraventions and compliance assistance where it would help achieve compliance. ${ }^{198}$

The next section on reactive enforcement returns to consider, in more detail, the use of Part III prosecutions. For the purposes of the present discussion, it is noteworthy that such prosecutions almost never result from a proactive inspection. Rather, they are launched only when a violation has resulted in a serious injury or a fatality. 
Enforcement action taken in response to proactive inspections, therefore, range from the provision of advice, to formal orders to Part I tickets for which there are set fines, currently no greater than $\$ 295.00$.

There is no overriding consensus on the best practice in regard to balancing between prosecution and compliance beyond the nostrum that neither a pure compliance nor a pure prosecution model is desirable. ${ }^{199}$ However, Richard Johnstone has raised serious questions about the appropriateness of limiting prosecutions to instances where violations have materialized in substantial harm as these outcomes may be unrelated to the degree of culpability of the duty holder. ${ }^{200}$ Rather, a more appropriate approach to prosecutions would take into account the extent to which the employer departed from regulatory requirements, the degree of risk posed by the noncompliance and the employer's track record. Using that metric, a best practice would result in prosecutions arising from proactive inspections in appropriate circumstances.

With regard to tickets, there have been few empirical studies of their effects, but a review of those studies and the practice of ticketing (infringement notices) in Australia supported the view they have a role to play in getting the message across and spurring preventive OHS activity. ${ }^{201}$ However, concerns have been raised by Garry Gray about the way ticketing is used in Ontario, particularly because in his study workers were the target of 37 percent of the tickets, supervisors 38 percent and employers 25 percent. In particular, Gray noted that supervisors were far more likely to be charged with failure to ensure safety than were employers. ${ }^{202}$ The result is to allow responsibility for compliance to be pushed down into the lowest reaches of the firm's managerial hierarchy rather than treating these violations as failure of the employer's OHS 
management system that needs to be corrected at a senior management level. The need for a bottom-up approach, discussed earlier, should be adopted as a best practice in regard to ticketing.

A fundamental problem facing enforcers of all forms of labour market regulation is the fissuring of the employment relationship. ${ }^{203}$ This entails the fragmentation of previously integrated systems of production, entailing contracting out of work to smaller firms and the use of contingent workers in the form of temporary employees, temporary agency workers, and self-employed workers. To the extent that disintegration strategies still involve having contingent workers perform work on an employer's site, the employer retains responsibility for their health and safety and inspectors who visit the site have the opportunity to observe whether these arrangements are creating observable OHS risks. They may not, however, be aware that disintegration strategies that may in themselves undermine good OHS management are being undertaken. For example, they may not know that some of the workers are employees of the inspected employer while others are agency workers sent for a temporary work assignment. In that regard, it is unclear how well the targeting criteria will detect firms where contingent workers are present onsite. While the MOL does take into account the presence of vulnerable workers, the term does not seem to be defined and this factor may be offset by an artificially low claims and cost experience due to the fact that temporary agencies will be charged for agency workers, and that self-employed workers may not have workers' compensation coverage or will have coverage in their own names.

The problems for inspection produced by workplace fissuring become even more difficult when the work is not performed on the employer's premises but at another site. 
This is because fragmentation and the expansion of supply chains are associated with an increase in small and medium-sized workplaces. Not only does this create more workplaces for inspectors to visit, but there is ample evidence that the health and safety performance of these workplaces is likely to be lower than in larger, more integrated enterprises and are "relatively impervious to the regular tools of the trade for assessing risk, providing service and designing interventions. ${ }^{204}$ Reasons for this include the lower likelihood that small workplaces will be unionized and provide a channel for worker voice, and the fact that small business are often lacking in management resources, knowledge, skill and time. As a result, not only are there more firms to regulate, but their regulation is more resource intensive. Although the $\mathrm{MOL}$ does take into account firm size as a criterion for targeting proactive inspections, in the absence of a corresponding growth in inspection resources the likelihood of a firm that fits the targeting criteria being inspected is likely to decrease. Therefore, a best practice, albeit one that no jurisdiction has realized, is to link the budget for inspection not only to the size of the labour force but also to some measure of the level of workplace fragmentation. Further work would be required to devise such a measure.

Because of the scale of the problem of regulating proliferating and lengthening supply chains and production networks, researchers have suggested that "upstream" approaches need to be emphasized, meaning that interventions should be designed to focus on the contextual and institutional factors that shape risk creation. ${ }^{205} \mathrm{~A}$ prominent example of this approach is supply chain regulation which in various forms seeks to place responsibility for downstream businesses on the upstream firms that contract with 
them, thereby improving downstream OHS performance and compliance while reducing the demand downstream for inspection and enforcement resources.

Phil James et al examine several options for supply chain regulation to improve OHS. ${ }^{206}$ The report shall return to voluntary approaches later. Here, the focus is regulatory initiatives. The first approach centres on the use of the government's contracting power. The principle is derived from fair wage resolutions, which are also a common Canadian practice, that require companies doing business with government to pay wages no less favourable than those provided in prevailing collective agreements. An analogous mechanism is the federal contractor's program under the Employment Equity Act that requires contractors to commit to implement employment equity and to establish employment equity programs that meet specified requirements and are subject to compliance reviews. Although these programs are not costless in terms of monitoring costs, and indeed have been criticized because of the lack of resources devoted to compliance review, ${ }^{207}$ they do potentially provide a cost efficient way of improving labour standards and compliance, especially where the consequence of noncompliance is loss of the ability to contract with the government. This approach could be adapted to require government contractors to commit to implement specified OHS management practices and to assume responsibility for the OHS practices of the firms with whom they may subcontract. An example of this approach is the Construction (Design and Management) Regulations in the UK. However, to be effective, best practices would require that adequate resources need to be devoted to compliance.

The second approach aims at the private sector. One example cited by James et al. that has already been canvassed in the discussion of ES is the "hot cargo" provision 
of the FLSA in the US. ${ }^{208}$ In principle, the threat that goods that are manufactured in violation of the OHSA will be prevented from entering into commerce could be used to leverage agreements from upstream companies to monitor their subcontractors' OHS performance and regulatory compliance. Another example provided is from Australia in relation to long distance truck drivers and fatigue. Not only are employers required to assess the risk of fatigue and take steps to reduce that risk, but it also extends this requirement to their contracts with self-employed carriers and imposes an obligation on freight consignors and consignees to monitor head carriers' compliance with their legal obligations and prohibits them from entering into contracts with carriers unless they have satisfied themselves on reasonable grounds that delivery times and work arrangements will comply with the driver fatigue management plan.

To this point, it does not appear that Ontario has taken steps to develop any form supply chain regulation of OHS. This best practice should be a priority. ${ }^{209}$

(ii) Voice

Unlike ES enforcement, OHS regulation provides institutionalized mechanisms for employee voice through the requirement for joint health and safety committees (JHSC) in workplaces with twenty or more workers and for worker health and safety representatives (HSR) in workplaces where the number of workers regularly exceeds five. One of the main purposes of JHSCs and HSRs is to identify workplace hazards. A comprehensive description of the operation and powers of JHSCs, worker JHSC members and HSRs is beyond the scope of this review. What follows is a basic overview of the mechanisms for enabling workers' voices to be part of a proactive process for managing OHS risks. 
JHSC members and HSRs must receive training, are entitled to obtain information from the employer, and most importantly here, conduct health and safety inspections of the workplace no less than once a month. Time spent carrying out these duties is deemed to be work time for which representatives are to be paid. The employer must respond to written recommendations within twenty-one days and shall either provide a timetable for implementing the recommendation or reasons why the employer does not accept the recommendation. There is no formal dispute resolution mechanism provided in the act, but if the worker representative believes that the recommendation is to correct a violation of the act, he or she can complain to the OHSD and that would trigger a reactive inspection. As well, if a certified member ${ }^{210}$ believes that there is a contravention of the act that poses a danger or hazard to a worker and that a delay in controlling the hazard may seriously impose a danger to a worker, the member may initiate a procedure leading to a stop work order by the two certified members. Certified worker members of JHSC do not have the unilateral power to order that work be stopped, unless the Ontario Labour Relations Board has made an order permitting it. To our knowledge, no such order has ever been issued. Worker representatives also have the power to investigate work refusals and investigate serious accidents. Finally, a worker JHSC member, HSR or other knowledgeable worker is also entitled to accompany the inspector.

Workers can also have a direct voice other than through JHSC members or HSRs. Workers can complain to the OHSD about OHS violations and most workers can refuse unsafe work where they have reasonable grounds to believe conditions in the workplace, including the threat of workplace violence, is likely to pose a danger to 
herself or himself, or to another worker. This initiates an internal inspection and if the worker is not satisfied with the result of that inspection the OHSD inspector is called, triggering a reactive inspection to determine whether the circumstance that led to the refusal is likely to harm the worker or another person.

As the above summary indicates, worker voice is institutionalized and enables workers to be eyes and ears on the shop floor identifying hazards and initiating actions to have them remedied. International literature confirms that worker participation is a best practice in $\mathrm{OHS}$ regulation. ${ }^{211}$ However, the literature also emphasizes that it is not enough to simply mandate worker voice. Rather, the effectiveness of worker voice varies depending on the presence or absence of a number of supports, including union representation, legislated support, worker training, active workplace inspectorates and an activist orientation by worker representatives. ${ }^{212}$ While Ontario continues to legislatively support worker voice, most recently evidenced in Bill 160's addition of a requirement for HSR training and a power for a single co-chair of a JHSC to make written recommendations to an employer, the decline in union representation and the proliferation of small workplaces are undermining the effectiveness of worker voice. ${ }^{213}$ As a result, worker protagonism is jeopardized, notwithstanding that the OHSA prohibits retaliation against a worker for exercising her or his rights under the act.

Indeed, the problem of retaliation against workers was raised before the Dean inquiry. In its report, it called for improved protection from reprisals to encourage workers to exercise their rights under the act, especially as other measures that it advocated, such as increasing worker training and awareness, would likely result in more workers raising OHS concerns. ${ }^{214}$ Bill 160 responded by enabling inspectors to 
refer a worker reprisal complaint directly to the Ontario Labour Relations Board, which adjudicates the complaint.

Such measures are helpful, but are unlikely to provide most workers generally and precarious workers in particular with the security they need to feel comfortable exercising their OHSA rights. Although there are no panaceas to compensate for changing structural conditions that undermine worker voice, the Swedish experience with regional health and safety representatives is a model that could be adopted to extend the reach of worker voice and increase the surveillance capacity of the inspectorate to smaller, hard to reach workplaces. Under Swedish law, trade unions have the right to appoint regional safety representatives for all small firms in which they have a member and in which there is no JHSC. According to Kaj Frick regional HSRs "mainly function as peripatetic 'local' representatives, who help to detect OHS hazards and discuss with managers how to abate them." ${ }^{215}$ Lacking formal enforcement powers (except in the face of imminent dangers), their effectiveness in large measure derives from their superior knowledge and broad experience in addressing OHS issues. Despite the erosion of the conditions in Sweden that supported the role of regional health and safety representatives, they still make an important contribution to OHS management in small firms.

In an environment in which union representation is declining and in which employer resistance to the presence of outside union-appointed HSRs is likely to be great, an alternative would be to seek out other intermediaries who are knowledgeable about health and safety to play this supporting role. Use of community partners might not be appropriate unless they have the requisite knowledge to be effective advisors 
and monitors. Perhaps a governmental office, similar to the Office of the Worker Advisor in workers' compensation might be considered, or non-governmental groups, like the Workers Health and Safety Legal Clinic or the Occupational Health Clinics for Ontario Workers could be funded and given a larger mandate to provide these services.

\section{Reactive Approaches}

Reactive inspection and enforcement occurs when there is a complaint about a violation, a work refusal or a serious injury or fatality that is required to be reported to the OHSD. There is no need here to go into the limits of a reactive strategy, except to reiterate that the willingness to complain or to exercise the right to refuse is shaped by many factors in addition to the hazards present in the workplace. ${ }^{216}$ This is especially true for precarious workers whose vulnerability makes them even less likely to make formal complaints. Similarly, the occurrence of a serious injury or fatality may or may not be indicative of a larger problem that requires intervention beyond dealing with the particular circumstances that caused the mishap. For these reasons, the OHSD has justifiably put more resources into proactive approaches.

However, when reactive inspections and enforcement actions are taken, it is important that they are effective and so this issue is critical to address. Examining reactive inspections in response to work refusals and retaliation complaints revealed that the mandate of the inspector is to determine whether or not there is a health and safety violation, not to determine whether a worker has suffered retaliation for enforcing his or her rights, which is to be determined either through arbitration, where a workplace is unionized, or through a complaint, and now an inspector referral, to the OLRB. This arrangement is reasonable. The question addressed here is whether further 
enforcement action should be taken in these circumstances. Here it is also to be noted that retaliation is also a violation of the OHSA for which an employer could be prosecuted. However, this is not a practice that has been adopted. The Dean Report called for a review of the MOL's policy in this regard and recommended that "enhanced enforcement" should be undertaken to address egregious or repeated violations of section 50 (the no-retaliation provision). ${ }^{217}$ This recommendation should be implemented. As well, consistent with the previous discussions of a bottom-up enforcement strategy, a finding that there has been retaliation should trigger a follow up inspection to insure that senior management has taken appropriate measures to insure that everyone in the organization understands that workers are not to suffer adverse consequences for exercising their rights under the act and that measures have been adopted to avoid a repetition of this unlawful employer behaviour. In the context of investigations of critical injuries and fatalities, it is notable that Ontario prosecutes employers far more frequently for OHS offences than do other Canadian jurisdictions. This is an important component of a best practices enforcement system as numerous commentators have reiterated that big sticks are needed at the top of an enforcement pyramid of escalating sanctions to deal with serious and repeat offenders. ${ }^{218}$ In this context, further work needs to be done to inquire into why criminal prosecutions have been used so infrequently and with so little success when they have been tried, for these should be integrated into and sit at the top of the pyramid of potential sanctions both for their specific and general deterrent effects, and to emphasize the Rule of Law principle that mainstream criminal law applies to the wrongdoing in the workplace as much as it does to wrongdoing in other settings. ${ }^{219}$ 
There is also a question of the use of sanctions other than criminal or Part III provincial offence prosecutions for contraventions that result in critical injuries or fatalities. As Gunningham and Johnstone noted for Australia, and is also true of Ontario, there is a split pyramid of sanctions, where lesser ones are used in the context of proactive inspections and stronger ones are used in the context of reactive inspections to critical injuries and fatalities. ${ }^{220}$ As already suggested, Part III POA prosecutions ought to be considered in appropriate cases for contraventions detected during a proactive inspection. The question here is whether other enforcement actions, either in lieu of or in addition to prosecution should be considered for contraventions that resulted in a critical injury or death.

Consistent with the position taken previously, that single incidents should trigger an examination of systemic problems, there is certainly a strong case to be made that follow up inspections should be conducted in the aftermath of a prosecution to ensure that specific deterrence has resulted in reform to the employer's OHS management system such that the likelihood of future contraventions going undetected and uncorrected is substantially reduced. Some Australian research has found that many employers respond to prosecutions in just this way, ${ }^{221}$ but follow-up inspections would increase the likelihood of improved OHS performance.

With respect to the use of lesser sanctions in lieu of more serious ones, further research is required to know more precisely the criteria that are used to determine whether and when contraventions that result in critical injuries or deaths do not result in a prosecution. Where they do not, the question arises as to whether there are lesser sanctions that would be appropriate. Some studies have reported that OHS compliance 
improves after a sanction has been imposed, regardless of its size. ${ }^{222}$ This might suggest that a ticket would be effective in this context; however, there is a serious concern that a ticket would trivialize the seriousness of the consequences and send the wrong signal. A more promising alternative is the use of enforceable undertakings, a practice that has been used in Queensland, Australia. Under this provision, a duty holder who has been charged with an OHS contravention can propose an enforceable undertaking, which will be accepted in lieu of the prosecution if it delivers benefits beyond compliance and tangible benefits to workers, the industry or the community. Undertakings will not be accepted where there has been a fatality or a serious breach of the Act. Enforceable undertakings include a description of the alleged offence, a statement of regret, an assurance about future behaviour, a requirement to provide third-party audit reports on compliance, and a commitment by the duty holder to pay the regulator's investigation and monitoring costs. More research is needed to assess the effectiveness of this enforcement tool and so it is too early to characterize it as a best practice; early accounts, however, are promising. ${ }^{223}$

\section{Voluntary Approaches}

This discussion has already averted to the limits of voluntary compliance measures, noting that they cannot be a substitute for public enforcement. However, as in the case of ES, there are private enforcement measures that can play a role in improving OHS management and performance, provided they are well designed and linked to public enforcement mechanisms.

Thus far, this report has described OHS management systems on a number of occasions but has not defined them and so it will be useful to do so here. According to 
Kaj Frick and John Wren, OHS management systems embrace five core principles: 1) OHS conditions are an aspect of production, therefore; 2 ) top management is responsible for OHS conditions; 3) to abate work hazards management must integrate OHS considerations into all other management decisions; 4) systematic assessment and evaluation of work hazards is an essential prerequisite to making decisions about abatement and prevention; and 5) implementation of prevention and abatement requires tasks and resources to be adequately distributed within the organization. ${ }^{224}$

Voluntary OHS management systems (OHSM) have their roots in the Safety First movement that emerged in the early decades of the twentieth century and have been developed by management consultants and various firms and associations who have produced and marketed a variety of products such as the Five Star System, the International Safety Rating System and the DuPont System. As well, many firms have developed their own internal OHSM systems. These systems are typically highly specified and often require external private auditing for participating firms to become certified. Because these systems are proprietary there is little independent research assessing their effectiveness. Moreover, international private standard-setting organizations, such as the ISO, have not created an OHSM standard equivalent to the ISO 14000 standard regarding environmental management.

One common feature of many of these private systems is that they use a behaviour-based safety model which emphasizes the importance of motivating employees to follow the employers' safety rules through a mixture of peer pressure (e.g. group incentives for consecutive no-lost time accident days), employer monitoring and discipline. An earlier study of OHSM in Ontario expressed concern about the use of 
such systems to marginalize worker participation and to promote the suppression of injury reporting and the shortening of recovery time. Moreover, in the absence of independent assessment, it also rejected the view that firms that voluntarily adopt privately monitored OHSM systems should be exempt from routine government inspection. ${ }^{225}$

Walters et. al.'s recent study of OHSM internationally endorses the view that voluntary approaches are inadequate to the task and instead its authors advocate regulated OHSM, in which public inspection plays a critical role. ${ }^{226}$ This involves, on the one hand, public standards for OHSM systems and on the other government monitoring of compliance with those systems. Internationally, a number of jurisdictions have established OHSM standards, including EU Framework Directive 89/391, which requires member states to implement principles of OHSM in their domestic OHS laws. In Ontario, the OHSA provides a basic infrastructure for OHSM, including worker participation and monthly workplace inspections by worker HSRs and JHSC members. However, the authors of the study are also wary of making strong claims even for regulated OHSM systems. ${ }^{227}$

In short, there is insubstantial evidence that the regulatory project pursued internationally to improve standards of OHSM has succeeded in significantly changing the ways in which most duty holders conceive or operationalise these arrangements in the workplaces for which they are responsible. Nor can it be said that its surveillance by regulatory inspection has effectively strengthened control over the improvement of the standards of OHSM. It also therefore remains unproven that the operation of this form 
of regulation has achieved the intended 'acceptable level' of protection for workers form the consequences of workplace risks.

Nevertheless, it has been almost two decades since Ontario last reformed the IRS provisions of the OHSA, and so it would be timely for a review to be undertaken to determine whether the legal infrastructure of OHSM complies with current best practices, especially in the context of the changing world of work and the challenges they pose for OHSM systems generally and for MOL monitoring of them. As has been well documented, ${ }^{228}$ the growth of triangular employment relationships, supply chains and self-employment are often accompanied by problems of disorganization, including communication breakdowns, more complicated lines of management control and a decreased ability on the part of workers to recognize hazards and protect themselves from them. Moreover, regulatory failure becomes more likely because laws and policies were often developed with the traditional employment relationship in mind and because monitoring production networks and chains puts a strain on available resources.

Finally, turning attention back to supply chain regulation, this time focusing on the role of voluntary codes, there has been a proliferation of voluntary codes relating to the responsibility of multinationals for the behaviour of their downstream contractors. A wide range of provisions are made in these codes for monitoring, some of which are more independent than others. For example, in Australia high profile transnational corporations involved in textile, clothing and footwear (TCF) production entered into an enforceable agreement with the union representing TCF workers under which all sites of production must be disclosed to the union, which is given the contractual authority to make unannounced inspections. ${ }^{229}$ As purely voluntary measures, supply chain 
regulation has received mixed reviews. Estlund, (who generally is favourably disposed toward the development of self-regulatory capacity, also recognizes that the programs she reviewed all had significant limitations. ${ }^{230}$ Supply chains must be headed by publicly visible companies with a significant stake in protecting their brand in order for them to be vulnerable to public pressure; activists must be able to sustain pressure indefinitely in order to ensure that voluntary agreements and monitoring arrangements do not lapse and degrade; resources must be available to support monitoring efforts, etc. So while some voluntary supply chain schemes are better than others, it would not be a best practice to give priority to the development of private regulation and private monitoring. The better approach to supply chain regulation requires that public regulatory authorities play a central role in establishing the obligations of the upstream duty holder, supervising the arrangements for monitoring the practices of contractors and sub-contractors and guaranteeing a role for worker voice in these arrangements. A number of these efforts were described in the proactive section of OHS best practices and will not be repeated here. 


\section{Policy Recommendations}

This report has mapped and drawn out an analysis of the limitations of current enforcement practices in ES and OHS. It has observed that where unions are present in the OHS structures for workers' voice, the self-regulatory model works better than when they are lacking. It has reviewed potential reform options based on best practices in Canadian and other jurisdictions. The report demonstrates that effective enforcement of labour standards to protect workers in precarious employment and regulate precarious labour markets will require multi-pronged proactive, reactive, and voluntary strategies. However, such strategies must be embedded in a strong public/government enforcement model. This model should be centered on proactive enforcement. Even though proactive approaches should be prioritized, as they offer the most promise of the three approaches in upholding the normative principles of providing for decent work, social minima, universality, and fairness, there is value in certain reactive and voluntary measures. Reactive enforcement must ensure effective voice and support for workers to enforce their ES and protection from reprisals. Voluntary strategies that rely on nonstate parties (i.e., employers, employer associations, workers, union and workers organizations), must ensure meaningful penalties for employers in non-compliance, on the one hand, and meaningful institutionalized involvement of workers and their organizations in furthering enforcement effectiveness, on the other hand. Under no circumstances are purely voluntary approaches recommended; they should only be used to augment otherwise strong and binding (ideally proactive) approaches.

A number of recommendations for changes in policy and practice flow from the survey of best practices contained in Section $\mathrm{V}$, considered in light of the deficiencies 
characterizing the current regimes of ES and OHS enforcement in Ontario documented in preceding sections. The recommendations are divided into these categories of proactive, reactive, and voluntary approaches, noting the connections between these proposals and such principles where relevant.

\section{A. ES Enforcement ${ }^{231}$}

\section{Proactive Approaches}

(i) Investigations \& Inspections

1. Shift model of proactive enforcement to detecting violations and enforcement of ES for current employees in addition to the current focus of bringing employers into compliance. Routinely follow-up inspections with audits to ensure social minima are met through ongoing compliance.

2. Pursue strategic enforcement: Develop enforcement priorities and proactively target employers in high-violation industries and substandard practices. This involves mapping labour market practices (i.e., in the interest of the fairness principle, following up on previous cases of employer violations, new forms of work organization, sectors and industries comprised of concentrations of young workers, recent immigrants, women, racialized workers and other indicators of high rates of employer violations) to develop strategic plans for inspections and year by year targets. Develop benchmarking to evaluate strategic enforcement.

3. Support expanded investigations: Where an individual claim has confirmed violations, this should be used to trigger a broader investigation of other 
violations of the employer to protect current employees as is common in other jurisdictions. This recommendation too is consistent with the goal of fairness.

4. Pursue multi-agency investigations of employers and targeted sectors or practices: Initiate multi-agency investigations, possibly beginning with the introduction of a pilot project in which OHS and ES inspectorates engage in joint initiatives. Through such investigations, target practices such as misclassification of employees as 'independent contractors' and sub-contracting (in this process, a reverse onus in which a worker is presumed to be an employee unless the employer can provide proof to the contrary should be pursued). Such measures elevate the principles of both universality - that is, extending existing protections to the greatest number of workers - and fairness given the need to safeguard misclassified workers.

5. Introduce state-supported up the chain inspections and investigations: The MOL should consider making agreements with large firms engaging subcontractors that make them responsible for their subcontractors at lower levels of the chain, through the introduction of a regime of inspection supervised by the Ministry or a joint taskforce involving workers and their advocates, and simultaneously strengthen provisions for joint and several liability in the ESA. ${ }^{232}$ Here again, fairness, universality and providing for social minima for all workers in the chain of production are key objects.

6. Introduce a 'positive duty' for employers to prevent violations of the ESA. ${ }^{233}$ This recommendation is directed at achieving all four principles but elevates fairness in particular. 
7. Enact a "hot cargo" provision to the ESA that would enable inspectors to impose an embargo on goods manufactured in violation of Act to ensure that, in fairness, penalties are felt by all parties to the chain of production. ${ }^{234}$

\section{(ii) Penalties \& Settlements}

8. Create an effective presumption of employer retaliation: In the interest of fairness, universality and establishing social minima, prevent employer retaliation by protecting workers who assert their rights by establishing a set fine for confirmed reprisals and providing interim reinstatement during claims investigation for workers that have been fired for seeking entitlements (i.e., establish a fast-track process for reinstatement and, in cases where reinstatement is not feasible, fast-track compensation of workers who have been penalized for attempting to enforce their rights, including all lost wages and costs of employer retaliation). ${ }^{235}$

9. Shift the costs of ES enforcement on those that violate the ESA: Consistent with the notion of fairness, make employers pay the administrative costs of inspecting violations and enforcing ES where they are found in violation of the ESA. ${ }^{236}$

10. Establish set fines (rather than giving ESO discretion) for confirmed violations (even in settlement): The current use of Part I tickets ( $\$ 360$ or less) does not provide adequate incentives to comply with the law. Rather, in pursuit of just social minima and fairness, fines doubling or tripling the amount owed, such as provided for in the New York State Wage Theft Protection Act, would provide a better incentive. Further, workers should receive interest on all unpaid wages owing. ${ }^{237}$ 
11. Simplify and improve the transparency of prosecution policy: Each and every repeat violation or non-payment of orders should be prosecuted under Part III Provincial Offences so that employers are fined and ordered to pay unpaid wages in line with the notion of universality.

(iii) Voice

12. Encourage partnerships between the MOL and Community organizations to improve enforcement: The MOL should work with workers' advocates and community organizations working directly with precariously employed workers to target companies and industries where wages go unpaid in order to promote both fairness and decent work. These organizations are most grounded in the experience of the workers in concern and thus it is only just to involve them in the administrative process as elsewhere.

13. Promote greater worker control over the labour standards through improved access to unionization and other workplace regulations fostering labour market security. The decline in union density, particularly in the private sector, coupled with the growth of precarious employment creates substantial challenges to workers voice and enforcing a floor of minimum standards. There is a need to not only redress continued de-collectivization and/or stagnation of labour relations in Ontario but to reverse this trend. In addition, introduce mechanisms of broaderbased bargaining for self-employed and other workers in precarious paid employment who face challenges to unionizing and/or, at a minimum, to benefiting from collectively agreed social minima (see also Vosko and Noack, in this LCO working paper series). ${ }^{238}$ 


\section{Reactive Approaches}

(i) Inspections \& Investigations

14. Allow for third-party and anonymous complaints to initiate inspections in order to minimize threats to workers whose rights are being violated. Implementing this recommendation would mean that the most precariously employed workers, facing heightened threats of reprisal, are not obliged to take on their employers in fairness to their situation and the goal of securing social minima.

15. Streamline the complaints process and reduce the complaints backlog by providing, as a first step in the claims process, person-to-person assistance to workers to prepare their claim so that investigators can expeditiously adjudicate the matter. Administratively, this proposal, if implemented, would both deliver a fairer process for all workers to secure minimum protections, including those lacking access to the internet and/or the language proficiency to make claims and assist investigators in doing their jobs.

\section{(ii) Penalties \& Settlements}

16. Update time limitations and monetary caps to reduce barriers to employment standards remedies: The increase in minimum wage and barriers to enforcing employment standards leaves many workers owed substantially more than the $\$ 10,000$ cap on monies recoverable under the ESA. For this reason, in the interest of fairness and to ensure that social minima are up to date (i.e., reflect labour market realities), the Act's limitation periods and amount of wages recoverable should be brought in line with Ontario's small claims court. 
Specifically, the monetary limit on monies that can be recovered should be changed to $\$ 25,000$ and the ESA time limit should be extended to 2 years to recover wages and entitlements. ${ }^{239}$

(iii) Voice

17. Worker Representation in the claims-making process: To ensure that all workers have access to the claims process (i.e., universality) and in fairness, allow representation and provide funding for workers to have representation in reporting violations and the claims process as a whole.

\section{Voluntary Approaches}

18. Purely voluntary approaches to ES regulation and management are not recommended.

(i) Investigations \& Inspections

19. Encourage the creation of a public procurement policy: The government of Ontario should require that its contractors adhere to not only minimum ES but industry norms so that the floor of social minima is elevated. In its aim of improving social minima consistent with the costs of living in Ontario, this recommendation is consistent with the call for raising the wage levels, and augmenting the wage package, contained in another LCO report (Vosko and Noack, in this series), although it asks the government to take on a leadership role as a model employer. ${ }^{240}$

20. Support partnerships between state agencies and worker organizations in improving enforcement: The review of best practices illustrates the merits of 
creating initiatives aimed at enforcing labour standards where organizations of workers assist government agencies, including labour inspectorates, with spotting and documenting violations as well as assisting workers in making claims. Such partnerships should be cultivated to ensure decent work for all.

\section{B. OHS Enforcement}

\section{Proactive Approaches}

1. Employ risk-based regulation: Use of risk-based regulation, which includes an assessment the OHS risks posed by an activity or by particular firms engaged in that activity based on their competence and commitment to control and manage those risks and is thus sensitive to ensuring that social minima and decent conditions of health and safety at work apply to all workers. In pursuit of this approach to regulation, develop leading rather than lagging indicators for the purposes of making such assessments (as recommended by the Dean Report).

(i) Investigations \& Inspections

2. Engage in safety blitzes: Safety blitzes based on appropriate risk assessments, which aim to ensure the principle of universality in that all workers are protected regardless of the industry in which they are located, should continue.

3. Enforce OHS from the bottom-up: Use of a "bottom-up" approach in enforcement, which requires that when officials detect a violation - whether in the context of a proactive or a reactive inspection - they should not treat it as a discrete event; rather, in fairness to all workers with a given firm, the violation should trigger a 
broader review of the employer's OHS management system to determine why the violation occurred and was not detected and corrected by management.

4. Prosecute before harm is done: To ensure social minima are in place, consider the use of Part III prosecutions as the result of proactive inspections that find significant departures from regulatory requirements notwithstanding that no harm has yet materialized.

5. Avoid downward levelling through the use of tickets: Uphold decent conditions of work and social minima by using tickets appropriately; that is, tickets should be used, but not in a manner that allows responsibility for OHS to be pushed downwards. A bottom-up approach (as above) requires that ticketed violations should be treated as a failure of the employer's OHS management system that needs to be addressed at senior levels.

6. Employ strategic enforcement practices in OHS enforcement: To ensure a fair and consistent approach to regulation, develop criteria for identifying sectors and firms in which employment fissuring has occurred so that they can be better targeted for proactive inspection.

7. Sync budgets for inspections to the size of the labour force and the degree of fissuring in workplaces: In the interest of fairness, linking the budget for inspection both to the size of the labour force and to the degree of workplace fissuring is necessary because of the greater demand that it places on inspection resources.

8. Develop supply chain regulation: To ensure universal treatment of all workers in a given chain of production, develop upstream approaches to supply chain 
regulation that increase the responsibility at the top end of the chain for OHS performance at the lower levels. ${ }^{241}$

9. Improve procurement policies: Government contracts, as model contracts, should require contractors to commit to specified OHS management practices, which include monitoring OHS performance by sub-contractors. Government must monitor this dimension of contract compliance in the interest of supporting social minima.

10. Enact a "hot cargo" provision to OHSA that would enable inspectors to impose an embargo on goods manufactured in violation of Act to ensure that social minima are respected and that all parties to production are penalized in a universal fashion. ${ }^{242}$

11. Monitor OHS performance by sub-contractors: Impose an obligation on private sector employers to monitor OHS performance by sub-contractors and to exercise due diligence to ensure that contract terms do not create undue pressure on contractors to engage in unsafe practices. Joint liability for downstream violations should be considered to ensure that all parties are treated fairly and subjected to the same requirements for providing for social minima for all workers in the chain of production. ${ }^{243}$

(ii) Voice

12. Create an institution of regional health and safety representatives: The decline in private sector union density creates a challenge for effective worker voice, a critical vehicle for securing fairness at work as well as social minima and decent terms and conditions, as does the growth of precarious employment. The 
creation of a functional equivalent to the Swedish institution of regional health and safety representatives should be considered, including the creation of the equivalent of an Office of the Worker Advisor or an expanded mandate for nongovernmental groups like the Workers' Health and Safety Legal Clinic or the Occupational Health Clinics for Ontario Workers. ${ }^{244}$

\section{Reactive Approaches}

(i) Investigations \& Inspections

13. Retaliatory behaviour should be penalized appropriately: In recognition of the unequal relationship between workers and employers, and in fairness to workers who pursue complaints about their employers despite this power imbalance, in the context of inspections triggered by a complaint that a worker has experienced retaliation for exercising her rights under the Act, inspectors should consider recommending Part III prosecutions for violations of the Act when appropriate (See Dean Report).

14. Mandate follow-up inspections in cases of employer retaliation: Consistent with the bottom-up approach which aims to ensure that social minima extend to all workers, where there has been a finding that retaliation has occurred, this should trigger a follow-up inspection to determination whether the employer's OHS management system has been reformed to insure that workers' OHS rights are now better protected.

15. Inquire into the limited use of criminal prosecutions: OHS regulation is about protecting workers from bodily harm. In the interest of universality through safety 
for all workers, investigate why criminal prosecutions have not been better integrated into the pyramid of enforcement.

16. Mandate follow-up inspections in cases of prosecutions under the OHSA or the Criminal Code: To promote decent work by ensuring that all workers are safe in the workplaces of known violators, follow-up inspections should occur after a successful prosecution under the Criminal Code or the OHSA to insure that the employer has responded by correcting the deficiencies in its OHS management system.

17. Consider introducing enforceable undertakings: Investigate the use of enforceable undertakings where OHS contraventions occurred but for which a prosecution is not required so that the social minima for all workers in the workplaces in question are protected. ${ }^{245}$

\section{Voluntary Approaches}

18. Purely voluntary approaches to OHS regulation and management are not recommended.

19. Review current regulation of OHS management systems in Ontario, taking into account the changing world of work and the challenges this poses to OHS management and to the regulation of OHS management in fairness to workers and to ensure that these systems keep a pace with workplace realities.

20. Employ the selective and strategic use of voluntary codes of conduct to supplement, but not replace, public regulations: In the context of supply chains, voluntary codes of conduct may provide some amelioration under certain conditions, but the preferable and fairest approach is for public regulatory 
authorities to play a central role in imposing obligations on upstream duty holders, including the arrangements for monitoring downstream compliance, and in guaranteeing a role for worker voice. 


\section{Endnotes}

${ }^{1}$ Equal authorship

${ }^{2}$ International Labour Organization (ILO), "Towards a Policy Framework for Decent Work” (2002) 141:1-2 International Labour Review, 161.

${ }^{3}$ Leah F. Vosko, "'Decent Work': The Shifting Role of the ILO and the Struggle for Global Social Justice" (2002) 2:1 Global Social Policy, 19; and, Leah F. Vosko, Managing the Margins: Gender, Citizenship, and the International Regulation of Precarious Employment (Oxford, UK: Oxford University Press, 2010).

${ }^{4}$ ILO, Programme on Promoting the Declaration on Fundamental Principles and Rights at Work (Geneva: ILO, 2004).

${ }^{5}$ ILO, ILO Declaration on Social Justice For A Fair Globalization (Geneva: ILO, 2008).

${ }^{6}$ Lance Compa, "NAFTA's Labour Side Agreement Five Years On: Progress and Prospects for the NAALC" (1999) 1:1 Can. Lab. \& Emp. L.J., 1.

${ }^{7}$ Archives of Ontario (AO) Record Group 7-78. Initial Submission, Management by Results and Estimates, 1979/80. 12 July 1978, 6.

${ }^{8}$ Archives of Ontario, Record Group 7-78, Letter, John R. Scott, Director, Re: The Employment Standards Act, 1974 \& The Automatic Car Wash Industry, 4 April 1975.

${ }^{9}$ Archives of Ontario Record Group 7-1, File 7-1-0-1532.1, box 54, Notice to Employers and Employees (1969).

${ }^{10}$ David Weil, "Crafting a progressive workplace regulatory policy: Why enforcement matters" (2007) 28 Comparative Labor.Law \& Policy J., 125.

${ }^{11}$ A. Haviland, R. Burns, W. Gray, T. Ruder, \& J. Mendeloff, "What kinds of injuries do OSHA inspections prevent?" (2010) 41 Journal of Safety Research, 339; K. Kilkon, J. Mendeloff, \& W. Gray, "The role of inspection sequence in compliance with the US Occupational Safety and Health Administration's (OSHA) standards: Interpretations and implications" (2010) 4 Regulation \& Governance, 48; K. Purse, \& J. Dorrian, "Deterrence and enforcement of occupational health and safety law" (2011) 27:1 The International Journal of Comparative Labour Law and Industrial Relations, 23; and, Weil note 10. 
${ }^{12}$ Department for Business Enterprise and Regulatory Reform (DBERR) Vulnerable worker enforcement forum: Final report and government conclusions (London: Department for Business, Enterprise and Regulatory Reform, 2008); R. Saunders and P. Dutil, New approaches in achieving compliance with statutory employment standards (Ottawa: Canadian Policy Research Networks Inc. \& The Institute of Public Administration of Canada,2005); P.L. Gallina, New compliance strategies: 'Hard law' approach, A report prepared for the Federal Labour Standards Review/Examen des Normes du Travail Federales (Ottawa: Human Resources Development Canada, 2005); National Employment Law Project (NELP) Just pay: Improving wage and hour enforcement at the United States Department of Labour (New York: National Employment Law Project, 2010); and, David Weil, Improving workplace conditions through strategic enforcement: A report to the Wage and Hour Division. (Boston, Mass.: Boston University, 2009). ${ }^{13}$ A. Pollert, "The Unorganised Worker: The Decline in Collectivism and New Hurdles to Individual Employment Rights" (2005) 34:3 Industrial Law Journal, 217.

${ }^{14}$ David Weil, "Public enforcement/private monitoring: Evaluating a new approach to regulating the minimum wage" (2005) 58:2 Industrial and Labour Relations Review, 238.

${ }^{15}$ See for example J. Fine \& J. Gordon, "Strengthening labor standards enforcement through partnerships with workers' organizations" (2010) 38 Politics \& Society, 552.

${ }^{16}$ G. Maconachie, \& M. Goodwin, "Recouping wage underpayment: Increasingly less likely?" (2006) 41:3 Australian Journal of Social Issues, 327.

${ }^{17}$ Gallina, note 12 and NELP note 12.

${ }^{18}$ Saunders \& Dutil note 12.

${ }^{19}$ Kent Elson, "Taking workers' rights seriously: Private prosecutions of employment standards violations" (2008) Windsor: University of Windsor Yearbook Access to Justice, 2008)need journal citation ${ }^{20}$ P. Macklem, \& M.Trebilcock, (2006) New labour standards compliance strategies: Corporate codes of conduct and social labeling programs. (Ottawa: Federal Labour Standards Review, 2006).

${ }^{21}$ T. Hardy, \& J. Howe, "Partners in enforcement? The new balance between government and trade union enforcement of employment standards in Australia" (2009) 23:3 Australian Journal of Labour Law, 306; and, Maconachie \& Goodwin note 16. ${ }^{22}$ Hardy \& Howe note 21. 
${ }^{23}$ D. Walters, \& P. James, (2011) "What motivates employers to establish preventive management arrangements within supply chains?" (2011) 49 (7), Safety Science, 988.

${ }^{24}$ C. Estlund, "Rebuilding the law of the workplace in an era of self-regulation" (2005) 105 (2) Columbia Law Review, 319.

${ }^{25}$ Macklem \& Trebilcock, note 20; and, M. Thomas, "Regulating Labour Standards in the Global Economy: Emerging Forms of Global Governance" In G. Teeple and S. McBride (eds.), Relations of Global Power: Neoliberal Order and Disorder. (Toronto: University of Toronto Press, 2011) 95.

${ }^{26}$ Gallina note 12 and Department for Business Enterprise and Regulatory Reform (DBERR) note 12.

${ }^{27}$ Saunders \& Dutil, note 12 and S. Tombs \& D. Whyte, "A deadly consensus: Worker safety and regulatory degradation under New Labour" (2010) 50, British Journal of Criminology 46.

${ }^{28}$ L. Dickens, "Delivering fairer workplaces through statutory rights? Enforcing employment rights in Britain" (2009) Paper presented at the $15^{\text {th }}$ World Congress of the International Industrial Relations Association, Sydney, Australia.

${ }^{29}$ Mark Thomas, Regulating Flexibility: The Political Economy of Employment Standards. (Montreal \& Kingston: McGill-Queen's University Press, 2009).

${ }^{30}$ Archives of Ontario, "Ontario Labour Minister Elgie Presents Ministry Year-End Review," News Release, 11 January 1982 RG 7-186.

${ }^{31}$ Ontario Ministry of Labour Bill 85 Amendments to the Employment Standards Act. Employment Standards Bulletin. (Toronto: Ministry of Labour, 1987).

${ }^{32}$ Archives of Ontario, "Labour Minister Announces the Creation of the Employee Wage Protection Program", News Release, 11 April 1991,RG 7-186,

${ }^{33}$ Eaton, J. (1996) "Province shifts employment standards responsibility. Changes put onus on unions to ensure rules are applied", Toronto Star, Monday, 2 December 1996, C3.

${ }^{34}$ M. Gellatly, J. Grundy, K. Mirchandani, A. Perry, M. Thomas and L.F. Vosko “'Modernizing' Employment Standards? Administrative Efficiency, Market Regulation, and the Production of the Illegitimate Claimant in Ontario, Canada" (2011) 22(2), Economic and Labour Relations Review, 81; and, Leah Vosko, "A New Approach to Regulating Temporary Agency Work in Ontario or Back to the Future?" (2011) 65(4), Relations Industrielles/Industrial Relations, 632. 
${ }^{35}$ Gellatly et el note 34 .

${ }^{36}$ Ontario Ministry of Labour, "Proposed Open for Business Act - What Others Are Saying", News Release, 17 May 2010,online: http://news.ontario.ca/medt/en/2010/05/proposed-open-for-business-act--what-others-are-saying.html [ accessed 10 December 2010].

${ }^{37}$ Ontario Ministry of Labour, "New Legislation Modernizes Ontario's Employment Standards" News Release, 25 October 2010, online: http://www.labour.gov.on.ca/english/news/bulletin ofba.php [accessed 15 Nov 2010].

${ }^{38}$ Ontario Ministry of Labour, note 36.

${ }^{39}$ Ontario Ministry of Labour, "Employment Standards Task Force" (2010) online: http://www.labour.gov.on.ca/english/es/pubs/is estf.php, [accessed 15 Nov 2010].

${ }^{40}$ The administration Manual for Employment Standards (AMES) sets out procedures for the administration and enforcement of the ESA, 2000. It documents the practices and procedures established by the Director and to be followed by ESOs and other program staff, whether conducting investigations or otherwise administering or enforcing provisions of the Act. Ontario Ministry of Labour, Administration Manual for Employment Standards (AMES), Employment Standards Program, (2010). On file with authors.

${ }^{41}$ Employer Workbook, Public Holiday Pay Calculator, Severance Tool, and Termination Tool. See Ontario Ministry of Labour, online: http://www.labour.gov.on.ca/english/es/tools/index.php [accessed 23 August 2011].

${ }^{42}$ Ontario Ministry of Labour "Employment Standards Program Annual Report, 2009-2010” (2010). On file with authors.

${ }^{43}$ For example, exceptions are made for young workers, live-in caregivers, people with language barriers or a disability, workers that are afraid to contact the employer, workers with non-monetary complaints, workers approaching the 6 month time limit or when the employer has closed or gone bankrupt.

${ }^{44}$ Marion Lane Administration in Action: An Institutional Analysis of the Ontario Employment Standards Branch (Berkeley: University of California, 1977). On file with authors.

${ }^{45}$ Office of the Provincial Auditor of Ontario, 2004 Annual Report, at 239. Online: http://www.auditor.on.ca/en/reports en. [accessed 12 July 2011]. 
${ }^{46}$ Ontario Ministry of Labour, note 42.

${ }^{47}$ Gellatly et al, note 34 .

${ }^{48}$ Ontario Ministry of Labour, note 40 Chapter 5,at 83 .

${ }^{49}$ Workers' Action Centre (2007) Working on the Edge, online:

http://www.workersactioncentre.org/!docs/pb WorkingOnTheEdge eng.pdf (accessed July 12, 2011).

${ }^{50}$ Ontario Ministry of Labour, Meeting with Workers' Action Centre \& Parkdale Community Legal

Services. ES Modernization Progress Update prepared by the Employment Practices Branch, (March 4, 2011). On file with authors.

${ }^{51}$ Ontario Ministry of Labour, note 42.

52 In 1996, the MOL privatized some of its collection activities. In cases where wages are not recovered through claims investigation or from the Trust Fund, collections are done by a private collection agency on contract with the Ministry.

${ }^{53}$ Employers seeking to appeal an Order to Pay must put the amount of monies owing into the Ministry of Labour Trust Fund to proceed at the Ontario Labour Board. These amounts are monies that workers received following the Labour Board Appeal.

${ }^{54}$ Ontario Ministry of Labour, note 40 at Chapter 4 - Inspections 4.

${ }^{55}$ Lane at note 44.

56 Ontario Ministry of Labour, "New Legislation and beefed up enforcement reaches out to vulnerable workers," 26 April 2004 Press Release. Online: http://news.ontario.ca/archive/en/2004/04/26/McGuintygovernment-acts-to-protect-workers.html [accessed 9 June 2011].

${ }^{57}$ Ontario Ministry of Labour, “Dedicated Team to Enforce New Laws That Protect Ontario's Vulnerable Workers" (2011) ; online: http://www.labour.gov.on.ca/english/es/pubs/es det.php; [accessed 28 August 2011].

${ }^{58}$ Ontario Ministry of Labour, Employment Standards Program Annual Report 2008-2009, (2009) at23. On file with authors.

${ }^{59}$ For a fuller discussion of racialized and gendered labour market segmentation, see Leah Vosko (ed) Precarious Employment: Understanding Labour Market Insecurity in Canada. (Montreal and Kingston: McGill-Queens University Press,2006) ; Mark Thomas, note 29 at 19 - 29; and Grace-Edward Galabuzi 
Canada's Economic Apartheid: The Social Exclusion of Racialized Groups in the New Century (Toronto: Canadian Scholars Press Inc., 2006).

${ }^{60}$ Leah Vosko, Temporary Work: The Gendered Rise of a Precarious Employment Relationship. (Toronto: University of Toronto Press, 2000) at.49.

${ }^{61}$ Annette Bernhardt, Heather Boushey, Laura Dresser and Chris Tilly (eds) The Gloves Off Economy: Workplace Standards at the Bottom of America's Labor Market (Labor and Employment Relations Association Series, 2008) at 3.

${ }^{62}$ Law Commission of Canada Is Work Working? Work Laws that do a Better Job: Discussion Paper. (2003) Online: http://dalspace1.library.dal.ca/dspace/handle/10222/10307 [accessed 5 July 2011] at 34. 63 Thomas note 29 at 137.

${ }^{64}$ While the gap has lessoned with recent minimum wage increases, Ontario's minimum wage is still below the poverty level. In 2008, a person working full time, all year in an urban centre would need $\$ 10.70$ per hour to reach the Low Income Cut Off. Statistics Canada Low Income Cut-offs for 2008 and Low Income measures for 2007 (2009) Online: http://www.statcan.gc.ca/pub/75f0002m/2010005/tbl/tbl02eng.htm [accessed 28 August 2011].

${ }^{65}$ Andrew Jackson, "Organizing Low Wage Workers: Performance and Prospects" Canadian Labour Congress, Thursday March 2, 2006. Online: http://www.canadianlabour.ca/newsroom/publications/organizing-low-wage-workers-performance-and-prosects [last accessed 11 January, 2010].

${ }^{66}$ For fuller discussions of this in Ontario, see Workers' Action Centre note 49 and Judy Fudge, “Reconceiving Employment Standards Legislation: Labour Law's Little Sister and the feminization of Labour" (1991) 7, Journal of Law and Social Policy, 73 and, in the United States, see Bernhardt et el note 61.

${ }^{67}$ See Fudge note 66, Vosko note 59, Workers' Action Centre note 49 and Saunders \& Dutil, note 12 ${ }^{68}$ Cynthia Cranford and Leah Vosko "Conceptualizing Precarious Employment: Mapping Wage Work Across Social Location and Occupational Context" in Leah Vosko note 59, 43-66.

${ }^{69}$ Workers' Action Centre, note 49. 
${ }^{70}$ Human Resources Development Canada, Evaluation of Federal Labour Standards (Phase I) Final Report (Ottawa: HRDC, 1997) at 41. Online: http://www.hrsdc.gc.ca/eng/cs/sp/hrsdc/edd/reports/1997000439/page00.shtml [acessed: 21 August 2011]

${ }^{71} 2005$ Statistics Canada Federal Jurisdiction Workplace survey of employment practices, cited in Harry Arthurs, Fairness at Work: Federal Labour Standards for the $21^{\text {st }}$ Century, (Ottawa: Federal Labour Standards Review, 2006) at 192.

${ }^{72}$ Workers' Action Centre, note 49 at 46

${ }^{73}$ Workers' Action Centre (2011) Unpaid Wages, Unprotected Workers: A Survey of Employment Standards Violations http://www.workersactioncentre.org/!docs/pb unpaidwagesunprotectedworkers eng.pdf. [accessed 29 August 2011]

${ }^{74}$ These figures are not adjusted for inflation and therefore understate the decline in funding. Data derived from Ontario Ministry of Labour, "Historical Funding - Operations, 1997-98 to 2006-07," Monday April 16, 2007. On file with authors; Ontario Ministry of Labour, "Annual Report of 2007-08”, July 8, 2008. On file with authors; and, Statistics Canada, Labour force survey, Table 282-0054, Online: http://www5.statcan.gc.ca/cansim/a05?lang=eng\&id $=2820054$

${ }^{75}$ Ontario Ministry of Labour, note 42.

${ }^{76}$ Saunders \& Dutil note 12 at 2.

${ }^{77}$ Ontario Ministry of Labour, note 42.

${ }^{78}$ The Ministry of Labour reports that in 2008 there were approximately 21,000 employees in Ontario working under the federal Live-in Caregiver Program. As of December 2008, the number of migrant workers under the federal temporary foreign worker program topped 250,000, greater than the number of newcomers who were granted permanent residency status. Ontario Ministry of Labour, "Ontario Helping Live-In Caregivers" Press release, October 21, 2009. Online: http://news.ontario.ca/mol/en/2009/10/ontario-helping-live-in-caregivers.html [accessed 14 July 2011]

${ }^{79}$ Statistics Canada, Employment Insurance, June 2009 The Daily August 25, 2009. Online: http://www.statcan.gc.ca/daily-quotidien/090825/dq090825a-eng.htm [accessed 14 July 20111] ${ }^{80}$ Office of the Provincial Auditor of Ontario, note 45. 
${ }^{81}$ Although those immigrants arriving in the last 10 yeas that live in urban centres are slightly more likely to use the internet than Canadians as a whole. Statistics Canada, "Canadian Internet Use Survey" The Daily, June 12, 2008. http://www.statcan.gc.ca/daily-quotidien/090612/dq080612b-eng.htm [accessed 12 July 2011]

${ }^{82}$ Data run by Soyini Barrington, Policy and Research, Legal Aid Ontario, July 8, 2009. On file with Authors.

${ }^{83}$ Cohl, Karen and George Thomson, Connecting Across Language and Distance: Linguistic and Rural Access to Legal Information and Services, (Toronto: The Law Foundation of Ontario, 2008), at 13. Online: http://www.lawfoundation.on.ca/pdf/linguistic rural report dec2008 final.pdf [accessed 18 July 2011] ${ }^{84}$ Grenier, S., S. Jones, J. Strucker, T.S. Murray, G. Gervais, and S. Brink (2008) International Adult Literacy Survey Learning Literacy in Canada: Evidence from the International Survey of Reading Skills, Statistics Canada, Catalogue no. 89-552-MIE-No. 19., p. 37. Online: http://www.nald.ca/library/research/stats/llc/llc.pdf [accessed 18 July 2011].

${ }^{85}$ Statistics Canada, “Low Income Lines: 2008-2009” Online: http://www.statcan.gc.ca/pub/75f0002m/2010005/tbl/tbl02-eng.htm [accessed 13 July 2011]. ${ }^{86}$ Sheila Block, Ontario's Growing Gap: The Role of Race and Gender, Growing Gap Series, (Toronto: Canadian Centre for Policy Alternatives, 2010) at 5.

${ }^{87}$ Cheryl Teelucksingh \& Grace-Edward Galabuzi, Working Precariously: The Impact of Race and Immigrant Status on Employment Opportunities and Outcomes in Canada (Toronto: The Canadian Race Relations Foundation, 2005) at 9.

${ }^{88}$ Arthurs note 72 at 71 ,

${ }^{89}$ Ontario Ministry of Labour, "BACKGROUNDER: Employment Standards Ministry Success" (2011) Online: http://www.labour.gov.on.ca/english/news/nr esenforcement110729.php [accessed: 6 September 2011]

${ }^{90}$ Eric Tucker, "Old Lessons for New Governance: Safety or Profit and the New Conventional Wisdom," paper for Theo Nichols Conference, "Safety or Profit", Cardiff University, January 11, 2011 [on file with authors]. 
${ }^{91}$ Ontario Ministry of Labour (2011) BACKGROUNDER: Employment Standards: Education and Enforcement. Online: http://www.labour.gov.on.ca/english/news/bg esenforcement110729.php. Accessed September 6, 2011

92 Tucker note 90 .

${ }^{93}$ Commonly referred to as the 'Dean Report'. Tony Dean, Expert Advisory Panel on Occupational Health and Safety: Report and Recommendations to the Ministry of Labour. (2010) Toronto: Ministry of Labour, Online: http://www.labour.gov.on.ca/english/hs/pdf/eap report.pdf [last accessed: September 28, 2011].

${ }^{94}$ Ontario (Labour) v. United Independent Operators Limited [2011] ONCA 33. I leave aside the question of when duties may be owed to members of the public who are present at a workplace. For example, see Blue Mountain Resorts Ltd. v. Den Bok [2011] ONSC 1909 (upholding an OLRB decision that the requirement under s. 51(1) to report deaths or critical injuries to "persons" at a workplace extends to guests).

${ }^{95}$ R. v. Inco Ltd. [2001] 54 O.R. (3d) 495 (ONCA); OHSA, s. 56.

${ }^{96}$ G. Gray, G. "The Responsibilization Strategy of Health and Safety." (2009) 49 British Journal of Criminology, 326 at 332 .

${ }^{97}$ Ontario Court of Justice, Set Fines I of the Provincial Offences Act, online: http://www.ontariocourts.on.ca/ocj/en/setfines/one/ [last accessed 3 October 20111].

${ }^{98}$ H. Glasbeek, \& S. Rowland, "Are Killing and Injuring at Work Crimes?” (1979) 17 Osgoode Hall Law Journal. 506; Eric Tucker "The Westray Mine Disaster and its Aftermath: The Politics of Causation." (1995) 10:1 Canadian Journal of Law and Society.91.

${ }^{99}$ Eric Tucker, Administering Danger in the Workplace: The Law and Politics of Occupational Health and Safety Regulation in Ontario 1850-1914 (Toronto: University of Toronto Press, 1990).

${ }^{100}$ G.G. Mackenzie \& J.I. Laskin, Report on the Administration of the Occupational Health and Safety Act (Toronto: Ontario Ministry of Labour, 1987) and, D. Smith, Consulted to Death. (Manitoba: Arbeiter Ring, 2000). 
${ }^{101}$ Eric Tucker, "The Politics of Occupational Health and Safety in a Cold Climate: Diverging Trends in Worker Protection and Participation in Canada, 1985-2000." (2003) 58, Relations Industrielles/Industrial Relations 395.

102 Ontario Ministry of Labour "Safe At Work Ontario" ( 2011) online:

http://www.labour.gov.on.ca/english/hs/sawo/about.php [accessed 5 August 2011].

${ }^{103}$ To my knowledge, the term is not defined so its meaning is ambiguous insofar as it could include young workers, new entrants to the labour market, self-employed workers, agency workers, etc.

${ }^{104}$ Ontario Ministry of Labour note 102.

105 Gray note 96.

${ }^{106}$ Ontario Ministry of Labour, Legal Services Branch special data run, April 2011 (on file with authors).

${ }^{107}$ Cheryl Edwards, "Where Are All the C-45 OHS Prosecutions?" Online:

http://www.heenanblaikie.com/en/media/pdfs/pdf/Where Are All the Bill C45 Prosecutions.pdf;jsessionid=94884D7F485727D18FFBDE0ED30ABFCA [accessed: 8 August 2011]. ${ }^{108}$ Canadian Employment Law Today, "C-45 Charges Against Ontario Crane Company Dropped" (4 January 2011) Online: http://www.employmentlawtoday.com/ArticleView.aspx?l=1\&articleid=2450 [accessed 8 August 2011]..

${ }^{109}$ Norm Keith, "Regulators Gone Wild!" Canadian Occupational Health and Safety (27 January 2011) online: http://www.cos-mag.com/Legal/Legal-Columns/regulators-gone-wild.html [accessed 8 August 2011].

${ }^{110}$ R. v. Transpavé Inc. [2008] QCCQ 1598.

${ }^{111}$ R. v. Scrocca, [2010] QCCQ 8218.

1122010 QCCQ 12364; Norman Keith \& Anna Abbott, “Acquittal in Quebec Bill C-45 Charges” Online: http://www.gowlings.com/KnowledgeCentre/enewsletters/ohslaw/htmfiles/ohslaw20110427.en.html, [accessed 8 August 2011].

${ }^{113}$ Stefan Dubowski, "Complexity, Confusion Stymies C-45 Charges." (2010) Canadian Occupational Health and Safety online: http://www.cos-mag.com/Legal/Legal-Stories/Complexity-confusion-stymies-C45-charges.html [accessed: 8 August 2011]. 
114 "BC Court: Union's Private Criminal Negligence Case Can Go Forward." OHS Insider (8 March 2011) online: http://ohsinsider.com/search-by-index/c45/bc-court-union $\% E 2 \% 80 \% 99$ s-private-criminalnegligence-prosecution-can-go-forward [accessed: 8 August 2011]; “Alert: Crown Dismisses Union Brought C-45 Case." OHS Insider (25 August 2011). Online http://ohsinsider.com/search-byindex/c45/aug-25-crown-dismisses-union-brought-c-45-case [accessed 5 September 2011].

${ }^{115}$ Ontario Ministry of Labour, Employment Rights and Responsibilities, "Protect Vulnerable Workers and Support Poverty Reduction” Ministry Activities: Results-based Plan Briefing Book 2010-11 (2010)

Online: http://www.labour.gov.on.ca/english/about/pubs/rbp/2010/rbp 2.php.[accessed: 15 September,2011].

${ }^{116}$ Bridget Hutter, "An Inspector Calls: The Importance of Proactive Enforcement in the Regulatory Context" (1986) 26(2) British Journal of Criminology 114; and, Weil note 12.

${ }^{117}$ Ian Ayres \& John Braithwaite, Responsive Regulation: Transcending the Deregulation Debate. (New York: Oxford University Press, 1992); Charles Sabel, Daraand O'Rourke, and Archon Fung "Ratcheting Labor Standards: Regulation for Continuous Improvement in the Global Workplace", (2000) Online: http://www.archonfung.net/papers/rls21.pdf [accessed 3 July 2011]; Estlund note 24; and, Macklem \& Trebilcock, note 20 .

${ }^{118}$ In this discussion, we use the term voice to refer to the ability of workers' and their organizations to themselves shape the enforcement processes such that they are able to meaningfully realize their rights rather than in the sense it used by scholars of the new governance school, such as Lobel, who introduces a 'voice principle', in the case of OHS regulation, to denote workers' participation in firms' health and safety management regimes. Eric Tucker, Administering Danger. (Toronto: University of Toronto Press, 2001) at 11.

${ }^{119}$ Approximately seventy studies and reports were surveyed. Where OHS enforcement measures provide lessons for ES enforcement, these best practices are also identified.

${ }^{120}$ To this end, the Auditor General's report noted that "during the 2003/04 fiscal year, the Ministry investigated more than 15,000 complaints from employees and carried out approximately 150 proactive inspections... the Ministry was focusing its efforts almost entirely on investigating complaints from 
individuals against their former employers. As a result, we concluded that the Ministry's inspection activities relating to protecting the rights of currently employed workers was inadequate. Many of the concerns identified during this audit were also reported on in our 1991 audit of the then Employment Standards Program" Office of the Provincial Auditor of Ontario, note 45.

${ }^{121}$ In making this criticism, the Auditor General noted that although

[O]ne or more violations were found to exist in about $70 \%$ of complaints filed... the majority of workplace violations are reported by former employees as current employees are generally reluctant to file claims for fear of losing their jobs, despite the protection of employee rights that exists in the Act. In fact, $90 \%$ of complaints were filed by individuals no longer working for the employers against which they filed claims. To be effective in fulfilling its mandate, the Ministry has an obligation to protect the employment rights of currently employed workers who may be reluctant to file claims" Office of the Provincial Auditor note 45 at 242.

${ }^{122}$ Contending that this situation needed to be rectified, the Auditor General's report described a complaint by a former employee against an employer in 2001 , which found unpaid wage, vacation pay, and termination pay violations but was not extended to include other employees at the time. It reported, "however, [that] from 2001 to 2003, four subsequent investigations of complaints against the same employer determined similar violations with a total assessed amount of about $\$ 25,000$ owing to those employees". Office of the Provincial Auditor note 45 at 242

${ }^{123}$ Broadly, the report suggested that although the Act permits an ESO to negotiate the resolution to a claim,

"most claims [are] in fact settled without the necessity to issue a formal order to pay and without the imposition of a fine and administrative fee. This approach to resolving complaints could be justified in certain situations such as when violations are minor and the employer has no previous violations and acts expediently to deal with employee complaints. However, if not deployed prudently, this practice could convey to employers that there is a level of tolerance for employers who do not voluntarily adhere to requirements of the Act, as there is little likelihood of a fine or penalty even if they do violate the Act. Any increased non-compliance with the Act on the part of 
employers also puts an additional burden on employees to initiate complaints with the Ministry to ensure their rights are respected." (italics added). Office of the Provincial Auditor, note 45 at 245.

${ }^{124}$ According to the Auditor General, "the collection agencies contracted by the Ministry were expected to have a successful collection rate of $35 \%$. However, the rate achieved was much lower, about $15 \%$ ".

Office of the Provincial Auditor note 45 at 239.

${ }^{125}$ Michael Quinlan and Rosemary Sokas, "Community Campaigns, Supply Chains, and Protecting the Health and Well-Being of Workers" (2009) 3,99 ( S3) American Journal of Public Health Supplement 538; Phil James, Richard Johnstone, Michael Quinlan, and David Walters, "Regulating Supply Chains to Improve Health and Safety", Industrial Law Journal 36(2): (2007) at 163; and, David Weil, Carlos Mallo, "Regulating Labor Standards via Supply Chains: Combining Public/Private Interventions to Improve Workplace Compliance" ,British Journal of Industrial Relations 45 (4): (2007) 791.

${ }^{126}$ Fine \& Gordon note 15.

${ }^{127}$ David Weil and Amanda Pyles, "Why Complain? Complaints, Compliance, and the Problem of Enforcement in the U.S. Workplace" Comparative Labour Law and Policy Journal 27: (2005) 59; and, David Weil, "Rethinking the Regulation of Vulnerable Work in the USA: A Sector-based Approach", The Journal of Industrial Relations 51(3) (2009) 411.

${ }^{128}$ UK Department for Business, Enterprise and Regulatory Reform Vulnerable Worker Enforcement Forum - Final Report and Government Conclusions. (2008) Online: http://www.Berr.Gov.Uk/Files/File47317.Pdf [accessed 3 July 2011]. ${ }^{129}$ See for example: David Fairey, (2005) Eroding Worker Protections: British Columbia's New 'Flexible' Employment Standards. British Columbia: Canadian Centre for Policy Alternatives (2005) Online: http://www.policyalternatives.ca/documents/BC Office Pubs/bc 2005/employment standards.pdf [accessed 3 July 2011]; and, Saunders \& Dutil note 12.

${ }^{130}$ see for e.g., Workers Action Centre and Employment Standards Work Group Modernizing Part III of the Canada Labour Code Submission to the Federal Labour Standards Review, Workers Action Centre at

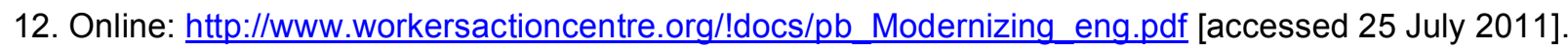


${ }^{131}$ Fine \& Gordon note 15; Hardy \& Howe note 21; and John Howe, Nicole Yazbek and Sean Cooney,(2011) "Study on Labour Inspection Sanctions and Remedies: The Case of Australia." International Labour Organization - Geneva. Online: http://www.ilo.org/wcmsp5/groups/public/--ed dialogue/---lab admin/documents/publication/wcms 154066.pdf [accessed 3 July 2011].

${ }^{132}$ David Weil, “A Strategic Approach to Labour Inspection”, International Labour Review 147(4):(2008) at 349-375; and Weil note 127.

${ }^{133}$ U.S. Department of Labor, “Strategic Plan Fiscal Years 2011-2016” (2011) at 104.Online:

http://www.dol.gov/ sec/stratplan/StrategicPlan.pdf [accessed 25 July 2011].

134 Weil note 12 at 25

${ }^{135}$ It should be emphasized from the outset that the weakness of this strategy is that it fails to reach up to firms at the top of the chain, which set terms that condition the employment relationships and standards in the most highly competitive parts of this labour market (i.e., at the bottom). This limitation calls for embedding the DOL strategy of sweeps in a strategy of liability between top and bottom.

${ }^{136}$ U.S. Department of Labor "US Labor Department's Initiative in South Florida Results in Nearly $\$ 800,000$ in Back Wage and Fines for Violations Affecting about 590 Farmworkers." News Release 06/27/2011. Online: http://www.dol.gov/opa/media/press/whd/whd20110845.htm [accessed 25 July 2011] ${ }^{137}$ U.S. Department of Labour note 136 (emphasis added)

${ }^{138}$ Other more direct examples of measures targeted to industries in the United States include focused inspections, undertaken by the WHD, in industries beyond those mentioned in the plan/prevent/protect agenda, such as gas stations and restaurants. For example, in 2011 , after recovering $\$ 1.2$ million in back wages for almost 400 employees at 100 New Jersey gas stations and finding "gas stations rife with violative pay practices such as paying workers a flat salary or 'straight time' wages for all hours," the WHD launched a state-wide initiative involving investigations at randomly chosen gas stations to educate operators about their obligation to pay the minimum wage and overtime requirements under the FSLA (Ference as cited by Harold Brubaker, "Feds Target Wages at N.J. Gas Stations" Philly.com (April 23 2011). Online: http://articles.philly.com/2011-04-23/business/29466702 1 minimum-wage-gas-stationsfair-labor-standards-act [accessed 3 July 2011]. 
A similar measure, known as a "neighbourhood sweep", involving labour officials at the State level, and focussing geographically on restaurants in Ithaca New York, found 77 percent of those visited to be violating New York State Labour Laws in 2009. New York State Department of Labor, "Targeted Labor Department Investigation Finds Ithaca Restaurant Workers Victimized by Wage Theft" Press Release December 10 2009. Online: http://www.labor.ny.gov/pressreleases/2009/December10 2009.htm. [accessed July 03 2011].

${ }^{139}$ Manitoba Employment Standards Code (C.C.S.M. c. E110).

${ }^{140}$ New Brunswick Employment Standards Act (1982) Chapter E-7.2.

${ }^{141}$ Newfoundland and Labrador Labour Relations Agency, Labour Standards Statistics (2010). Online: http://www.gov.nl.ca/lra/stats/standardsstats.html [accessed 3 July 2011].

${ }^{142}$ Dickens note 28.

${ }^{143}$ Safe Work Australia, Explanatory Memorandum - Model Work Health and Safety Bill. (2011) Online: http://www.safeworkaustralia.gov.au/ABOUTSAFEWORKAUSTRALIA/WHATWEDO/PUBLICATIONS/Pa ges/ExplanatoryMemorandum.aspx [accessed 25 July 2011].

144 Safe Work Australia note 143 at Part 2, Division 4, S. 27.

145 Weil \& Mallo note 125 at 796.

${ }^{146}$ Vosko note 3 at $184-185$. A similar best practice with regard to investigations in OHS regulation also exists in the Australian state of New South Wales. Through the Occupational Health and Safety Amendment Act (Long Distance Truck Driver Fatigue) 2005, New South Wales requires both trucking operators and those further up the chain (e.g., shippers, freight brokers etc.) to monitor the fatigue levels of the subcontractors they engage to ensure that the road transport firms or owners and drivers have systems in place to manage, and are managing, the fatigue of their employees, including the hours of drivers arriving at warehouses.

Although this regulation is state-based, from its inception it had nation-wide effects since almost $80 \%$ of trucking passes through New South Wales (James et al note 125 at 182-184; Quinlan \& Sokas note 125 at S542). 
147 Christopher Buscaglia, "Crafting a Legislative Solution to the Economic Harm Of Employee Misclassification" (2009) University of California Davis Business Law Journal 9:111-136 at 118. 148 Joint Enforcement Task Force on Employee Misclassification, Annual Report of The Joint Enforcement Task Force on Employee Misclassification.(2011) Online: http://www.labor.ny.gov/ui/PDFs/2011\%202011\%20Misclassification\%20Report\%20to\%20the\%20Govern or\%20(4)\%20(2).pdf [accessed 9 July 2011] at 2.

${ }^{149} \mathrm{An}$ individual is "considered an employee unless he or she is free from direction and control in performing the job, AND the work performed is not part of the usual work done by the business that hired the individual, AND the individual has an independently established business (Fair Play Act s. 861(c); see also Joint Enforcement Task Force on Employee Misclassification note 148.

${ }^{150}$ Twelve other U.S. States are also following the lead of New York and initiating similar taskforce. New York State Department of Labor, "Targeted Labor Department Investigation Finds Ithaca Restaurant Workers Victimized by Wage Theft." Press Release December 10 2009. Online: http://www.labor.ny.gov/pressreleases/2009/December10 2009.htm[accessed 3 July 2011]. In British Columbia, as well, cross agency collaboration in the detection of violations in the agricultural sector once existed through what was known as the Agricultural Compliance Team, although it was abandoned in the early 2000s. See Graeme Moore, Hand-Harvesters of Fraser Valley Berry Crops: New Era Protection of Vulnerable Employees. A Report Prepared for the B.C. Federation of Labour. Online: http://www.bcfed.com/files/1000-4rep_hand_harvesters_moore.pdf [Accessed 3 July 2011], and Fairey note 129 at 30 .

${ }^{151}$ Fine \& Gordon note 15 at 563-4.

152 Fine \& Gordon note 15.

${ }^{153}$ Fine \& Gordon note 15 at 560.

${ }^{154}$ Weil note 132.

155 Catherine Ruckelshaus, “Labor's Wage War”(2008) Fordham Urban Law Journal XXXV, 373 at 391 94; and Karina Muniz, "The Janitorial Industry and the Maintenance Cooperation Trust Fund" in Ruth 
Milkman, Joshua Bloom and Victor Narro (eds.) Working For Justice: The L.A. Model of Organizing and Advocacy, (Ithaca: Cornell University Press, 2010) 211.

${ }^{156}$ Ruckelhaus note 155 at $393 .$.

${ }^{157}$ Fine \& Gordon note 15 at 568-570.

${ }^{158}$ Fine \& Gordon note 15 at 568-570. A further project making similar inroads in the State of New York is the Workplace Justice Project, led by Make the Road New York, which hosts two projects run by democratic committees of predominantly immigrant workers - Trabajadores en Acci'on ("Workers in Action") and Trabajadores Unidos ("Workers United") - based at the organization's neighbourhood centres - that engage in employer-focused campaigns, collaboration with government enforcement agencies at the federal and state levels (principally involving tracking agencies' complaints process and working with them to create larger enforcement initiatives), strategic targeting of industries with unions, and drafting, and working to pass, legislation to improve the workplace rights of low-wage workers. Andrew Friedman and Deborah Axt, "In Defense of Dignity” (2010) 45 Harvard Civil Rights-Civil Liberties Law Review. 577.

159 Tucker note 90 at 17.

${ }^{160}$ Andrea M. Noack and Leah F. Vosko, "Precarious Jobs in Ontario: Mapping Dimensions of Labour Market Insecurity by Workers' Social Location and Context" (2011) Paper for Law Commission of Ontario Vulnerable Workers and Precarious Work Project.

${ }^{161}$ Saskatchewan Ministry of Advanced Education, Employment and Labour, "Anonymous Complaint Form" Labour Standards Division. (2010) Online: http://www.aeei.gov.sk.ca/anonymous-thirdparty-complaint-form [accessed 25 July 2010].

${ }^{162}$ National Employment Law Project “Winning Wage Justice: An Advocate's Guide to State and City Policies to Fight Wage Theft" (2011) at 58. Online: http://www.nelp.org/page//Justice/2011/WinningWageJustice2011.pdf?nocdn=1 [accessed 3 July 2011] .

163 See Timothy Glynn, "Taking the Employer out of Employment Law? Accountability for Wage and Hour Violations in an Age of Enterprise Disaggregation”, (2011) 15 Employee Rights And Employment Policy Journal, 101 on duty-base regimes. See also Brishen Rogers, "Toward Third-Party 
Liability for Wage Theft", (2010) 31 University of California Berkeley Journal of Employment and Labor Law, 1.

${ }^{164}$ California Labour Code $§ 2810$ (2003) s.2810(a)

${ }^{165}$ Glynn note 163 at 123.

166 California Labour Code $\S 2810$ (2003) s.2810(d). Notably, the law contains an escape clause which indicates that the manufacturer is not in violation if there is an agreement in writing that labour standards will be followed.

${ }^{167}$ See Vosko note 3.

${ }^{168}$ Guy Davidov describes a similar measure experimented with in Israel by the Tel-Aviv Regional Labour Court. In this instance, the Labour Court placed direct responsibility for the violation of ES on a bank concerning its dealings with a janitor working on its premises through a contractor because the contract between the bank and the cleaning firm was "patently money-losing for a law-abiding contractor." Guy Davidov, 'The Enforcement Crisis in Labor Law and the Fallacy of Voluntarist Solutions', (2010) 26(1) International Journal of Comparative Labour Law and Industrial Relations 61 at 81.

He also offers another concrete example which prohibits public agencies from contracting with firms that have violated key ES in the past. Known as The Public Entities Contracts Law of 1976, this measure "prohibits public sector employers from engaging with contractors convicted of violating Minimum Wage Law or the Migrant Workers Law more than twice, unless a year has passed since the last conviction" (at 61).The law is built on the principle that the government should not engage with repeater violators of labour law and should rather be a model employer; however, as he shows, the law is relatively meaningless in practices as ES enforcement is so weak.

169 National Employment Law Project note 62 at 12.

${ }^{170}$ National Employment Law Project note 162 at 20.

171 on the content of these standards and the shift to the Fair Work Act, see Vosko note 3 at 115-117 ${ }^{172}$ Howe, Yazbek, \& Cooney note 131 at 32 . There nevertheless remain significant barriers to union participation in enforcement in Australia under its Fair Work regime, including constraints on unions' rights of entry to investigate suspected violations and/or hold meeting with employees for which they now require a permit, which was not the case under a previous regime (Vosko 3 at Chapters 4 and 6). 
Furthermore, as Howe et al note 131 at 32-33) note, since the Fair Work Ombudsman under the Fair Work Act now has the responsibility for enforcing its terms, including its intention to control unlawful union activity, such as strikes, it is also unclear the extent to which unions are able to use their remaining powers effectively.

173 see for example, Tim Bartley, "Corporate Accountability and the Privatization of Labor Standards: Struggles Over Codes of Conduct in the Apparel Industry", (2005) 14 Research in Political Sociology 211; James et el note 125; Simon Deakin \& Richard Hobbs, "False Dawn for CSR? Shifts in Regulatory Policy and the Response of the Corporate and Financial Sectors in Britain" (2007) 15(1) Corporate Governance, 68; Macklem and Trebilcock note 20; and Walters and James 2011 note 23.

${ }^{174}$ see for example, Tombs \& Whyte note 27; Weil note 12; and, Tucker note 90.

175 (Macklem and Trebilcock note 20.

${ }^{176}$ At the level of a vision, Estlund's) model of "monitored self-regulation" also provides helpful guideposts for taking into consideration the foremost weaknesses of such practices as she envisions "us[ing] targeted public enforcement and private litigation to back up [initiatives such as CSR], and to induce entry into a system of monitored, quasi-tripartite regulation." Estlund note 24 at 61.

177 Jacues Igalens and Martine Combemale, "Fair Labour Association Model” in Jan Jonker and Marinus Cornelis de Witte (eds.) Management Models for Corporate Social Responsibility (Berlin: Springer, 2006) 180-186. A complementary example covering a smaller geographic area that does not target an industry in which subcontracting is common and involves a partnership between a state agency and employers, is the New York State Labor Bureau's Greengrocer Code of Conduct requiring such employers to pay legally required minimum wages and overtime, provide for reasonable vacation and sick days as well as days of rest, attend labour law seminars hosted by the State, display a poster publically with the terms of the Code and, most notably, maintain pay records that the State Attorney General can access Campaign to End Wage Theft, "Protecting New York's Workers: How the State Department of Labor Can Improve Wage-and-Hour Enforcement" Recommendations from New York's Community Groups, Immigrant Advocates, and Legal Assistance Providers. (2006) Online: http://www.mfy.org/wpcontent/uploads/reports/Protecting-Workers-Dept-of-Labor.pdf [accessed 3 July 2011] at 9. 
${ }^{178}$ see for example, Dickens note 28; Australian Council of Trade Unions, "Government Procurement Policy: Australian Jobs, Industry and Decent Industrial Relations" (2009) Online: http://www.actu.org.au/Images/Dynamic/attachments/6562/Procurement\%20Policy\%20-\%20final.pdf [accessed 3 July 2011]; and, Trade Union Congress, "Hard Work, Hidden Lives: The Short Report of the Commission on Vulnerable Employment". (2008) Online: http://www.fairpaynetwork.org/uploadedPDF/CoVE report.pdf [accessed 3 July 2011]. ${ }^{179}$ Eurofoundation, "Public Sector Procurement Policy” (2009) Ireland. Online: http://www.eurofound.europa.eu/areas/labourmarket/tackling/cases/ie002.htm [accessed 3 July 2011] at 1.

${ }^{180}$ Eurofoundation note 179 at 2.

${ }^{181}$ Eurofoundation, note 179 at 2 . For a parallel and relatively successful further example of public procurement policy where a state, rather than national, government has used its contracting power to improve employment standards in the cleaning sector, see John Howe and Ingrid Landau, 'Light Touch' Labour Regulation by State Governments in Australia"(2007) 31 Melbourne University Law Review 367, on the case of New South Wales Australia.

182 Sweatfree Purchasing Consortium, "Sweatfree Purchasing Guide" Version 1. (2011) Online: http://buysweatfree.org/image/File/Guide\%20to\%20Sweatfree\%20Procurement.pdf [accessed 25 July2011] at 7 .

${ }^{183}$ Sweatfree Purchasing Consortium note 182 at 11.

${ }^{184}$ Sweatfree Purchasing Consortium note 182 at 14.

${ }^{185}$ Fair Work Ombudsman "Horticulture Industry Shared Compliance Program" (2010)

Online: http://www.fairwork.gov.au/campaignresults/National/Horticulture-Industry-Shared-ComplianceProgram-2010.pdf [accessed 4 July 2011].

${ }^{186}$ The program has also had limited success due to a lack of funding.

${ }^{187}$ Fair Work Ombudsman, "Pro-active Compliance Deed Between McDonald's Australia Limited and the Commonwealth of Australia" (2011) Online:

http://www.fairwork.gov.au/Documents/Proactive-Compliance-Deed-McDonalds-Aust-and-FWO.PDF [accessed 3 July 2011]. 
${ }^{188}$ see especially Paul Teague, "Reforming the Anglo-Saxon Model of Labour Inspection: The Case of the Republic of Ireland"(2009) 15(2) European Journal of Industrial Relations, 207.

189 Saunders and Dutil note 12 at 20.

${ }^{190}$ See for example, J. Black, and R. Balwin, "Really Responsive Regulation” (2010) 32 Law and Policy : $181-215$.

${ }^{191}$ Such an approach requires that there will be occasions where some risk-creating activities should be prohibited and that there should be policies in place to encourage the reduction of risks. However, because we are concerned here with enforcement, our focus is on ensuring that permissible activities are conducted lawfully.

${ }^{192}$ Weil note 132 and Weil note 127.

${ }^{193}$ See for example R. Cox and K. Lippel, "Falling Through the Legal Cracks: The Pitfalls of Using Workers' Compensation Data as Indicators of Work-Related Injuries and IIInesses" (2008) 6:2 Policy and Practice in Health and Safety, 63.

${ }^{194}$ Dean Report note 93

195 D. Walters, R. Johnstone, K. Frick, M. Quinlan, G. Baril-Gingras and A.Thebaud-Mony, Regulating Workplace Risks in Times of Change: A Comparative Study. (London: Edward Elgar, forthcoming).

${ }^{196}$ W. Von Richtofen, Labour Inspection: A Guide to the Profession. (Geneva: International Labour Office, 2002) at 205-07.

${ }^{197}$ Dean Report note 93 at 2.43 .

${ }^{198}$ Inspectors face competing pressures to enforce or educate. The issue of managerial control over inspection activity was contentious in the Bill 160 debates and resulted in the removal of a section from the original bill that authorized the Director to establish written policies respecting the interpretation, administration and enforcement of the OHSA and that required inspectors to follow such policies. In regard to the latter issue, an agreement was reached with the union representing inspectors regarding the matter. See D. Birch, "A New View.” 2011 OHS Canada. June/July (forthcoming).

${ }^{199}$ N. Gunningham, “Prosecution for OHS Offences: Deterrent or Disincentive?" (2007) 29 Sydney Law Review, 359. 
${ }^{200}$ Richard Johnstone, . "From Fiction to Fact - Rethinking OHS Enforcement." Working Paper No. 11, National Research Centre for Occupational Health and Safety Regulation. (Canberra: Australian National University, 2003). Online http://ohs.anu.edu.au/publications/pdf/wp\%2011\%20-\%20Johnstone.pdf [accessed 12 August 2011].

${ }^{201}$ L. Bluff, "The Use of Infringement Notices in OHS Law Enforcement." Working Paper No.231, National Research Centre for Occupational Health and Safety Regulation. (Canberra: Australian National University, 2004). Online http://ohs.anu.edu.au/publications/pdf/wp \%2023\%20-\%20Bluff.pdf [accessed 12 August 2011].

${ }^{202}$ Gray note 96

${ }^{203}$ David Weil, "Enforcing Labor Standards in Fissured Workplaces: The US Experience." (2011) 22:2 Economic and Labour Relations Review, 33.

204 J. Eakin, D. Champoux, and E. McEachern, "Health and Safety in Small Workplaces: Refocusing Upstream" (2010) Canadian Journal of Public Health 101(Suppl. 1): S29-S33.

205 J. McKinlay, "A Case for Refocusing Upstream: The Political Economy of Illness" in Jaco, EG (ed.), Patients, Physicians, and Illness: A Sourcebook in Behavioural Science and Health. (New York: Free Press, 1979) 9.

206 James, Johnstone, Quinlan \& Walters note 125.

${ }^{207}$ H. Jain, J. Lawler, B. Bai, and E. Lee, "Effectiveness of Canada's Employment Equity Legislation for Women (1997-2004): Implications for Policy Makers." (2010) 65 Relations Industrielles, 304.

208 James note 125.

${ }^{209}$ The Dean Report (note 93),called for measures to address OHS concerns in the underground economy and this might provide a spur to the development of supply chain regulation as one means of reaching unregistered firms operating below the radar of enforcement authorities.

${ }^{210}$ A certified member is worker or employer representative on a JHSC who has received special training. There must be one worker and one employer member on each JHSC who is certified.

211 D. Walters and T. Nichols, Worker Representation and Workplace Health and Safety. (Basingstoke: Palgrave Macmillan, 2007). 
${ }^{212}$ A. Hall, et al. "Making a Difference: Knowledge Activism and Worker Representation in Joint OHS Committees"(2007) 61 Relations Industrielles, 408; and, B. Barnetson, The Political Economy of Workplace Injury in Canada. (Edmonton: Athabasca U.P., 2010) at 63-65.

${ }^{213}$ N. Gunningham, "Occupational Health and Safety, Worker Participation and the Mining Industry in a Changing World of Work." (2008) 29 Economic and Industrial Democracy, 336 and, R. Storey and E. Tucker, "All that is Solid Melts into Air: Worker Participation and Occupational Health and Safety Regulation in Ontario, 1970-2000" in Morgenson, V., ed. Worker Safety Under Siege: Labor, Capital and Workplace Safety in a Deregulated World. (Armonk, NY: M.E. Sharpe, 2006)157.

${ }^{214}$ Dean Report note 93.

${ }^{215}$ Kaj Frick, "Health and Safety Representation in Small Firms: A Swedish Success under Threat" in D. Walters and T. Nichols, (eds), International Perspectives on Worker Representation. (Basingstoke: Macmillan, 2009), 154 at 156.

${ }^{216}$ Weil and Pyles note 127

217 Dean Report note 93 at 50.

218 Ayres \& Braithewaite note 117and, N. Gunningham and R. Johnstone, R., Regulating Workplace Safety: Systems and Sanctions. (Oxford: Oxford University Press1999).

${ }^{219}$ K. Carson and R. Johnstone, "The Dupes of Hazard: Occupational Health and Safety and the Victorian Sanctions Debate" (1990) 26 Australia New Zealand Journal of Sociology, 126.

${ }^{220}$ Gunningham \& Johnstone, note 218.

221 T. Schofield, B. Reeve, and R. McCallum, “Deterrence and OHS Prosecutions: Prosecuted Employers' Responses" (2009) 25:4 Journal of Occupational Health and Safety - Australia and New Zealand , 263.

${ }^{222}$ W.G. Gray and J.T. Scholz, "Does Regulatory Enforcement Work? A Panel Analysis of OSHA Enforcement" (1993) 27 Law and Society Review,177.

${ }^{223}$ R. Johnstone, and C. Parker, "Enforceable Undertakings in Action - Report of a Roundtable Discussion with Australian Regulators." Working Paper No. 72, National Research Centre for Occupational Health and Safety Regulation (Canberra: Australian National University, 2010) Online http://ohs.anu.edu.au/publications/pdf/wp \%2071\%20- 
\%20Parket\%20Final\%20EU\%20Working\%20Paper\%2017\%20Feb\%202010.pdf [Accessed 16 August 2011].

${ }^{224}$ Kaj Frick and John Wren, "Reviewing Occupational Health and Safety Management - Multiple Roots, Diverse Perspectives and Ambiguous Outcomes" in K. Frick et al. eds., Systematic Occupational Health and Safety Management. (Amsterdam: Elsevier Science, 2000). 17 at 18.

${ }^{225}$ T. Nichols and E. Tucker, "OHS Management Systems in the United Kingdom and Ontario, Canada: A Political Economy Perspective" in K. Frick et al. eds., Systematic Occupational Health and Safety Management. (Amsterdam: Elsevier Science, 2000) 285; and, S.M. Hart, “Self-regulation, Corporate Social Responsibility, and the Business Case: Do they Work in Achieving Workplace Equality and Safety?" (2009) 92 Journal of Business Ethics, 585.

${ }^{226}$ For example Walters et el 195

${ }^{227}$ Walters et el note 195 at $443-44$

${ }^{228}$ For example, Michael Quinlan, "The Implications of Labour Market Restructuring in Industrialized Societies for Occupational Health and Safety" (1999) 20 Economic and Industrial Democracy, 427. 229 James et al. note 125

${ }^{230}$ C. Estlund, Regoverning the Workplace: From Self-Regulation to Co-Regulation (New Haven: Yale University Press, 2010).

${ }^{231}$ Some of the ideas discussed in this section were also discussed in "Good Idea: A new, improved and enforced Employment Standards Act" Talking About Jobs. Online http://doc-14-94docsviewer.googleusercontent.com/viewer/securedownload/dsn1aovipa7/846lsfcf94nedj8q2p4u/r7ts3psl6 ps9eqsp7hbv7fdeknc1ovqa/1320349500000/Ymw=/AGZ5hq8BgbJY1gwaOYx83cPOdNw6/QURHRUVTa WEyQzBZX0staDk4bDJ1ZVI1Q3VsRU50OHo5U2VfYIpBUEpkRGd5TE5TMXE1ZWRIVnM3VIBQRIYxdG IkQXM5NnU1QVRkbWhPSjNpdGY1OE9oWEFOdGUtanpLYjIMZ2JDbUJzLXVDY08zdDdUOTctS1NDZG xWVW1tZW80Sm5uT1kxUFNqV2c=?chan=EAAAAGZ/rnRSJD3XTL2o3fp9vSAiRBAXReo/1/aCIWvsTHt

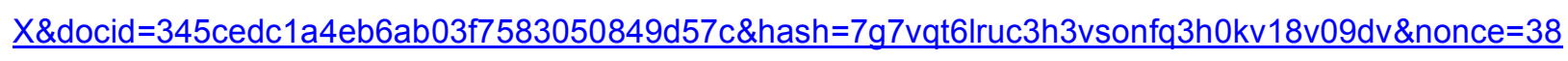
01s37t2flom\&sec=AHSqidZOiC6aSVURoSsaoKqoH1laOnGV22zzXq2NBZIONoZFhzgCDRHDYNyrxq Q k7PVI0a94dEa\&a=gp\&filename=A-new-and-improved-employment-standardsact.pdf\&user=AGZ5hq8BgbJY1gwaOYx83cPOdNw6 [accessed 3 November 2011]. 
${ }^{232}$ This may involve legislative change.

${ }^{233}$ This would involve legislative change.

${ }^{234}$ This would involve legislative change.

${ }^{235}$ This would involve legislative change.

${ }^{236}$ This would involve legislative change.

${ }^{237}$ This would involve legislative change

${ }^{238}$ This would involve legislative change.

${ }^{239}$ This would involve legislative change.

${ }^{240}$ This may involve regulatory or legislative change.

${ }^{241}$ This may involve regulatory change.

${ }^{242}$ This would involve legislative change.

${ }^{243}$ This would involve legislative change.

${ }^{244}$ This would involve legislative change.

${ }^{245}$ This may involve legislative change. 